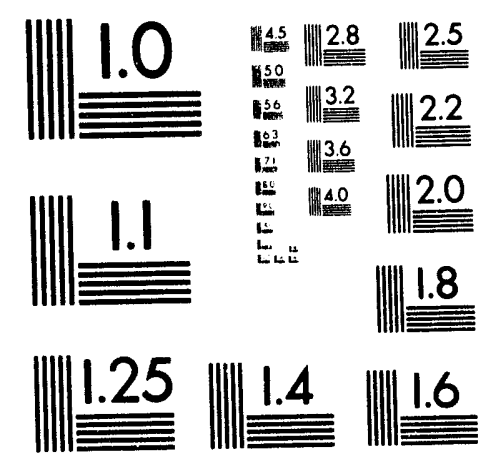



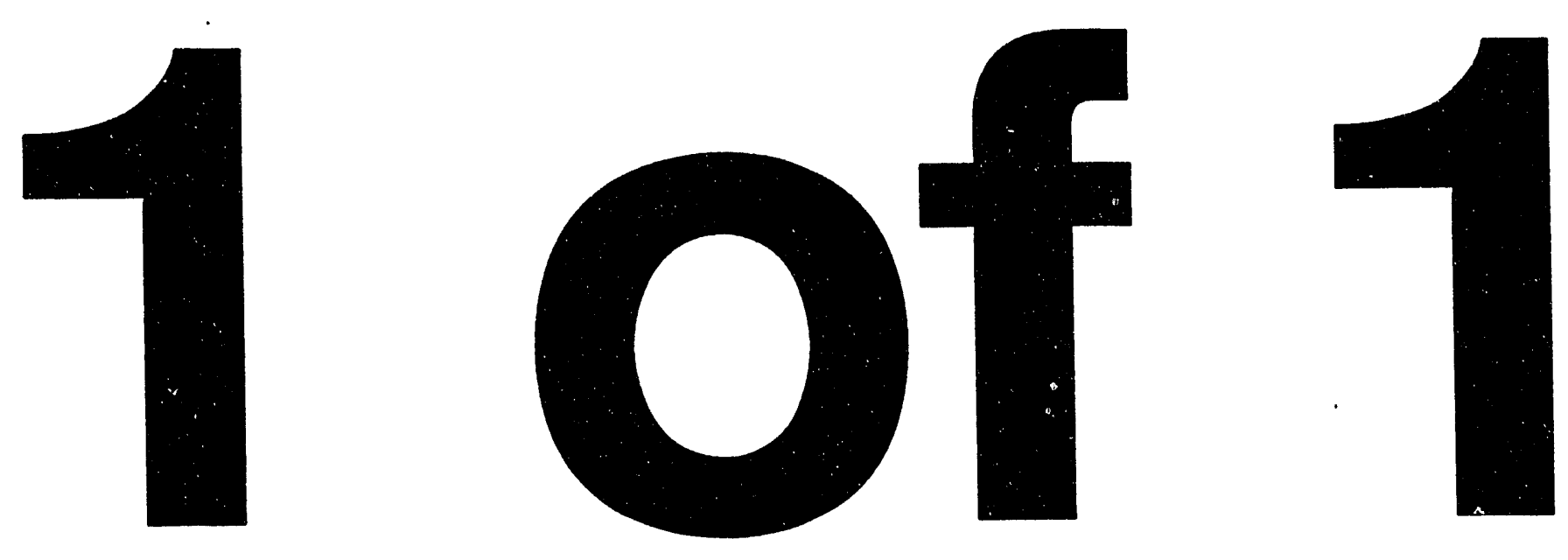
NUREG/CR-5782

ORNL/TM-11945

$\mathrm{RF}$

\section{Pressurized Thermal Shock Probabilistic Fracture Mechanics Sensitivity Anaiysis for Yankee Rowe Reactor Pressure Vessel}

Manuscript Completed: June 1993

Date Published: August 1993

Prepared by

T. L. Dickson, R. D. Cheverton, J. W, Bryson, B. R. Bass,

D. K. M. Shum, J. A. Keeney

Oak Ridge National Laboratory

Managed by Martin Marietta Energy Systems, Inc.

Oak Ridge National Laboratory

Oak Ridge, TN 37831-6285

Prepared for

Division of Engineering

Office of Nuclear Regulatory Research

U.S. Nuclear Regulatory Commission

Washington, DC 20555-0001

NRC FIN B0119

Under NRC Contract No. DE-AC05-840R21400 
Abstract

\begin{abstract}
The Nuclear Regulatory Commission (NRC) requested Oak Ridge National Laboratory (ORNL) to perform a pressurized-thermal-shock (PTS) probabilistic fracture mechanics (PFM) sensitivity analysis for the Yankee Rowe reactor pressure vessel for the fluerices corresponding to the end of operating cycle 22, using a specific small-break-loss-of-coolant transient as the loading condition. Regions of the vessel with distinguishing features were to be treated individually - upper axial weld, lower axial weld, circumferential weld, upper plate spot welds, upper plate regions between the spot welds, lower plate spot welds, and the lower plate regions between the spot welds. The fracture analysis methods used in the analysis of through-clad surface flaws were those contained in the established OCA-P computer
\end{abstract}

code, which was developed during the Integrated Pressurized Thermal Shock (IPTS) Program. The NRC request specified that the OCA-P code be enhanced for this study to also calculate the conditional probabilities of failure for subclad flaws and embedded flaws. The results of this sensitivity analysis provide the NRC with (1) data that could be used to assess the relative influence of a number of key input parameters in the Yankee Rowe PTS analysis and (2) data that can be used for readily determining the probability of vessel failure once a more accurate indication of vessel embrittlement becomes available.

This report is designated as HSST report No. 117. 


\section{Contents}

Page

Abstract.

List of Figures.

vii

List of Tables

ix

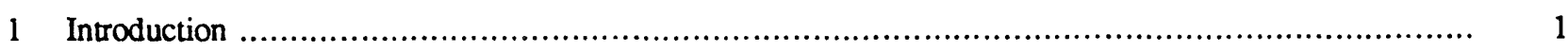

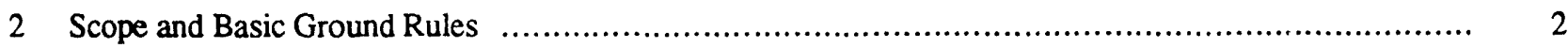

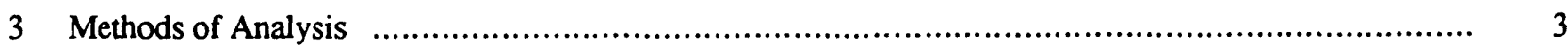

3.1 Probabilistic Methodology ..................................................................................

3.2 Combining Probabilities of Failure for Individual Regions of the Vessel ..................................

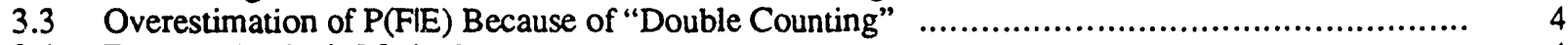

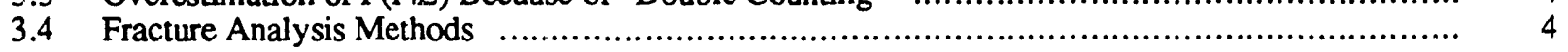

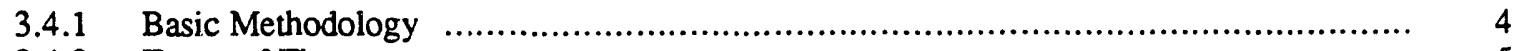

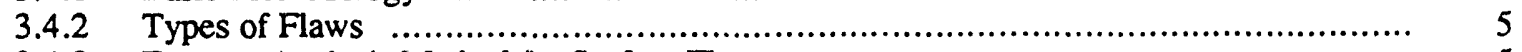

3.4.3 Fracture Analysis Method for Surface Flaws ................................................... 5

3.4.4 Fracture Analysis Method for Subclad Flaws ….................................................. 5

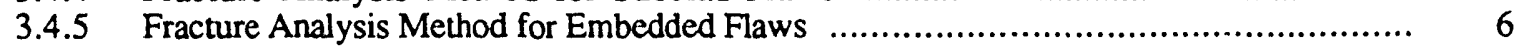

3.5 Methodologies for Estimating Fracture Toughness f............................................ 6

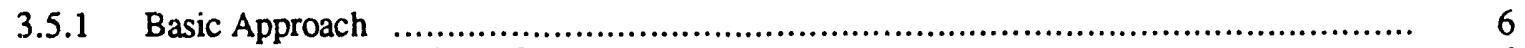

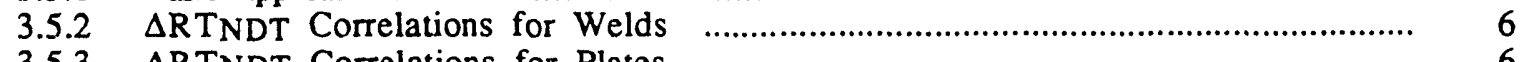

3.5.3 $\triangle$ RTNDT Correlations for Plates …............................................................. 6

3.6 Residual-Stress Considerations ........................................................................ 7

3.7 Method of Analysis to Include Dynamic Fracture ….............................................. 7

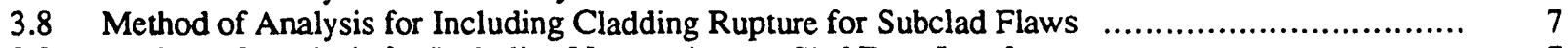

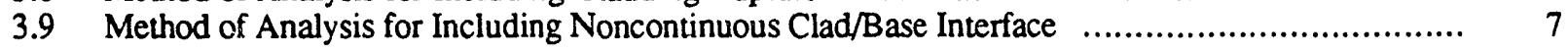

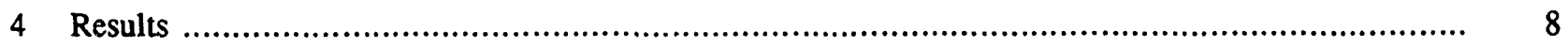

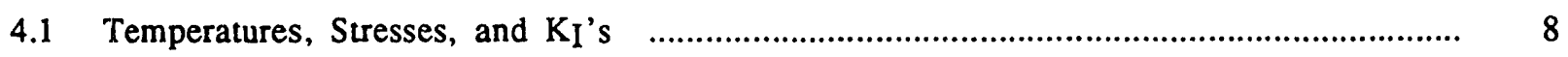

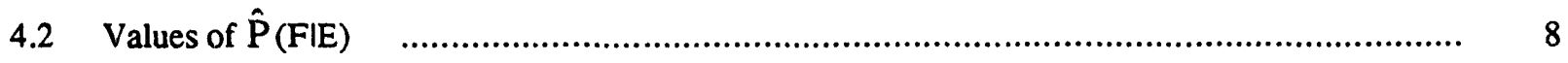

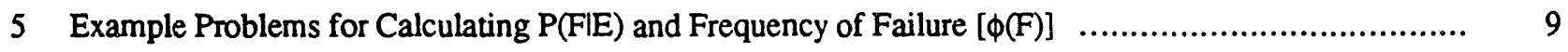

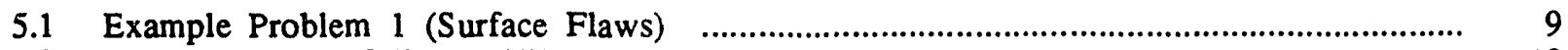

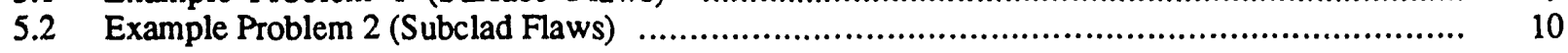

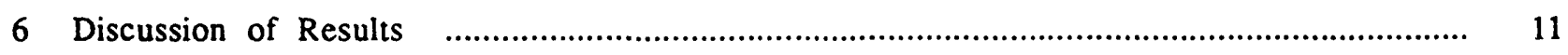

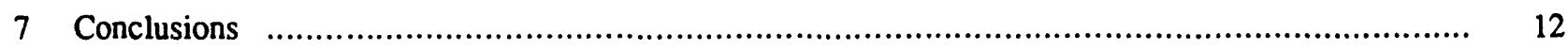

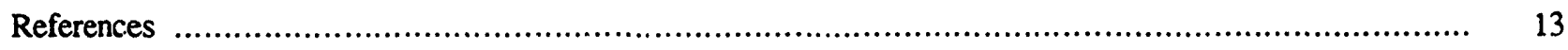

Appendix A: Transient Definition and Resulting Loads ................................................. A.1

Appendix B: Surface-Flaw Model and PFM Methodology ............................................. B.1

Appendix C: Subclad-Flaw Model and PFM Methodology ................................................... C.1

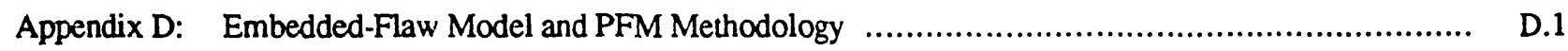


Appendix E: Methodology for Simulating Fracture Toughness for Welds ….................................... E.1

Appendix F: $\quad$ Methodology for Simulating Fracture Toughness for Plates ...................................... F.1

Appendix G: Residual-Stress Considerations …................................................................ G.1

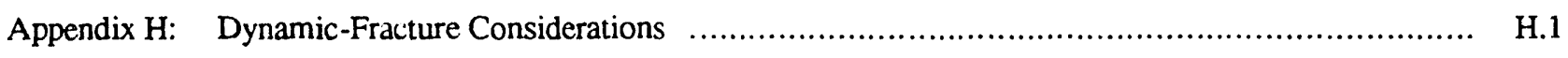

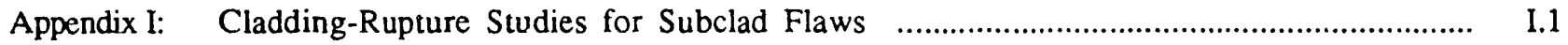

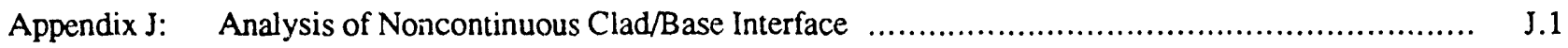




\section{List of Figures}

1 Unadjusted best-estimate conditional probability of failure. Upper Axial W'eld

Unadjusted best-estimate conditional probability of failure. Lower Axial Weld .

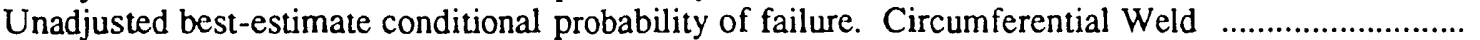

Unadjusted best-estimate conditional probability of failure. Upper Plate

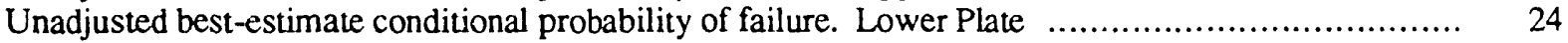

A.1 Yankee Rowe SBLOCA7 thermal and pressure transient

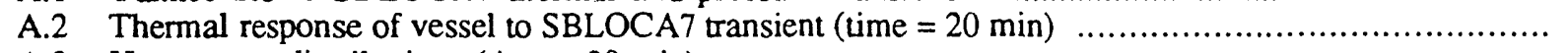

A. 4

A.3 Hoop stress distributions (time $=20 \mathrm{~min}$ )

A.4 Axial stress distribution (time $=20 \mathrm{~min}$ )

A. 5

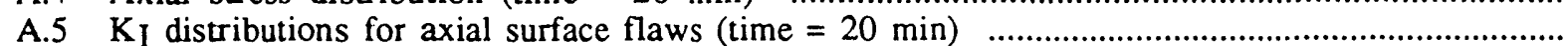

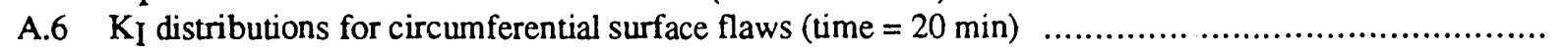

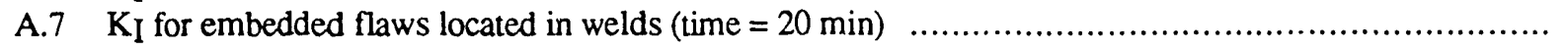

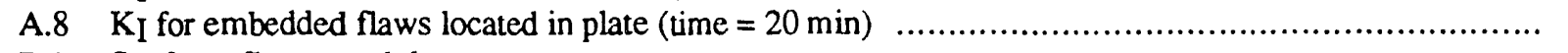

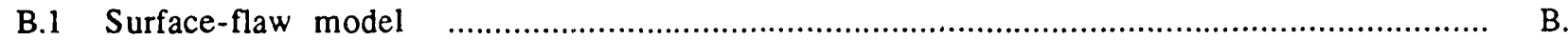

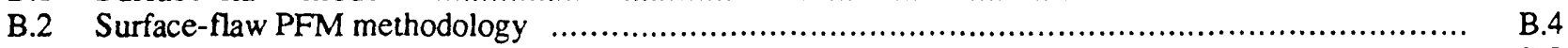

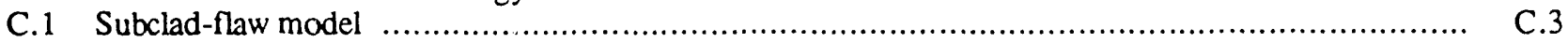

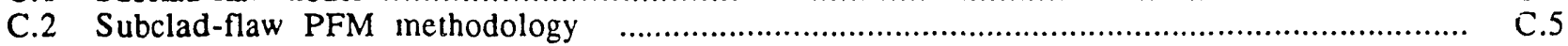

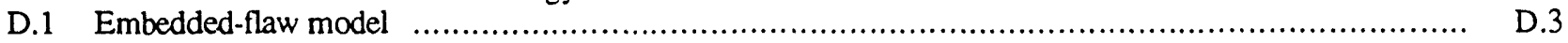

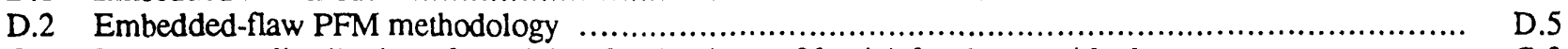

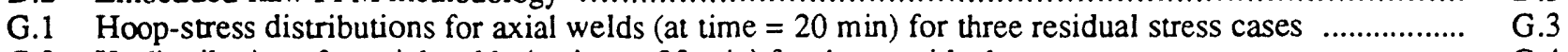

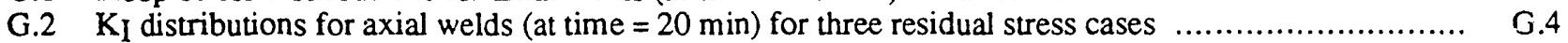

G.3 Best-estimate unadjusted conditional probability of failure for upper axial weld for

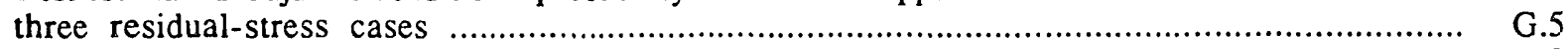

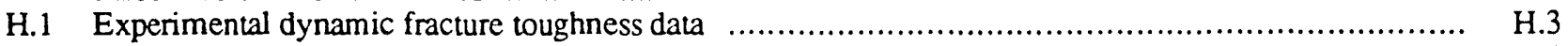

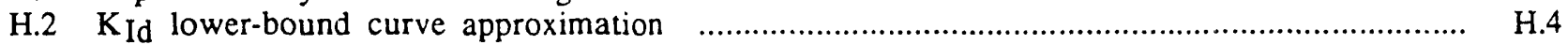

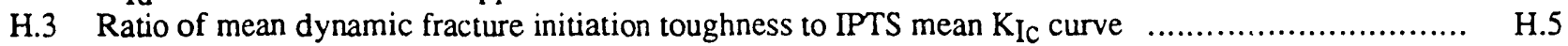

I.1 Stress/strain curve for 7 th irradiation series three-wire cladding materiai $\left(\mathrm{T}=550^{\circ} \mathrm{F}\right) \ldots \ldots \ldots \ldots \ldots \ldots \ldots$

I.2 Finite-element model employed for cladding-rupture studies ............................................. I.7

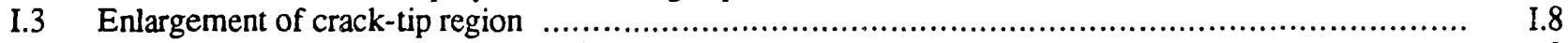

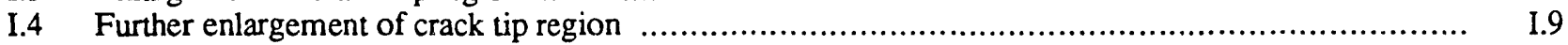

I.5 J-integral values at each crack tip for a 2-in. subclad flaw, SBLOCA7 transient, 0.25 -in. cladding $\ldots . . . \quad I .10$

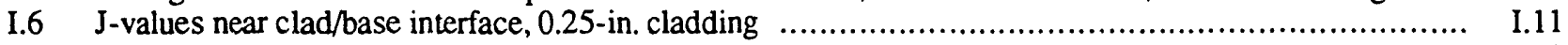

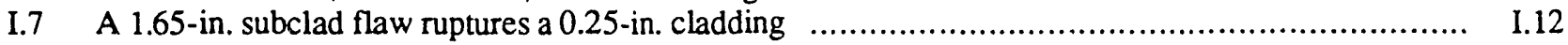

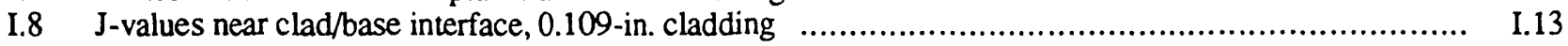

I.9 Jo-Block specimen for measuring fracture properties of cladding oyer a subclad flaw $\ldots \ldots \ldots \ldots \ldots \ldots \ldots \ldots$ I.1.

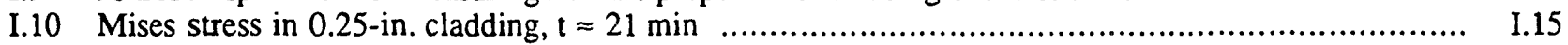

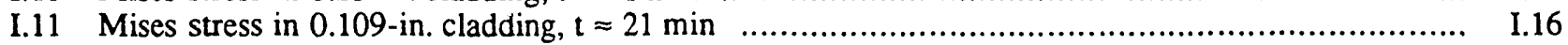

J.1 Schematic showing a portion of an RPV with a flaw that is modeled using finite-element techniques

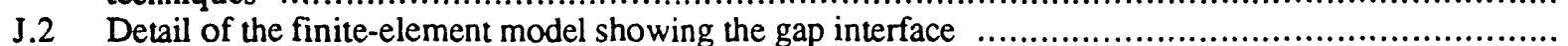

J.3 Hoop stress distribution for OCA-P and ADINA analyses (SBLOCA7 transient, $\mathrm{t}=20 \mathrm{~min}$ ) $\ldots \ldots \ldots \ldots$

J.4 Distribution of $\mathrm{K}_{\mathrm{I}}$ values for finite-element models with and without interface gap 


\section{List of Tables}

Page

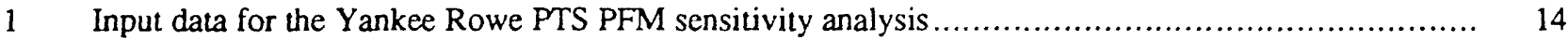

2 Best-estimate unadjusted conditional probabilities of failure [ $\hat{\mathrm{P}}(\mathrm{FIE})]$ for welds .......................... 16

3 Best-estimate unadjusted conditional probabilities of failure $[\hat{\mathrm{P}}(\mathrm{F} \mid \mathrm{E})]$ for plate (between spot welds)...... 17

4 Best-estimate unadjusted conditional probabilities of failure $[\hat{\mathrm{P}}(\mathrm{F} \mid \mathrm{E})]$ for plate (at spot welds) ............. 18

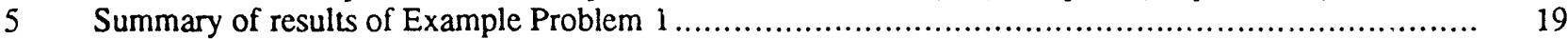

I.1 Parameters used in subclad-flaw rupture studies ..................................................... $\quad$ I.3

1.2 Comparison of J-values near clad/base interface for two different clad penetration models,

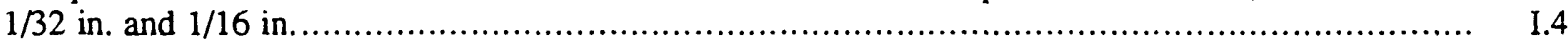

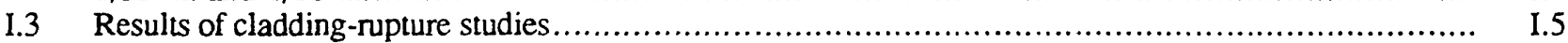




\section{Introduction}

Following the Oak Ridge National Laboratory (ORNL) review ${ }^{1}$ of the Yankee Atomic Electric Company reactor pressure vessel evaluation report for the Yankee Rowe reactor, 2 the Nuclear Regulatory Commission (NRC) requested ORNL to perform a pressurized-thermal-shock probabilistic fracture mechanics (PFM) sensitivity analysis for the vessel, using a specific small-break loss-ofcoolant transient (SBLOCA-Case 7) as the loading condition." Subsequent discussions regarding the details of the methodologies to be used in performing the specified analyses were held between members of the NRC staff and ORNL staff in meetings at Rockville, Maryland, on March 22 and May 14, 1991.
The objective of this study was two fold: (1) provide the NRC with results that could be used to assess the relative influence of a number of key input parameters in the Yankee Rowe PTS analysis and (2) provide data that can be used for readily estimating the probability of vessel failure once a more accurate indication of vessel embrittement becomes available.

This report discusses the scope, ground rules, analytical methodologies applied, and the results.

\footnotetext{
Mayfield, M. E., NRC, personel communication to W. E. Pennell, ORNL, February 15, 1991.
} 


\section{Scope and Basic Ground Rules}

The initial NRC request specified that the OCA-P computer code 3 be enhanced to calculate the conditional probability of failure for subclad and embedded flaws as well as for through-clad (surface) flaws. The NRC also specified that the spatial variation of fluence be considered to the extent practical, and ORNL modified OCA-P to enhance this capability. All calculations were to be performed for fluences corresponding to the end of operating cycle $22\left(\sim 21 \mathrm{EFPY}^{*}\right)$.

Regions of the vessel with distinguishing features were to be treated individually; they are the upper axial weld, lower axial weld, circumferential weld, upper-plate spot welds, upper-plate regions between the spot welds, lower-plate spot welds, and lower-plate regions between the spot welds. (Spot welds attach the cladding to the base material, except over the vessel welds, where the cladding is weld deposited.)

The fracture-analysis methods to be used in the analysis of the surface flaws were those represented by the established OCA-P methodology, which was developed during the Integrated Pressurized Thermal Shock (IPTS) Program. 4 Fracture-analysis methodology for suiclad and embedded flaws were not available in OCA-P, and thus they had to be developed for the present study. Because of the tight schedule, less precise methods than used for the surface flaws were considered acceptable.

The PFM sensitivity analyses for weld regions were to be performed with copper concentration as the independent variable ( 0.15 to $0.35 \mathrm{wt} \%$ in increments of 0.05 ), while the analyses for plates were to be performed with surface RTNDT as the independent variable. The upperplate surface RTNDT values were to range from 250 to $325^{\circ} \mathrm{F}$ in increments of $25^{\circ} \mathrm{F}$, and the lower-plate surface RTNDT values were to range from 250 to $400^{\circ} \mathrm{F}$ in increments of $25^{\circ} \mathrm{F}$.

These and other specified input data for the Yankee Rowe PTS PFM sensitivity analysis are included in Table 1.

*Effective full-power years (EFPY). 


\section{Methods of Analysis}

\subsection{Probabilistic Methodology}

The probabilistic fracture mechanics analyses were performed using an enhanced version of OCA-P, which is based on Monte Carlo techniques; i.e., a large number of vessels is generated, and each vessel is subjected to a deterministic fracture mechanics analysis to determine whether the vessel will fail. In each deterministic analysis, the region of the vessel being analyzed contains one flaw. Each vessel is defined by probabilistically selecting values of several parameters that are judged to have significant uncertainties associated with them, primarily the flaw size and the parameters that determinc the degree of embrittlement (Appendices $E$ and F). The conditional probability of failure ("conditional" in the sense that the transient is assumed to occur), based on one flaw per region (referred to herein as the unadjusted conditional probability of failure) is simply the number of vessels that fail divided by the total number of vessels simulated. The conditional probbility of failure for each vessel region based on the "actual" number of flaws per region is obtained by multiplying the unadjusted value by the number of flaws that exist in the vessel region. Thus,

$$
P_{j}(F \mid E)=\left(N_{j} \star V_{j} \star I\right) \star \hat{P}_{j}(F \mid E)
$$

where

$$
\begin{aligned}
& P_{j}(F \mid E)=\text { conditional probability of } \\
& \text { failure for the } \mathrm{j}^{\text {th }} \text { region } \\
& \hat{P}_{j}(F I E)=\text { unadjusted conditionial } \\
& \text { probability of failure for the } \mathrm{j}^{\text {th }} \\
& \text { region (failures/ flaw) } \\
& \mathrm{N}_{\mathrm{j}}=\text { flaw density of the } \mathrm{j}^{\text {th }} \text { region } \\
& \text { (flaws/unit volume) } \\
& v_{j}=\text { volume of the } j^{\text {th }} \text { region } \\
& I=\int_{0}^{w} f(a) * B(a) d a= \\
& 0.587 \text { for these studies }
\end{aligned}
$$

The conditional probability of failure for the entire vessel is calculated by summing the $P_{j}(F \mid E)$ values over all regions of the vessel. Thus,

$$
P(F \mid E)=\sum_{j} P_{j}(F \mid E)=\sum_{j}\left(N_{j} \star V_{j} \star I\right) \star \hat{P}_{j}(F \mid E)
$$

where $P(F \mid E)=$ total conditional probability of failure for the vessel.

The Marshall probability of-nondetection function really can not be applied to the unbonded-cladding region because ultrasonic detection could not have penetrated the gap between the cladding and base material. The function was included for consistency with the previous ORNL analysis of Yankee Rowe. 1 The effect on $\mathrm{P}_{\mathrm{j}}(\mathrm{F} \mid \mathrm{E})$ is less than a factor of two.

\subsection{Combining Probabilities of Failure for Individual Regions of Vessel}

When adding the probabilities of failure for the individwal regions of the vessel, it is necessary to make sure that the individual values constitute a consistent set with regard to plant operating time and the spatial distribution $(z, \varphi)^{*}$ of the fluence. The reason for the concern is that for this particular study the effect of fluence spatial distribution on the potential for crack initiation was considered, and fluence values corresponding to 21 EFPY were used for calculating $\hat{P}(F \mid E)$ for the welds, while a range of values of RTNDT was used, without reference to specific values of fluence, for calculating $\hat{\mathrm{P}}(\mathrm{F} \mid \mathrm{E})$ for the plate regions. Calculated values of $\hat{\mathrm{P}}(\mathrm{F} \mid \mathrm{E})$ for the welds (Table 2, Figs. 1-3) are consistent and correspond to 21 EFPY; they can be added as indicated in Eq. (2).

The calculated values of $\hat{P}(F \mid E)$ in Tables 3 and 4 and Figs. 4 and 5 for the two plate regions are not consistent with each other and are not necessarily consistent with "alues for the welds. They can not be added to each other or to values for the welds in the manner indicated by Eq. (2). Inst zad, the process described below must be used.

The independent variable used in calculating $\hat{P}(F[E)$ for the plates is RTNDT at the inner surface of the vessel at the location of the maximum value of the fluence within the specific plate region. Because the maximum fluences and the chemistries are not the same in the two plate regions, maximum values of RTNDT for the two regions will not be the same. To obtain consistent maximum values for the two plate regions, the corresponding fluence values, and, of course, chemistries, must be used.

\footnotetext{
*Longirudinal (z) and azimuthal $(\Phi)$
} 
As indicated in Sect 3.5 and Appendix F, Odette ${ }^{*}$ recommends the following correlations between fluence and $\triangle R T N D T$ for the upper and lower plate regions:

$$
\begin{aligned}
& \left(\Delta \mathrm{RT}_{\mathrm{NDT}}\right)_{\mathrm{UP}}=\mathrm{A} \Phi_{\mathrm{UP}}^{\mathrm{B}}, \\
& \left(\Delta \mathrm{RT}_{\mathrm{NDT}}\right)_{\mathrm{LP}}=\mathrm{A} \Phi_{\mathrm{LP}}^{\mathrm{B}}+\mathrm{C} .
\end{aligned}
$$

Thus,

$$
\left(\frac{\Phi_{\mathrm{UP}}}{\Phi_{\mathrm{LP}}}\right)^{\mathrm{B}}=\frac{\left(\Delta \mathrm{RT} \mathrm{T}_{\mathrm{NDT}}\right)_{\mathrm{UP}}}{\left(\Delta \mathrm{R} \mathrm{T}_{\mathrm{NDT}}\right)_{\mathrm{LP}}-\mathrm{C}}
$$

or

$$
\left(\Delta \mathrm{RT}_{\mathrm{NDT}}\right)_{\mathrm{LP}}=\left(\frac{\Phi_{\mathrm{LP}}}{\Phi_{\mathrm{UP}}}\right)^{\mathrm{B}}\left(\Delta \mathrm{RT} \mathrm{T}_{\mathrm{NT}}\right)_{\mathrm{UP}}+\mathrm{C},(6)
$$

where

$$
\begin{aligned}
& (\triangle \mathrm{RTNDT}) \mathrm{UP}=\Delta \mathrm{RTNDT} \text { in upper plate } \\
& (\triangle R T N D T)_{L P}=\Delta R T N D T \text { in lower plate } \\
& \Phi \text { UP }=\text { maximum value of fluence in } \\
& \text { upper plate }=2.74 \mathrm{E} 19 \mathrm{n} / \mathrm{cm}^{2} \\
& \text { (21 EFPY) } \\
& \Phi_{\mathrm{LP}}=\text { maximum value of fluence in } \\
& \text { lower plate }=2.439 \mathrm{E} 19 \mathrm{n} / \mathrm{cm}^{2} \\
& \text { (21 EFPY) } \\
& A=183 \text { from Odette } \\
& \mathrm{B}=0.315\} \text { correlations for } \\
& \mathrm{C}=80 \quad \mathrm{~T} \text { in }{ }^{\circ} \mathrm{F}
\end{aligned}
$$

Thus, if a maximum value of RTNDT corresponding to 21 EFPY is somehow obtained for the upper or lower plate region, the corresponding value in the other plate can be estimated.

Equations (3) and (4) were used to account for the spatial distribution $(z, \varphi)$ of the fluence in the calculation of $\mathrm{P}_{\mathrm{j}}(\mathrm{FIE})$. For instance, for the upper plate, $\triangle R T N D T$ $\left(\mathrm{z}_{\mathrm{m}}, \varphi_{\mathrm{n}}\right)$ was obtained from

$$
\frac{\Delta \mathrm{RT}_{\mathrm{NDT}}\left(\mathrm{z}_{\mathrm{m}}, \varphi_{\mathrm{n}}\right)}{\Delta \mathrm{RT}_{\mathrm{NDT}}(\max )}=\left[\frac{\Phi\left(\mathrm{z}_{\mathrm{m}}, \varphi_{\mathrm{n}}\right)}{\Phi(\max )}\right]^{\mathrm{B}},
$$

and for the lower plate,

$$
\begin{aligned}
& \Delta \operatorname{RT}_{\mathrm{NDT}}\left(z_{m}, \varphi_{n}\right)=\left[\frac{\Phi\left(z_{m}, \varphi_{n}\right)}{\Phi_{(\max )}}\right]^{\mathrm{B}} \times \\
& {\left[\Delta \mathrm{RT}_{\mathrm{NDT}}(\max )-\mathrm{C}\right]+\mathrm{C},}
\end{aligned}
$$

\footnotetext{
*Odeute, G. R., College of Engineering, Univ. of Califomia, Santa
} Barbara, personal communication to A. Taboda, NRC, July 30, 1990. where $\mathrm{z}_{\mathrm{m}}$ and $\varphi_{\mathrm{n}}$ are axial and azimuthal coordinates. Thus, even if Eq. (6) is not used to obtain the necessary relation between the upper and lower plate regions, the Odette correlations [Eqs. (3) and (4)], with the exception of the value of $A$, are used in the analysis (used to construct the map of $\triangle R T_{\text {NDT} \text { ). }}$

\subsection{Overestimation of $\mathrm{P}(\mathrm{F} \mid \mathrm{E})$ Because of "Double Counting"}

In the present version of OCA-P, the number of flaws in the vessel is accounted for as indicated in Eq. (2). If $\Sigma \mathrm{N}_{\mathrm{j}} \mathrm{VjI}$ is less than unity for regions of the vessel that contribute significantly to $P(F \mid E)$, Eq. (2) is appropriate. If not, there is the possibility of overestimating $P(F \mid E)$ because only one flaw can result in failure of the vessel. More than a single flaw does increase $P(F \mid E)$ because it increases the chances of having a flaw of critical size, but the increase in $P(F I E)$ is less than indicated by Eq. (2). However, if $P(F \mid E) \ll 1, \Sigma N_{j}$ VjI can be substantially greater than unity without Eq. (2) being significantly in error. 4

\subsection{Fracture Analysis Methods}

\subsubsection{Basic Methodology}

All fracture analyses were performed in accordance with linear elastic fracture mechanics (LEFM) theory. Based on this methodology, flaws are predicied to commence propagation (initiate) when the stress intensity factor $(\mathrm{KI})$ is equal to the static crack-initiation fracture toughness (KIc) or the dynamic-loading fracture toughness (KId). Arrest of a fast running crack is predicted when $\mathrm{KI}=\mathrm{KIa}$, the crack-arrest toughness. Dynamic loading is introduced when one portion of a crack front initiates under static loading conditions, thereby subjecting the remainder stationary part of the crack front to dynamic loading.

In the fracture analysis of flaws residing in welds, the $\mathrm{KI}$ 's corresponding to crack tips that reside in the first inch of base metal include the effect of a 6-ksi tensile residual stress. The KI's for crack tips in the cladding and the remainder of the base material do not inciude the effect of residual stresses. (See Sect. 3.6 and Appen$\operatorname{dix} \mathrm{G}$ for a more detailed discussion regarding the inclusion of residual stresses in the fracture-mechanics analyses.)

In the fracture analyses of subclad and embedded flaws, dynamic effects have been included to the extent of including the dynamic-loading fracture toughness (KId) for sp : ific crack-initiation events. The KId curve was approsimated by shifting the KIc curve $33^{\circ} \mathrm{F}$, and it was 
used in the prediction of crack initiation in the base material at the time step for which the cladding was predicted to fail. (See Sect. 3.7 and Appendix H for details of how dynamic effects were included in the analyses.)

\subsubsection{Types of Flaws}

As indicated in Sect. 2, the basic types of flaws considered are surface flaws and embedded flaws, of which a subclad flaw is a special category. All flaws analyzed were considered to be normal to the surface and oriented in either an axial (longitudinal) or azimuthal (circumferential) direction. All other flaws that might exist were ignored.

The length of an initial flaw in the axial or circumferential direction is more likely to be short th.an long, but upon propagation, short flaws have a tendency to become long flaws. $5{ }^{*}$ Previous studies have indicated that under thermal-shock loading, a semicircular surface flaw' has a greater potential for surface extension than other shor flaws and about the same potential for surface propagation as that for radial propagation of a long surface flaw of the same initial depth. Thus, the assumption was made that all initial surface flaws were semicircular, in which case the spatial distribution $(z, \varphi)$ of the fluence could be considered for the first initiation event, but the $\mathrm{K}_{\mathrm{I}}$ values used were those for a very long flaw.

Initial embedded flaws were also assumed to be short so that the spatial distribution of the fluence could be considered. Even though the shorter embedded flaws have less potential for propagating, the embedded-flaw $\mathrm{KI}$ values used were for long flaws. In any subsequent studies, the more realistic shorter flaw should be considered.

As indicated above, when flaws propagate, they tend to extend in length to become long flaws. However, the length can be limited by increases in toughness (decreasing fluence and/or changes in chemistry). For Yankee Rowe, the decrease in toughness appears to be rather large for both the plate and welds, and thus the length of axial flaws would be limited only by the steep attenuation of the fluence at the ends of the core. It appears that for this length $(\sim 100 \mathrm{in}$.) there will be significant finite-length-flaw effects on $\mathrm{K}_{\mathrm{I}}$ for deep flaws that should be taken advantage of for crack arrest and reinitiation. This effect was not considered but should be in an extension of the study. (The effect is negligible for the very shallow initial flaws.)

Propagating circumferential flaws may also be limited in length, although variations in chemistry (in a circumferential weld) and in fluence tend to be relatively small.

\footnotetext{
* Where the cladding is not bonded between the spol welds there may be a small range of shallow flaw depths for which surface extension in the base material will not take place. This has not been considered in this study.
}

\subsubsection{Fracture Analysis Method for Surface Flaws}

Surface flaws are flaws that penetrate the cladding and base metal from the inner surface of the vessel. The stress intensity factors $\left(\mathrm{K}_{\mathrm{I}}\right)$ used in the PFM analyses of surface flaws were calculated in the usual OCA-P manner, i.e., a superposition technique that applies a large number of $\mathrm{KI}$ influence coefficients (calculated by a 2-D finite-element method) and the stresses induced in the uncracked vessel as a function of time and radial position in the pressure vessel wall (calculated by a 1-D finiteelement thermal and stress analysis). ${ }^{3}$ It should be noted that all surface-flaw KI's used in these analyses are for flaws of infinite surface length.

It is of interest to note that the ASME Sect. XI procedure for calculating $\mathrm{K}_{\mathrm{I}}$ 's for surface flaws 6 was also included in the specialized code for performing the Yankee Analysis. The values calculated by the ASME methodology are very close to those calculated by the OCA-P methodology (discussed above) for very shallow flaws; however, they diverge for greater depths, with the ASME values being higher. Probabilities of failure for surface flaws, calculated using the ASME $\mathrm{K}_{\mathrm{I}}$ methodology, are higher than those using the OCA-P $\mathrm{K}_{\mathrm{I}}$ methodology by approximately a factor of 2 .

Details of the surface-flaw model and the flow-chart logic for performing the deterministic fracture mechanics analysis of each of the probabilistically simulated embrittled vessels containing a surface flaw are included in Appendix B.

\subsubsection{Fracture Analysis Method for Subclad Flaws}

A subclad flaw is a flaw that has its inner crack tip at the clad/base interface, and thus its outer crack tip is in the base metal. The outer flaw tip is checked for initiation according to LEFM principles.

If the subclad-flaw size reaches the critical size for waich cladding is predicted to fail, the subclad flaw is converted to a surface flaw, and the KI's for surface flaws are then used to predict initial initiation, crack arrest, and subsequent reinitiation of the outer crack tip. At the time step corresponding to cladding failure, dynamic effects were simulated by using a value of $\mathrm{K}_{\mathrm{Id}}$, instead of $\mathrm{K}_{\mathrm{Ic}}$, to predict initiation. (Dynamic fracture considerations are included in Sect. 3.7 and Appendix H).

If the cladding does not fail, the probability of initiation of the subclad flaw is less than that of a surface flaw. Analysis of thermal-shock experiments performed at ORNL indicate that at times of maximum loading, the $\mathrm{KI}$ for a subclad flaw is approximately $34 \%$ less than that for a surface flaw. ${ }^{7}$ Based on these experimental results, the stress intensity factors for predicting the initial initiation of subcritical (cladding has not failed) subclad flaws were calculated by reducing $\mathrm{K}_{\mathrm{I}}$ for a surface 
flaw (with the crack tip at the same radial wall location) by $35 \%$.

Subclad flaws that exist in the plate regions between the spot welds are treated differently than the subclad flaws analyzed for welds and plate regions in the spot welds. These subclad flaws are treated like surface flaws, i.e., the $\mathrm{K}_{\mathrm{I}}$ 's are not reduced by $35 \%$, because a gap (assumed to be 3-mils) exists between the cladding and base material. ADINA-T, 8 a general purpose multidimensional finite-element thermal analysis program, was used to calculate the thermal response of the plate region between the spot welds assuming the 3-mil gap to be filled with water. The insulating effect of the gap slightly reduces the severity of the thermal shock [1ower thermal stresses, and high fracture toughness (Figs. A.2, A.3, and A.5)].

Details of the subclad-flaw model and the flowchart logic for performing the deterministic fracture mechanics analysis of each of the probabilistically simulated vessels containing a such:iad flaw are included in Appendix C.

\subsubsection{Fracture-Analysis Method for Embedded Flaws}

An embedded flaw is ce nsidered in be a flaw that resides entirely in the hase metal. In the probahilistic analysis, the location of the inner tip of the embedded flaw is probabilistically simulated, i.e., located randomly along the mesh between the clad/base interface and the vessel outer wall. The tlaw has equal probability of being located at any one of the mesh points in the base metal. It should be noted that the calculated probability of failure is sensitive to the mesh size, presumably because of its effect on the minimum distance between inner crack tip and clad/base interface. Mesh convergence analyses were performed, and it was determined that a mesh spacing of 0.005 in. is converged with respect to the probability of failure.

The ASME Sect. XI procedure for subsurface flaws 6 was used to calculate KI's for the embedded flaws. The mathematical representation of the ASME curves was Laken from Ref. 9.

The inner tip of the embedded flaw is checked for initiation according to LEFM principles. If the inner tip initiates, it is assumed that the flaw propagates all the way through the cladding, because the flaw is propagating into a region of higher embrittlement and higher thermal stress. Therefore, an embedded flaw that initiates at the inner tip is converted to a surface flaw. Su:face-flaw $\mathrm{K}_{\mathrm{I}}$ 's are then used to predict subsequent initiation and arrest events. Dynamic effects (as described above for subclad flaws) are included for the time step at which the flaw breaks through the cladding.

Details of the embedded-flaw model and the flow-chan logic for performing the deterministic fracture mechanics analysis of each of the simulated vessels containing an embedded flaw are included in Appendix D.

\subsection{Methodologies for Esti- mating Fracture Toughness}

\subsubsection{Basic Approach}

The mean fracture toughness for all regions of the vessel was obtained from the ASME lower-bound relations with a modification to convert from lower-bound to mean. 4 The relations are

$$
\begin{aligned}
\overline{\mathrm{K}}_{\mathrm{lc}}= & 1.43 *\{33.2+2.806 * \exp [0.02 * \\
& (\mathrm{T}-\mathrm{RTNDT}+100)]\}, \\
\overline{\mathrm{K}}_{\mathrm{ld}}= & 1.43 *\{33.2+2.806 * \exp [0.02 * \\
& (\mathrm{T}-\mathrm{RTNDT}+67)]\}, \\
\overline{\mathrm{K}}_{\mathrm{la}}= & 1.25 *\{26.80+1.223 * \exp [0.01449 \\
& *(\mathrm{~T}-\mathrm{RTNDT}+160)]\},
\end{aligned}
$$

where

$$
\begin{aligned}
\overline{\mathrm{K}} & =\text { mean values of } \mathrm{K}_{\mathrm{Ic}}, \mathrm{K}_{\mathrm{Id}}, \mathrm{K}_{\mathrm{Ia}}(\mathrm{ksi} \sqrt{\mathrm{in} .}), \\
\mathrm{T} & =\text { temperature at tip of flaw }\left({ }^{\circ} \mathrm{F}\right) .
\end{aligned}
$$

Details of the methodologies used for determining the fracture toughness for welds and plates are included in Appendices $E$ and $F$, respectively.

\subsection{2 $\Delta$ RT TDT $_{\text {NDT }}$ Correlations for Welds}

For the case of welds, the sensitivity analyses were performed with copper as the independent variable; and Reg. Guide 1.99 Revision 2 (welds), ${ }^{10}$ plus a $50^{\circ} \mathrm{F}$ lowtemperature-irradiation correction factor, were used to calculate $\triangle R T N D T$. The correction factor was added because the Yankee Rowe vessel operates at approximately $500^{\circ} \mathrm{F}$ instead of $550^{\circ} \mathrm{F}$, for which Reg. Guide 1.99 is most appropriate.

\subsection{3 $\Delta$ RT $_{\text {NDT }}$ Correlations for Plates}

For the case of plates, the sensitivity analyses were performed with RTNDT at the inner surface of the vessel as the independent variable, and values of $\triangle R T$ NDT were calculated using Odette's correlations. The correlations are as follows:

$$
\begin{aligned}
& \text { Upper Plate: } \Delta \mathrm{RT}_{\mathrm{NDT}}\left({ }^{\circ} \mathrm{F}\right)=183 *\left(\frac{\Phi}{1019}\right)^{0.315}, \\
& \text { Lower Plate: } \Delta \mathrm{RT}_{\mathrm{NDT}}\left({ }^{\circ} \mathrm{F}\right)=183 *\left(\frac{\Phi}{1019}\right)^{0.315}+80,
\end{aligned}
$$$$
\text { where } \Phi=\text { neutron fluence }\left(E>1.0 \mathrm{MeV}, \mathrm{n} / \mathrm{cm}^{2}\right. \text { ) }
$$ 


\subsection{Residual-Stress Considerations}

Before selecting a residual stress distribution for the Yankee Rowe sensitivity study, the effect of three different residual-stress assumptions waz evaluated. The assumptions were

1. No residual stresses.

2. A $6 \mathrm{ksi}$ tensile residual stress acting across the entire pressure vessel wall thickness. In this case, the residual stress enhances the probability of initiation and diminishes the probability of a stable crack arrest.

3. A $6 \mathrm{ksi}$ tensile residual stress across the first inch of base metal. In this case, the residual stress enhances the probability of initial crack initiation but has little or no effect on crack arrest and reinitiation.

Case 1 is corsidered to be nonconservative; case 2 is considered to be unnecessarily conservative; and case 3 is considered to be a more realistic method because residual stresses are self equilibrating; as the crack propagates, the residual stress is relieved.

Figure G.1 shows the hoop stresses at a time of $20 \mathrm{~min}$ for the above three cases and Fig. G.2 shows the corresponding $\mathrm{K}_{\mathrm{I}}$ distributions for axial surface flaws.

Figure $\mathrm{G} .3$ shows that $\hat{\mathrm{P}}(\mathrm{FIE})$ for case 2 is higher by a factor of approximately 2 than that for case 1 , and case 3 is bracketed by case 1 and case 2 .

The models used in this report to calculate probabilities of failure for welds incorporated method 3. No residual stresses were included in the analysis of the plate regions.

\subsection{Method of Analysis to Include Dynamic Fracture}

In the analysis of subclad and embedded flaws, rapid loading effects caused by cladding failure were included by using $\mathrm{K}_{\mathrm{Id}}$, instead of $\mathrm{K}_{\mathrm{Ic}}$, to predict crack initiation in the base metal (outer crack tip) for the time step at which the cladding fails. Figure H.1 shows experimental dynamic fracture initiation toughness datall as a function of loading rate and temperature. Values of $\mathrm{KId}_{\mathrm{Id}}$ for a loading rate of $10^{5} \mathrm{ksi} \sqrt{\mathrm{in} .} / \mathrm{s}$ and various temperatures are plotted in Fig. H.2, which shows that the lower-bound $\mathrm{KIc}$ curve shifted by $33^{\circ} \mathrm{F}$ is a reasonable lower-bound approximation for the $\mathrm{K}_{\mathrm{Id}}$ experimental data. Figure H. 3 shows that for T-RTNDT $=0^{\circ} \mathrm{F}$, which corresponds to many of the initiation events, the value of KId is $\sim 75 \%$ of $\mathrm{KIC}$.

\subsection{Method of Analysis for Including Clad Rupture for Subclad Flaws}

Analyses were perforned to determine the minimum flaw size and corresponding time during the SBLOCA7 transient for which the cladding would fail. The results of these analyses indicated that for welds, with 0.25 -in. cladding, a subclad flaw with $a \geq 1.65$ in. would result in cladding failure at a time of $21 \mathrm{~min}$ into the transient. For the case of plates, with 0.109 -in. cladding, a subclad rlaw with $a \geq 0.75$ in. would result in cladding failure at a time of $21 \mathrm{~min}$ into the transient.

The details of these studies are presented in Appendix I.

\subsection{Method of Analysis for Including Noncontinuous Clad/Base Interface}

The plate regions between the spot welds were specified as having a water-filled gap of -3 mils between the cladding and the base metal. As explained below, the noncontinuous interface reduces the probaility of crack propagation for flaws that exist in the plate regions between the spot welds and increases the probability of crack propagation for flaws that exist in the plate spot welds.

Flaws that exist in the plate regions between the spot welds do not penetrate the cladding and are subjected to lower thermal stresses and reside in a region of higher fracture toughness (deeper flaw for same flaw size), and higher temperatures. This reduction in the probability of flaw propagation was included in the analysis.

Flaws that exist in the plate region spot welds are subjected to higher loads because of load transfer resulting from the existence of the adjacent 3-mil gap. However, as indicated below, the effect on P(FIE) is small and for that reason was not included in the sensitivity study.

Three-dimensional thermoelastic finite-element analyses were performed to determine the variation in $\mathrm{K}_{\mathrm{I}}$ along a straight axial flaw that connects two or more spot welds. The SBLOCA7 transient (time $=20 \mathrm{~min}$ ) was used for the mechanical and thermal loadings, and a cladding thickness of $0.109 \mathrm{in}$. and a flaw depth of $0.25 \mathrm{in}$. were used. The calculated $\mathrm{K}_{\mathrm{I}}$ value was higher by only $5 \%$ at the spot weld than at the center of the unbonded region . The details of the three-dimensional finite-element analyses are included in Appendix J. 


\section{Results}

\subsection{Temperatures, Stresses, and KI's}

Plots of the thermal response and loads for the different vessel regions are included in Appendix A. It suffices to say here that the maximum load occurs at $\sim 20$ min into the transient.

\subsection{Values of $\hat{\mathbf{P}}(\mathbf{F} \mid \mathbf{E})$}

Best-estimate values of $\hat{P}(F I E)$ for each flaw type and region of the vessel are presented in Tables $2-4$ and Figs. 1-5, and two example problems are included in Sect. 5 to demonstrate the mechodology for obtaining values of $P(F \mid E)$ and $\phi(F)$ from these results. 


\section{Example Prokiems for Calculating $P(F \mid E)$ and Frequency of Failure $[\phi(F)]$}

\subsection{Example Problem 1 (Surface Flaws)}

Assumed conditions:

\author{
Flaws are surface flaws \\ Flaw Density for welds = \\ $1 \mathrm{flaw} / \mathrm{m}^{3}=0.028 \mathrm{flaw} / \mathrm{ft}^{3}$ \\ Flaw Density for plates $=$ \\ $1 \mathrm{flaw} / \mathrm{m}^{3}=0.028 \mathrm{flaw} / \mathrm{ft}^{3}$ \\ Weld Copper Content $=$ \\ $0.30 \mathrm{wt} \%$ \\ Upper Plate Surface R INDT \\ $=280^{\circ} \mathrm{F}$ \\ Lower Plate Surface RTNDT \\ $=351^{\circ} \mathrm{F}^{*}$
}

As discussed in Sect. 3.1, the contribution of each region must be included in the calculation of $P(F \mid E)_{\text {total: }}$

$$
P(F \mid E) \text { total }=\sum_{j} P_{j}(F \mid E)
$$

where $\mathrm{j}=$ all regions of the vessel.

Therefore,

$$
\begin{aligned}
& \mathrm{P}(\mathrm{F} \mid \mathrm{E}) \text { total }=\mathrm{P}(\mathrm{F} \mid \mathrm{E}) \text { uaw }+\mathrm{P}(\mathrm{F} \mid \mathrm{E}) \text { law }+ \\
& \mathrm{P}(\mathrm{F} \mid \mathrm{E}) \mathrm{cw}+\mathrm{P}(\mathrm{F} \mid \mathrm{E}))_{\mathrm{up}}+\mathrm{P}(\mathrm{F} \mid \mathrm{E})_{\mathrm{l}} \mathrm{p},
\end{aligned}
$$

where

$$
\begin{aligned}
& \text { uaw }=\text { upper axial weld } \\
& \text { law }=\text { lower axial weld } \\
& \mathrm{cw}=\text { circumferential weld } \\
& \text { up }=\text { upper plate } \\
& \text { lp }=\text { lower plate. }
\end{aligned}
$$

A convenient grouping is as follows:

$$
\mathrm{P}(\mathrm{F} \mid \mathrm{E}) \text { total }=\mathrm{P}(\mathrm{FIE})_{\text {welds }}+\mathrm{P}(\mathrm{FIE}) \text { plates } .
$$

\section{Welds}

$\mathrm{P}(\mathrm{F} \mid \mathrm{E})_{\text {welds }}$ can be obtained by simply adding values from Tables $2-4$ (Figs. 1-5) because these values are properly normalized with regard to the fluence spatial distribution. Thus,

$$
\begin{aligned}
P(F \mid E)_{\text {welds }} & =\sum_{j}\left(N_{j} V_{j} I\right) \times \hat{P}_{j}(F \mid E) \\
& =N I\left\{V_{\text {uaw }} \hat{P}(F \mid E) \text { uaw }+ \text { Vlaw } \hat{P}(F \mid E)\right. \text { law } \\
& \left.+V_{c w} \hat{P}(F \mid E) c w\right\}
\end{aligned}
$$

where

$$
\begin{aligned}
& \hat{P}_{j}(F \mid E)= P_{j}(F \mid E) / N_{j} V_{j} I \\
& V_{\text {uaw }}= \begin{array}{l}
\text { Volume of upper axial weld in } \\
\text { beltline region }=0.675 \mathrm{ft}^{3} \text { (from }
\end{array} \\
&\text { Table } 1) \text { Volume of lower axial weld in } \\
& V_{\text {law }}=\begin{array}{l}
\text { beltline region }=0.30 \mathrm{ft}^{3} \\
\text { bolume of circumferential weld in }
\end{array} \\
& V_{\mathrm{cw}}=\begin{array}{l}
\text { Volume } \\
\text { beltline region }=2.73 \mathrm{ft}^{3}
\end{array}
\end{aligned}
$$

Obtaining values of $\hat{P}(F ; E)$ from Table 2 ,

$$
\begin{aligned}
\mathrm{P}(\mathrm{FE})_{\text {welds }}= & (0.028)(0.587)[(0.675)(0.074) \\
& +(0.30)(0.049)+ \\
& (2.73)(0.0024)] \\
= & 0.00117
\end{aligned}
$$

Plates

To obtain P(FIE) for the plates, values of RTNDT at specific locations in the plates must be known, and they must be consistent with the fluence spatial distribution, including that in the welds (see Sect. 3.2). Consistent values are given for this sample problem; for the more general case, see Sect. 3.2.

Surface flaws in the plates are assumed to exist only in the cladding-attachment spot welds, which occupy $~ 52 \%$ of the plate surface area: multipling the total plate volume by 0.52 and considering that consistent values of RTNDT are given,

$$
\begin{aligned}
\mathrm{P}(F \mid E)_{\text {plates }} & =0.52 \sum_{j}\left(\mathrm{~N}_{j} \mathrm{~V}_{j} I\right) \times \hat{\mathrm{P}}_{j}(\mathrm{~F} \mid \mathrm{E}) \\
& =0.52 \mathrm{NI}\left[\mathrm{V}_{\mathrm{up}} \hat{\mathrm{P}}(\mathrm{F} \mid \mathrm{E})_{\mathrm{up}}+\mathrm{V}_{\mathrm{lp}} \hat{\mathrm{P}}(\mathrm{F} \mid \mathrm{E})_{\mathrm{lp}}\right],
\end{aligned}
$$

where

$$
\begin{aligned}
& V_{l p}=\begin{array}{l}
\text { total volume of upper plate in beltline } \\
\text { region } \left.=144 \mathrm{ft}^{3} \text { (Table } 1\right)
\end{array} \\
& V_{l p}=\begin{array}{l}
\text { total volume of lower plate in beltline } \\
\text { region }=64 \mathrm{ft}^{3}
\end{array} \\
& \hat{\mathrm{P}}(\mathrm{F} \mid \mathrm{E})_{\mathrm{u}} \text { and } \hat{\mathrm{P}}(\mathrm{F} \mid \mathrm{E})_{\mathrm{lp}} \text { correspond to surface flaws } \\
& \text { in the spot welds (Table 4). }
\end{aligned}
$$

Thus,

$$
\begin{aligned}
& \mathrm{P}(\mathrm{FIE}) \text { plates }=(0.52)(0.028)(0.587) \\
& \{(144)(0.017)+(64)(0.068)\}=0.0581
\end{aligned}
$$

and

\footnotetext{
*See Sect. 3.2.
} 
The mean value of $P(F \mid E)$ is estimated roughly by multiplying the best-estimate value by the ratio of mean flaw density to best-estimate flaw density. For this study that ratio is 45 . Thus,

$$
\mathrm{P}(\mathrm{F} \mid \mathrm{E})_{\text {mean }}=0.059 \times 45=2.7 .
$$

Of course, $F(F \mid E)$ can not actually exceed unity but does in this case because of double counting. In the absence of a proper correction for double counting, let $P(F \mid E)_{\text {mean }} \leq 1.0$. With this conservative simplifying assumption made, and taking the event frequency to be $2 \times 10^{-3} / \mathrm{yr}$, the frequency of failure is

$$
\phi(\mathrm{F})_{\text {mean }}=1.0(0.0020)=2.0 \mathrm{E}-3 \text { failures } / \mathrm{yr} \text {. }
$$

In a previous ORNL study of the Yankee Rowe reactor pressure vessel, 1 only the upper axial weld was calculated in detail. The reported value of $P(F \mid E)=8 E-4$ compares well with the value calculated here $\mathrm{fc}^{-}$the upper axial weld, $[(0.028)(0.587)(0.675)(0.074)=8 \mathrm{E}-4]$, even though there are some slight differences in the two analyses. In the earlier study, the contribution of the other regions and the effect of double counting were estimated by doubling the value of $P(F \mid E)$ calculated for the urper axial weld. In this example, each region was treated in detail, and double counting was accounted for in a different way, leading to larger values of $P(F \mid E)$ and $\phi(F)$. The actual effect of double counting has yet to be determined.

\subsection{Example Problem 2 (Subclad Flaws)}

Assumed conditions: Flaws are assumed to be subclad flaws

Flaw density for welds =

$1 \mathrm{nlaw} / \mathrm{m}^{3}=0.028 \mathrm{flaw} / \mathrm{ft}^{3}$

Flaw density for plates $=$

$1 \mathrm{flaw} / \mathrm{m}^{3}=0.028 \mathrm{flaw} / \mathrm{ft}^{3}$

Weld copper content $=0.25 \%$ Upper-plate surface RTNDT = $250^{\circ} \mathrm{F}$

Lower-plate surface RTNDT = $322^{\circ} \mathrm{F}^{*}$

Following the same methodology demonstrated in Example 1:

Welds:

$\mathrm{P}(\mathrm{F} \mid \mathrm{E})$ welds $=$ $N I\left[V_{\text {uaw }} \hat{P}(F \mid E)_{\text {uaw }}+V_{\text {law }} \hat{P}(F \mid E)_{\text {law }}+V_{c w} \hat{P}(F \mid E)_{c w}\right]$

$$
\begin{aligned}
\mathrm{P}(\mathrm{F} \mid \mathrm{E})_{\text {welds }=} & (0.028)(0.587)\{(0.675) \\
& (0.0053)+(0.30)(0.0031)+ \\
& (2.73)(0.0)\} \\
= & 0.000074 .
\end{aligned}
$$

\section{Plates:}

Subclad flaws in plates exist in the spot welds $(52 \%$ of plate surface area) and in the area between the spot welds (48\% of plate surface area); therefore, the method for combining $\mathrm{P}(\mathrm{F} \mid \mathrm{E})$ for the upper and lower plates is as follows:

$$
\begin{aligned}
& P(F \mid E)_{\text {plates }}=0.52\left[\sum_{j}\left(N_{j} V_{j} I\right) \hat{P}_{j}(F \mid E)\right]_{i s w}+0.48 \\
& {\left[\sum_{j}\left(N_{j} V_{j} I\right) \hat{P}_{j}(F \mid E)\right]_{\text {bew }}} \\
& \mathrm{P}(\mathrm{F} \mid \mathrm{E})_{\text {plates }}=(0.52)(0.028)(0.587) \\
& \left\{\mathrm{V}_{\mathrm{up}} \hat{\mathrm{P}}(\mathrm{F} \mid \mathrm{E})_{\mathrm{up}}+\mathrm{V}_{\mathrm{lp}} \hat{\mathrm{P}}(\mathrm{F} \mid \mathrm{E})_{\mathrm{lp}}\right\}_{\mathrm{sw}}+ \\
& (0.48)(0.028)(0.587) \\
& \left\{\mathrm{V}_{u p} \hat{\mathrm{P}}(\mathrm{F} \mid \mathrm{E})_{u p}+\mathrm{V}_{\mathrm{lp}} \hat{\mathrm{P}}(\mathrm{F} \mid \mathrm{E})_{\mathrm{p}}\right\}_{\text {bow }}
\end{aligned}
$$

where

$$
\begin{array}{ll}
\mathrm{V}_{\text {up }}, \mathrm{V}_{\mathrm{lp}}= & \begin{array}{l}
\text { Volume of upper and lower } \\
\text { plates (Table } 1)
\end{array} \\
\hat{\mathrm{P}}(\mathrm{F} \mid \mathrm{E})= & \begin{array}{l}
\text { appropriate values for subclad } \\
\text { flaws in the upper and lower } \\
\text { plates for regions in the spot } \\
\text { welds (Table } 4 \text { ) and regions } \\
\text { between the spot welds }
\end{array} \\
& \begin{array}{l}
\text { (Table } 3 \text { ) } \\
\text { isw }
\end{array} \\
\text { designates plate regions in the } \\
\text { bsw } \quad \begin{array}{l}
\text { spot welds } \\
\text { designates plate regions between } \\
\text { the spot welds. }
\end{array}
\end{array}
$$

Obtaining values of $\hat{P}(F \mid E)$ for subclad flaws from Table 3 and 4 ,

$$
\begin{aligned}
\mathrm{P}(\mathrm{F} \mid \mathrm{E})_{\text {plates }=} & 0.00855\{(144)(0.00051)+(64) \\
& (0.0033)\}+0.00789\{(144) \\
& (0.001)+(64)(0.011)\} \\
= & 0.00243+0.00669=0.00912 \\
\mathrm{P}(\mathrm{F} \mid \mathrm{E})_{\text {total }}= & 0.000074+0.00912=0.00919
\end{aligned}
$$

and

$\mathrm{P}(\mathrm{F} \mid \mathrm{E})_{\text {mean }}=0.00919 \times 45=0.41$.

Taking the event frequency to be $2 \times 10^{-3} / \mathrm{yr}$,

$$
\phi(\mathrm{F})_{\text {mean }}=(0.41)(0.002)=8.2 \mathrm{E}-4 .
$$

* See Sect. 3.2. 


\section{Discussion of Results}

The sensitivity of $P(F i E)$ to variations in the several parameters considered depends on the values of $P(F \mid E)$ and RTNDT. As $P(F \mid E)$ approaches unity the sensitivity decreases, and when RTNDT corresponds to the lower shelf of the fracture-toughness curve, $P(F \mid E)$ is not sensitive in RTNDT and thus chemistry and $\Phi$.

Values of $\hat{P}_{j}(F \mid E), N_{j} V_{j} I$ and $P_{j}(F \mid E)$ for Example Problem 1 are summarized in Table 5. It is of interest to note that the upper and lower plate regions are the dominant regions [contribute the most to $P(F \mid E)_{\text {total] }}$ Also, the total number of flaws in the beltline is substantially greater than unity, indicating a double counting problem. The extent of the problem depends on the total number of flaws and the value of $P(F \mid E)_{\text {total }}$; for this case, if $P(F \mid E)_{\text {total }}<10^{-2}$, double counting is probably not significant. Obviously, there is a serious problem because $P(F \mid E)_{\text {total }}>1.0$. For the best-estimate case (flaw density $=1 \mathrm{flaw} / \mathrm{m}^{3}$ ) double counting is not a significant problem because

$$
\sum_{j}\left(N_{j} V_{j} I\right)=1.8 \text { and } P(F \mid E)_{\text {total }}=0.06
$$

For a given value of copper, values of $\hat{P}(F \mid E)$ for the upper axial weld are higher than those for the lower axial weld by approximately a factor of 2 . This is attributed to the higher fluences used for the upper axial welds. The average surface fluence in the upper axial weld is $0.914 \times 10^{19}$, whereas for the lower axial weld, the average surface fluence is $0.605 \times 10^{19}$. Also, the volume of the upper axial weld in the beltline region is over double that of the lower axial weld; therefore, the upper axial weld will contribute to the total vessel probability of failure more than the lower axial weld by approximately a factor of 4 , assuming the same value of copper and flaw density.

$\hat{P}(F \mid E)$ values for circumferential flaws, which exist in the circumferential weld, are lower than those in the upper axial weld by between 1 and 2 orders of magnitude; therefore, the circumferential flaws are relatively small contributors to the overall value of vessel failure. The probability of initial initiation for flaws in the circumferential weld is approximately the same as for the upper axial weld; however, the smaller bending effect for circumferential flaws (Fig. A.6), results in considerably more stable arrests and subsequently less failures for the circumferential flaws.
RTNDT values and thus $\hat{P}(F I E)$ values for the upper and lower plates are nearly identical even though the fluences for the upper plate are considerably higher than those for the lower plate (the average fluence for upper plate is $1.689 \times 10^{19}$; for lower plate it is $1.074 \times 10^{19}$ ) because the Odette $\triangle R T N D T$ correlation for the lower plate adds $80^{\circ} \mathrm{F}$ to that for the upper plate to account for the higher nickel concentration in the lower plate.

For the upper and lower axial welds, $\hat{\mathrm{P}}(\mathrm{F} \mid \mathrm{E})$ values for subclad and embedded flaws are approximately 1 and 3 orders of magnitude lower than those for surface flaws, respectively.

For upper and lower plates in the spot weld regions, $\hat{P}(F ! E)$ values for subclad flaws and embedded flaws are approximately 1 and 2 orders of magnitude lower than those for surface flaws, respectively. The reason that there is only 1 order of magnitude difference in the subclad flaws and the embedded flaws for the plates in the spot-weld region (relative to 2 orders of magnitude difference in the case of welds) is because $\mathrm{KI}$ values for embedded flaws are very sensitive to the location of the inner flaw tip (see Figs. A.7 and A.8). For the case of plates (clad thickness of 0.109 in.), the embedded flaw inner tip locations reside in a higher stress field, which results in more initiations and failures.

The fact that $\hat{P}(F \mid E)$ values for the subclad flaws for the upper and lower plate regions between the spot welds are higher than for the plate at the spot-weld regions at first seems surprising since these flaws are subjected to a less severe thermal load because of the insulating effect of the 3-mil gap between the clad and base. Another difference, however, is that the subclad flaws between the spot-weld regions are treated as surface flaws instead of subclad flaws. This competing effect more than offsets the effect of the reduced thermal load.

$\hat{P}(F \mid E)$ values for the embedded flaws in the plate region between the spot welds are considerably lower than those for embedded flaws in the plate region at the spot weld because of the insulating effect of the 3-mil gap between the cladding and base metal. This results in a reduced thermal shock to the base metal, lower thermal stresses, and higher fracture toughness. 


\section{Conclusions}

A. The results of this sensitivity analysis provides the NRC with data (Tables 2-4, Figs. 1-5) and a methodology (Sect. 5) to assess the relative influence of key input parameters on the conditional probability of failure [P(FE)] and the frequency of failure $[\varphi(F)]$ for the Yankee Rowe reactor pressure vessel.

B. When using the above data to estimate $P(F \mid E)$ and $\varphi(F)$, one must be careful to use values of $P(F \mid E)$ that are consistent with the overall fluence spatial distribution and the time of reactor operation.
C. Double counting may have to be accounted for, depending on the total number of flaws and the value of $P(F \mid E)_{\text {total. If the total number of flaws }}$ is less than unity, there is no double-counting effect.

D. The consideration of finite flaw length for arrest and reinitiation of surface flaws and initial initiation of embedded flaws could reduce the values of $\mathrm{P}(\mathrm{F} \mid \mathrm{E})$ substantially. 


\section{References}

1. R. D. Cheverton et al., Martin Marietta Energy Systems, Inc., Oak Ridge National Lab., Review of Reactor Pressure Vessel Evaluation Report for Yankee Nuclear Power Station (YAEC No. 1735), NUREG/CR-5799 (ORNL/TM-11982), March 1992. ${ }^{a}$

2. Yankee Atomic Electric Company, Reactor Pressure Vessel Evaluation Report for Yankee Nuclear Power Station, YAEC-1735, July 9,1990. ${ }^{b}$

3. R. D. Cheverton and D. G. Ball, Union Carbide Corp., Nuclear Division, Oak Ridge National Lab., Oak Ridge, Tenn., OCA-P, A Deterministic and Probabilistic Fracture Mechanics Code for Application to Pressure Vessels, NUREG/CR3618 (ORNL-5991), May 1984.

4. D. L. Selby et al., Martin Marietta Energy Systems, Inc., Oak Ridge National Lab., Pressurized Thermal Shock Evaluation of the HB. Robinson Nuclear Power Plant, NUREG/CR-4183 (ORNL/TM-9567), September $1985 .^{\circ}$

5. R. D. Cheverton et al., Martin Marietta Energy Systems, Inc., Oak Ridge National Lab., Pressure Vessel Fracture Studies Pertaining to the PWR Thermal Shock Issue: Experiment TSE-7, NUREG/CR-4304 (ORNL-6177), July $1985 .^{\circ}$

6. The American Society of Mechanical Engineers Boiler and Pressure Vessel Code, Sect. XI, Rules for Inservice Inspection of Nuclear Power Plant Components, Appendix A, "Analysis of Flaws," Article A-3000, Method For KI Determination, $1989 . .^{c}$
7. W. J. McAfee et al., "A Specimen and Method for Evaluating the Effect of Cladding on the Behavior of Subclad Flaws," ASME Pressure Vessel and Piping Pressure Vessel and Piping, PVP Vol. 213/MPC Vol. 32-Pressure Vessel Integrity, June 1991. ${ }^{d}$

8. K. J. Bathe, "ADINAT - A Finite Element Program For Automatic Dynamic Incremental Nonlinear Analysis of Temperatures," Massachusetts Institute of Technology, Cambridge, Mass., December $1978 .^{c}$

9. R. C. Cipola et al., Failure Analysis Associates, Computational Method to Perform the Flaw Evaluation Procedure as Specified in the ASME Code, Sect. XI, Appendix A, EPRI Report NP1181, September 1979.c

10. U.S. Nuclear Regulatory Commission. Regulatory Guide 1.99, Revision 2, "Radiation Embrittlement of Reactor Vessel Materials," May 1988.

11. W. O. Shabbits, Dynamic Fracture Toughness Properties of Heavy Sect. A533 Grade B Class 1 Steel Plate, Westinghouse R\&D Center, December $1970 .^{b}$

\footnotetext{
$a_{\text {Available for purchase from Govemment Printing Office Sales }}$ Program.

${ }^{b}$ Available from NRC Public Document Room for a fee.

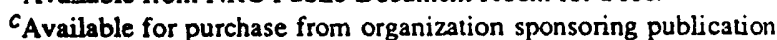
cited, and/or iuthors, and/or recipients (docurnented letters).
}

\footnotetext{
${ }^{a}$ Available for purchase from Govemment Printing Office Sales Program.

${ }^{b}$ Available from NRC Public Document Room for a fee.

${ }^{c}$ Available for purchase from organization sponsoring publication citcd, and/or authors, and/or recipients (documented letters).

d Available in Public Technical Libraries.
} 


\section{Vessel Geometry:}

Inner vessel radius $=54.5 \mathrm{in}$.

Wall thickness $=7.875$ in.

\section{Cladding Thickness:}

Weld regions $=0.250$ in.

Plate regions $=0.109$ in .

\section{Cladding Thermal-Elastic Material Properties:*}

Modulus of elasticity $(E)=27,000 \mathrm{ksi}$

Poisson's ratio $(v)=0.3$

Thermal expansion coefficient $\left(\alpha_{\text {clad }}\right)=9.9 \mathrm{E}-6 /{ }^{\circ} \mathrm{F}$

Thermal conductivity $(k)=10 \mathrm{BTU} / \mathrm{h}-\mathrm{ft}-{ }^{\circ} \mathrm{F}$

Specific heat $\left(c_{p}\right)=0.12 \mathrm{BTU} / \mathrm{lb}-{ }^{\circ} \mathrm{F}$

Density $(\rho)=488 \mathrm{lb} / \mathrm{ft} 3$

\section{Base Metal Thermal-Elastic Material Properties:*}

Modulus of elasticity $(E)=28,000 \mathrm{ksi}$

Poisson's ratio $(v)=0.3$

Thermal expansion coefficient $\left(\alpha_{\text {base }}\right)=7.85 \mathrm{E}-6 /{ }^{\circ} \mathrm{F}$

Thermal conductivity $(\mathrm{k})=24 \mathrm{BTU} / \mathrm{h}-\mathrm{ft}-{ }^{\circ} \mathrm{F}$

Specific heat $\left(c_{p}\right)=0.12 \mathrm{BTU} / \mathrm{lb}-{ }^{\circ} \mathrm{F}$

Density $(F)=488 \mathrm{lb} / \mathrm{ft} 3$

\section{Plate Regions Between Spot Welds:}

Gap between clad and base metal $=3$ mils

Thermal conductivity of water $(\mathrm{k})=0.32 \mathrm{BTU}, \mathrm{h} \cdot \mathrm{it}^{\circ}{ }^{\circ} \mathrm{F}$

Specific heat of water $=1.00 \mathrm{BTU} / \mathrm{lb}-{ }^{\circ} \mathrm{F}$

Density of water $=62.4 \mathrm{lb} / \mathrm{ft}^{3}$

\section{Operating Conditions:}

Initial vessel temperature $=515^{\circ} \mathrm{F}$

Initial water temperature $=515^{\circ} \mathrm{F}$

Coefficient of Convective Heat Transfer $=504 \mathrm{BTU} / \mathrm{h}-\mathrm{ft}^{2}-{ }^{\circ} \mathrm{F}$

Fluence Map Corresponding to the End of Cycle 22

Volume of Vessel Regions in Beltline:

Upper-axial weld: $0.675 \mathrm{ft} 3$

Lower-axial weld: $0.300 \mathrm{ft}^{3}$

Circumferential weld: $2.73 \mathrm{ft} 3$

Lower plate: $64 \mathrm{ft} 3$

Upper plate: $144 \mathrm{ft} 3$

See footnotes at end of table. 


\section{Fracture Properties:}

Initial (unirradiated) RTNDTo for weld material $=10^{\circ} \mathrm{F}$

Initial (unirradiated) RTNDTo for plate material $=30^{\circ} \mathrm{F}$

Maximum $\mathrm{K}_{\mathrm{Ia}}=200 \mathrm{ksi} \sqrt{\mathrm{in} \text {. }}$

Flow stress $=80.0 \mathrm{ksi}$

$\mathrm{K}_{\mathrm{Ic}}$ and $\mathrm{K}_{\mathrm{Ia}}$ mean curves were same as those used in the original IPTS studies, i.e.:

$\mathrm{K}_{\mathrm{Ia}}$ mean $=1.25 *$ ASME lower bound $\mathrm{K}_{\mathrm{Ia}}$ curve

$\mathrm{K}_{\mathrm{Ic}}$ mean $=1.43 *$ ASME lower bound $\mathrm{K}_{\mathrm{Ic}}$ curve

$\mathrm{K}_{\mathrm{Id}}$ mean $=1.43 * \mathrm{ASME}$ lower bound $\mathrm{K}_{\mathrm{Ic}}$ curve shifted by $33^{\circ} \mathrm{F}$

\section{RTNDT Correlations:}

Weld material:

Regulatory Guide 1.99 Revision 2 (welds) $+50^{\circ} \mathrm{F}$ for a low operating temperature correction factor.

Plate material:

Upper Plate - Odette correlation: $\triangle \mathrm{RTNDT}\left({ }^{\circ} \mathrm{F}\right)=183 *$ fluence 0.315

Lower Plate - Odette correlation: $\triangle \mathrm{RTNDT}\left({ }^{\circ} \mathrm{F}\right)=(183 *$ fluence 0.315$)+80$

\section{Probabilistic Parameters:}

$\triangle$ RTNDT standard deviation (welds) $=24^{\circ} \mathrm{F}$

$\triangle$ RTNDT standard deviation (plates) $=37^{\circ} \mathrm{F}$

RTNDTo standard deviation $=17^{\circ} \mathrm{F}$

$\mathrm{K}_{\mathrm{Ia}}$ standard deviation $=0.15$

$\mathrm{K}_{\mathrm{Ic}}$ standard deviation $=0.10$

$\triangle \mathrm{RT}$ NDT truncation $=+$ or $-3 \sigma$

$\mathrm{K}_{\mathrm{Ic}}$ truncation $=+$ or $-3 \sigma$

$\mathrm{K}$ Ia truncation $=+$ or $-3 \sigma$

Fluence standard deviation (fraction of mean) $=0.1$

Fluence variability truncation $=+$ or $-3 \sigma$

Mean nickel $=0.6 \mathrm{wt} \%$

Copper standard deviation $=0.07 \mathrm{wt} \%$

Marshall flaw size distribution function used

Marshall flaw nondetection function used (simulates preservice inspection)

All flaws were assumed to be infinite length.**

\footnotetext{
* No temperature dependence of material properies included in analysis.

** See Sect. 3.4.2.
} 
Table 2. Best-estimate unadjusted conditional probabilities of failure $[\hat{\mathrm{P}}(\mathrm{FIE})]$ for welds

$$
\text { Sensitivity with respect to copper }
$$

\begin{tabular}{llllll}
\hline \multicolumn{5}{c}{ Upper Axial Weld } \\
& $\mathrm{Cu}=0.15$ & $\mathrm{Cu}=0.20$ & $\mathrm{Cu}=0.25$ & $\mathrm{Cu}=0.30$ & $\mathrm{Cu}=0.35$ \\
\cline { 2 - 6 } Surface flaw & $1.3 \mathrm{E}-2$ & $2.5 \mathrm{E}-2$ & $4.5 \mathrm{E}-2$ & $7.4 \mathrm{E}-2$ & $1.0 \mathrm{E}-1$ \\
Subclad flaw & $7.3 \mathrm{E}-4$ & $2.0 \mathrm{E}-3$ & $5.3 \mathrm{E}-3$ & $1.1 \mathrm{E}-2$ & $2.0 \mathrm{E}-2$ \\
Embedded flaw & $7.0 \mathrm{E}-6$ & $2.5 \mathrm{E}-5$ & $7.4 \mathrm{E}-5$ & $1.5 \mathrm{E}-4$ & $2.2 \mathrm{E}-4$ \\
\hline & & Lower Axial & Weld & & \\
\hline & & & & & \\
\hline Surface flaw & $8.7 \mathrm{E}-3$ & $1.7 \mathrm{E}-2$ & $3.0 \mathrm{E}-2$ & $4.9 \mathrm{E}-2$ & $7.1 \mathrm{E}-2$ \\
Subclad flaw & $3.8 \mathrm{E}-4$ & $1.2 \mathrm{E}-3$ & $3.1 \mathrm{E}-3$ & $7.1 \mathrm{E}-3$ & $1.2 \mathrm{E}-2$ \\
Embedded flaw & $3.0 \mathrm{E}-6$ & $1.0 \mathrm{E}-5$ & $3.0 \mathrm{E}-5$ & $6.9 \mathrm{E}-5$ & $1.2 \mathrm{E}-4$ \\
\hline
\end{tabular}

Circumferential Weld

\begin{tabular}{lcrrrr}
\hline Surface flaw & $9.1 \mathrm{E}-5$ & $3.8 \mathrm{E}-4$ & $1.0 \mathrm{E}-3$ & $2.4 \mathrm{E}-3$ & $4.7 \mathrm{E}-3$ \\
Subclad flaw & $<1.0 \mathrm{E}-6$ & $<1.0 \mathrm{E}-6$ & $<1.0 \mathrm{E}-6$ & $<1.0 \mathrm{E}-6$ & $<1.0 \mathrm{E}-6$ \\
Embedded flaw & $<1.0 \mathrm{E}-6$ & $<1.0 \mathrm{E}-6$ & $2.0 \mathrm{E}-6$ & $4.5 \mathrm{E}-6$ & $1.5 \mathrm{E}-5$ \\
\hline
\end{tabular}


Table 3. Best-estimate unadjusted conditional probabilities of failure $[\hat{P}(F \mid E)]$ for plate (between spot welds)

\section{Sensitivity with respect to surface RTNDT}

\begin{tabular}{|c|c|c|c|c|c|c|c|}
\hline \multicolumn{8}{|c|}{ Upper Plate } \\
\hline RTNDT $_{\mathrm{s}}{ }^{a}=$ & 250 & 275 & 300 & 325 & & & \\
\hline Subclad flaw* & $1.0 \mathrm{E}-3$ & $2.7 \mathrm{E}-3$ & $6.2 E-3$ & $1.2 \mathrm{E}-2$ & & & \\
\hline Embedded flaw & $1.5 \mathrm{E}-5$ & $4.0 \mathrm{E}-5$ & $9.0 \mathrm{E}-5$ & $1.8 \mathrm{E}-4$ & & & \\
\hline \multicolumn{8}{|c|}{ Lower Plate } \\
\hline RTNDT $_{\mathrm{s}}{ }^{a}=$ & 250 & 275 & 300 & 325 & 350 & 375 & 400 \\
\hline Subclad flaw ${ }^{b}$ & $1.1 \mathrm{E}-3$ & $2.8 \mathrm{E}-3$ & $5.7 \mathrm{E}-3$ & $1.1 \mathrm{E}-2$ & $1.7 \mathrm{E}-2$ & $2.5 \mathrm{E}-2$ & $3.3 \mathrm{E}-2$ \\
\hline Embedded flaw & $1.6 \mathrm{E}-6$ & $3.5 \mathrm{E}-5$ & $7.6 \mathrm{E}-5$ & $1.6 E-4$ & $2.7 E-4$ & $4.2 \mathrm{E}-4$ & $5.7 \mathrm{E}-4$ \\
\hline
\end{tabular}

a Maximum value in region

bSubclad flaws treated as surface flaws. 
Table 4. Best-estimate unadjusted conditional probabilities of failure $[\hat{\mathrm{P}}(\mathrm{FIE})]$ for plate (at spot welds)

\section{Sensitivity with respect to surface RTNDT}

\begin{tabular}{|c|c|c|c|c|c|c|c|}
\hline \multicolumn{8}{|c|}{ Upper Plate } \\
\hline RTNDT $_{\mathrm{s}}{ }^{a}=$ & 250 & 275 & 300 & 325 & & & \\
\hline Surface flaw & $6.9 \mathrm{E}-3$ & $1.7 \mathrm{E}-2$ & $3.0 \mathrm{E}-2$ & $5.2 \mathrm{E}-2$ & & & \\
\hline Subclad flaw & $5.1 E-4$ & $1.1 \mathrm{E}-3$ & $2.0 \mathrm{E}-3$ & $3.6 \mathrm{E}-3$ & & & \\
\hline Embedded flaw & $1.0 \mathrm{E}-4$ & $2.2 \mathrm{E}-4$ & $4.2 \mathrm{E}-4$ & $6.9 \mathrm{E}-4$ & & & \\
\hline \multicolumn{8}{|c|}{ Lower Plate } \\
\hline RTNDT $_{s}{ }^{a}=$ & 250 & 275 & 300 & 325 & 350 & 375 & 400 \\
\hline Surface flaw & $7.4 \mathrm{E}-3$ & $1.5 \mathrm{E}-2$. & $2.8 \mathrm{E}-2$ & $4.5 \mathrm{E}-2$ & $6.8 \mathrm{E}-2$ & $9.1 \mathrm{E}-2$ & $1.1 \mathrm{E}-1$ \\
\hline Subclad flaw & $5.3 E-4$ & $1.1 \mathrm{E}-3$ & $2.0 \mathrm{E}-3$ & $3.3 \mathrm{E}-3$ & $5.2 E-3$ & $7.3 \mathrm{E}-3$ & $1.0 \mathrm{E}-2$ \\
\hline Embedded flaw & $1.2 \mathrm{E}-4$ & $2.3 \mathrm{E}-4$ & $3.9 \mathrm{E}-4$ & $6.4 \mathrm{E}-4$ & $9.1 \mathrm{E}-4$ & $1.2 \mathrm{E}-3$ & $1.5 \mathrm{E}-3$ \\
\hline
\end{tabular}

a Maximum value in region. 
Table 5. Summary of results of Example Problem 1

\begin{tabular}{llll}
\hline Region & $\hat{\mathrm{P}}_{\mathrm{j}}$ (FE) & $\begin{array}{c}\text { Number of flaws } \\
\mathrm{N}_{\mathrm{j}}^{*} \mathrm{~V}_{\mathrm{j}}^{* I}\end{array}$ & $\mathrm{P}_{\mathrm{j}}(\mathrm{FIE})$ \\
\hline UAW & 0.074 & 0.011 & 0.0008 \\
LAW & 0.049 & 0.005 & 0.0003 \\
CW & 0.0024 & 0.045 & 0.0001 \\
UP & 0.017 & 1.231 & 0.0209 \\
LP & 0.068 & 0.547 & 0.0372 \\
Totals (best estimate) & & 1.839 & 0.0593 \\
Totals (mean) & & 82.755 & 2.669 \\
\hline
\end{tabular}




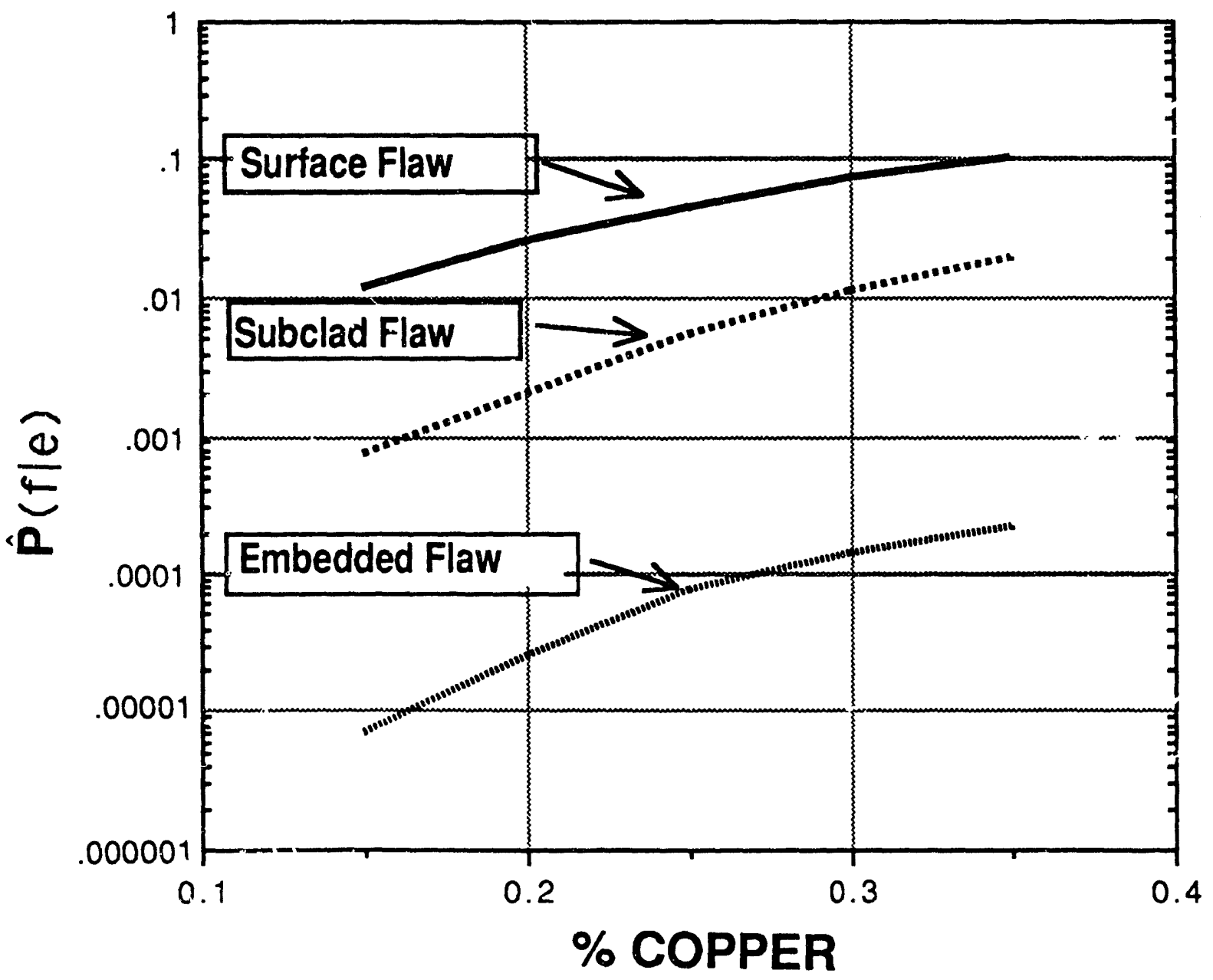

Fig. 1. Unadjusted best-estimate conditional probability of failure. Upper Axial Weld. 


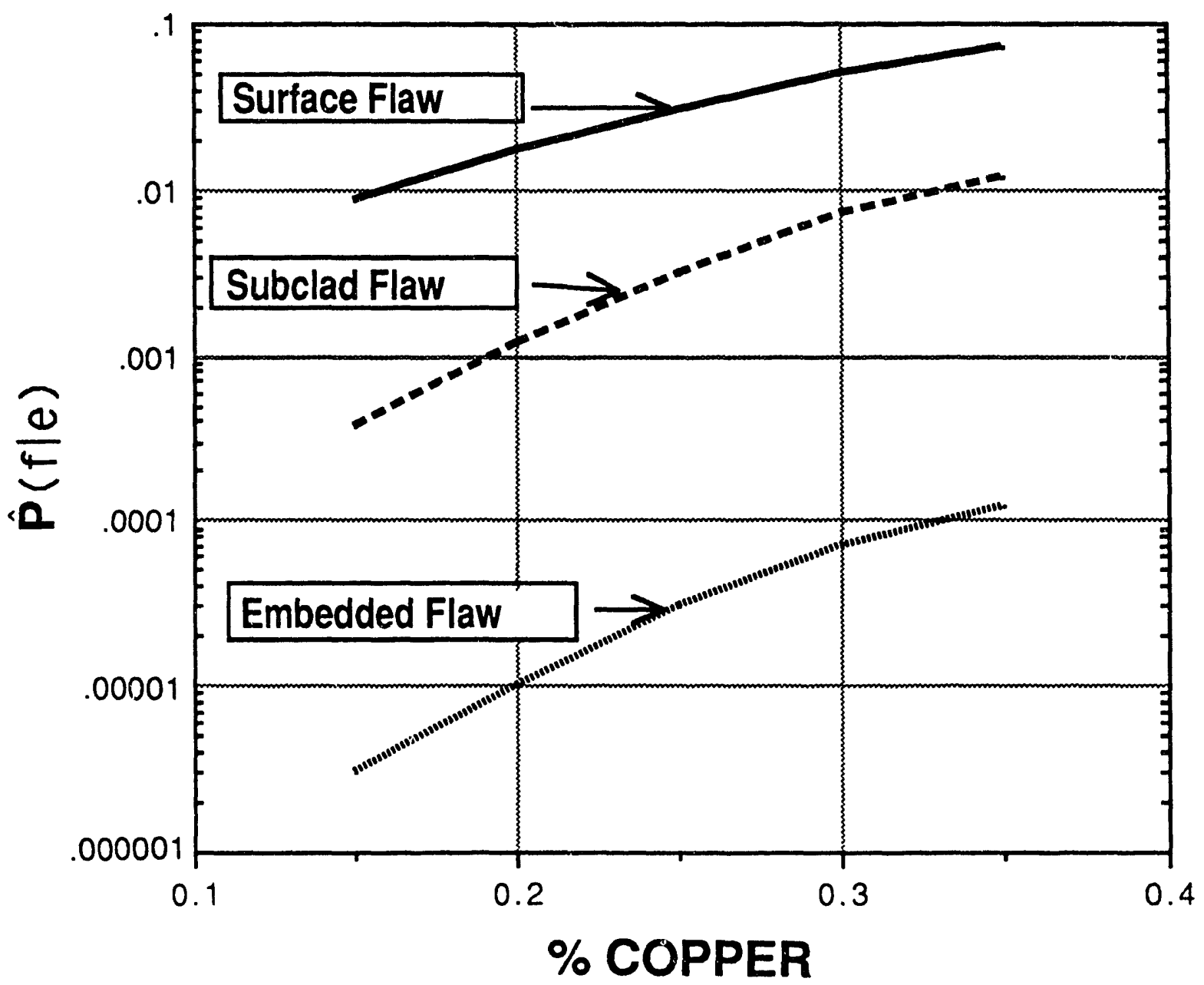

Fig. 2. Unadjusted best-estimate conditional probability of failure. Lower Axial Weld. 


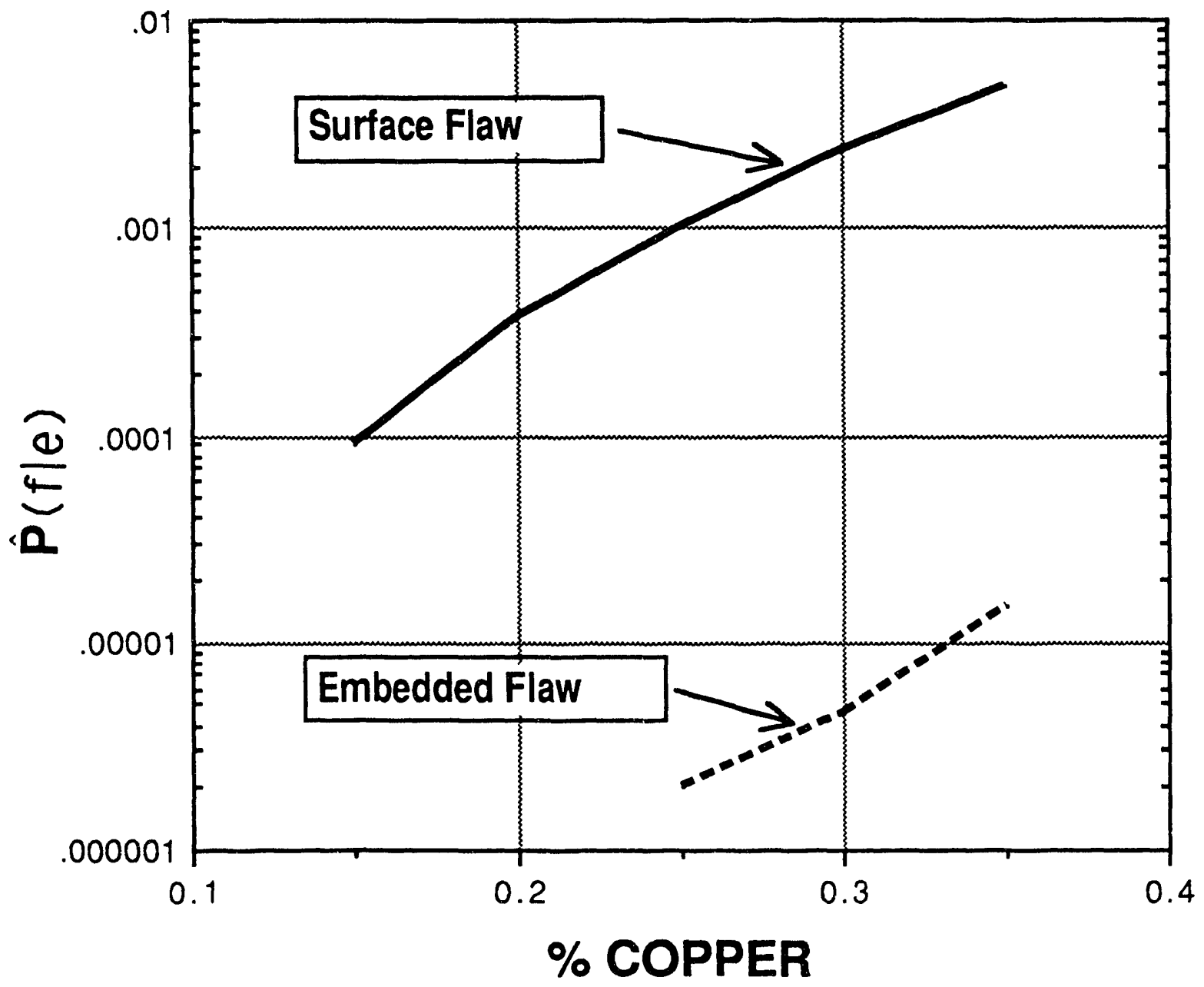

Fig. 3. Unadjusted best-estimate conditional probability of failure. Circumferential Weld. 


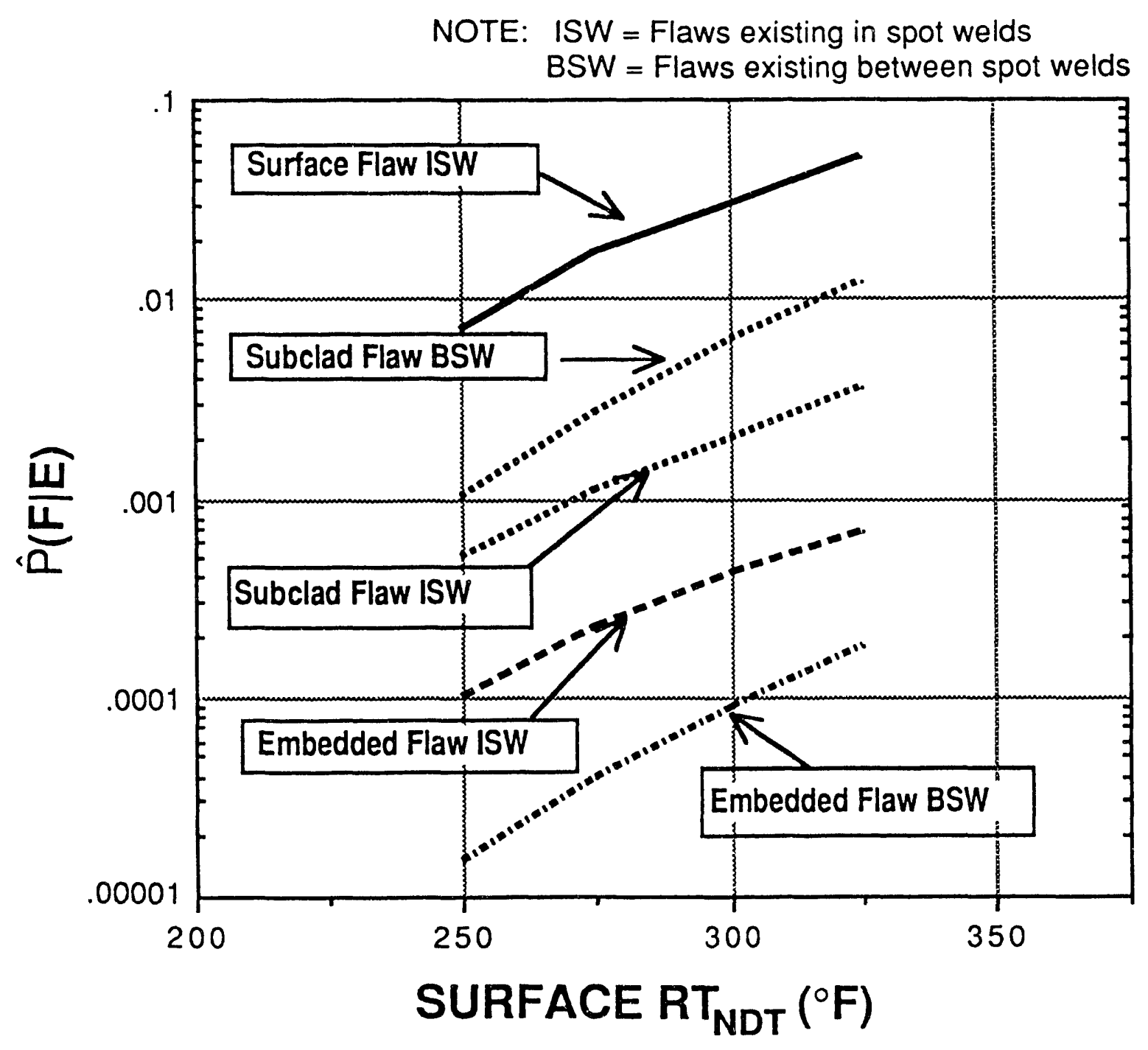

Fig. 4. Unadjusted best-estimate conditional probability of failure. Upper Plate. 


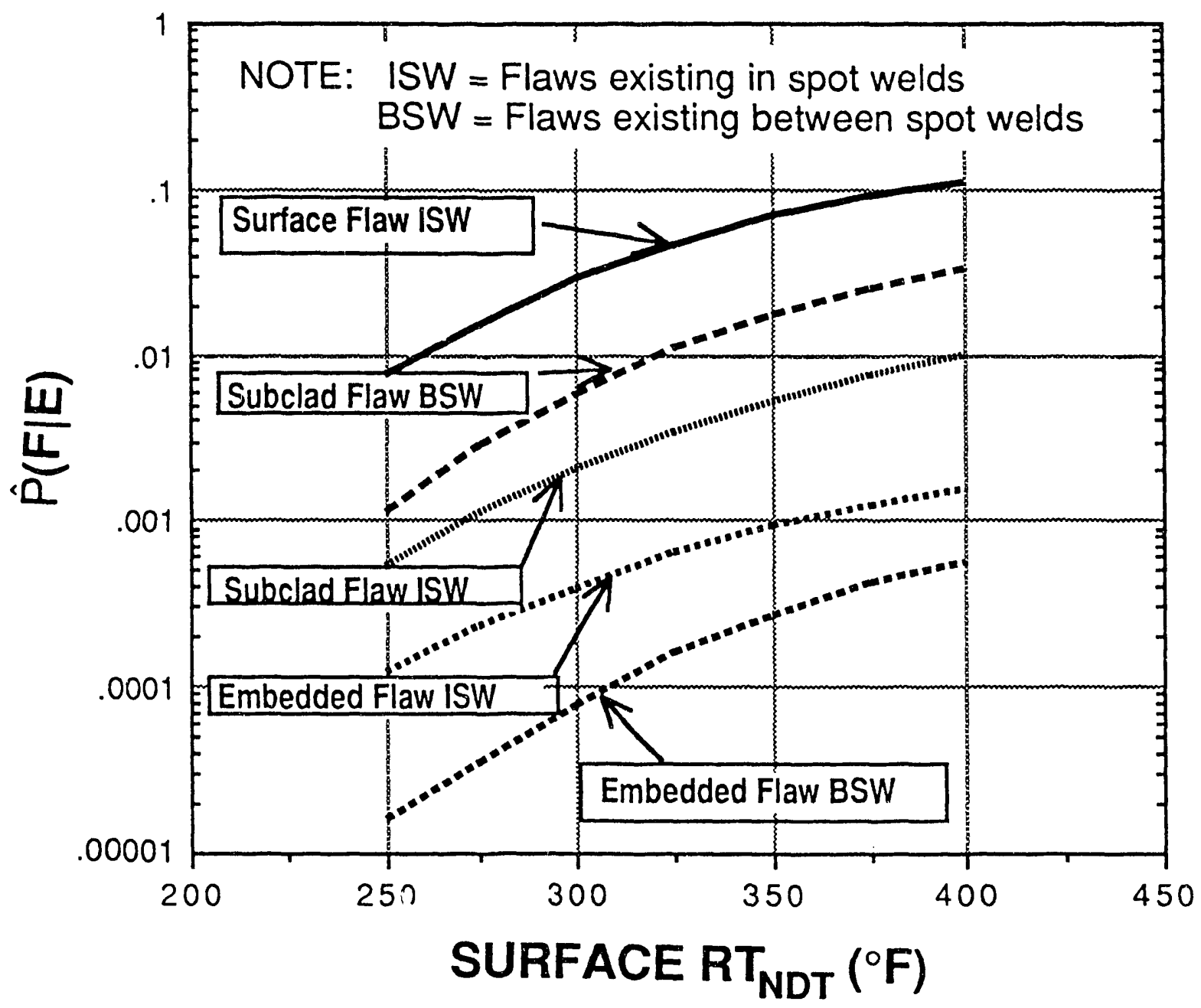

Fig. 5. Unadjusted best-estimate conditional probability of failure. Lower Plate. 


\section{Appendix A: Transient Definition and Resulting Loads}

Figure A.1. Yankee Rowe SBLOCA7 Thermal and Pressure Transient.

Figure A.2. Thermal Response of Yankee Rowe Vessel to SBLOCA7 Transient (time $=20 \mathrm{~min}$ ).

Figure A.3. Hoop Stress Distributions (time $=20 \mathrm{~min}$ ).

Figure A.4. Axial Stress Distribution (time $=20 \mathrm{~min}$ ).

Figure A.5. $\mathrm{K}_{\mathrm{I}}$ Distributions for Axial Surface Flaws (time $=20 \mathrm{~min}$ ).

Figure A.6. $\mathrm{K}_{\mathrm{I}}$ Distribution for Circumferential Surface Flaws (time $=20 \mathrm{~min}$ ).

Figure A.7. $\mathrm{K}_{\mathrm{I}}$ for Embedded Flaws Located in Welds (time $=20 \mathrm{~min}$ ).

Figure A.8. $\mathrm{K}_{\mathrm{I}}$ for Embedded Flaws Located in Plate (time $=20 \mathrm{~min}$ ). 


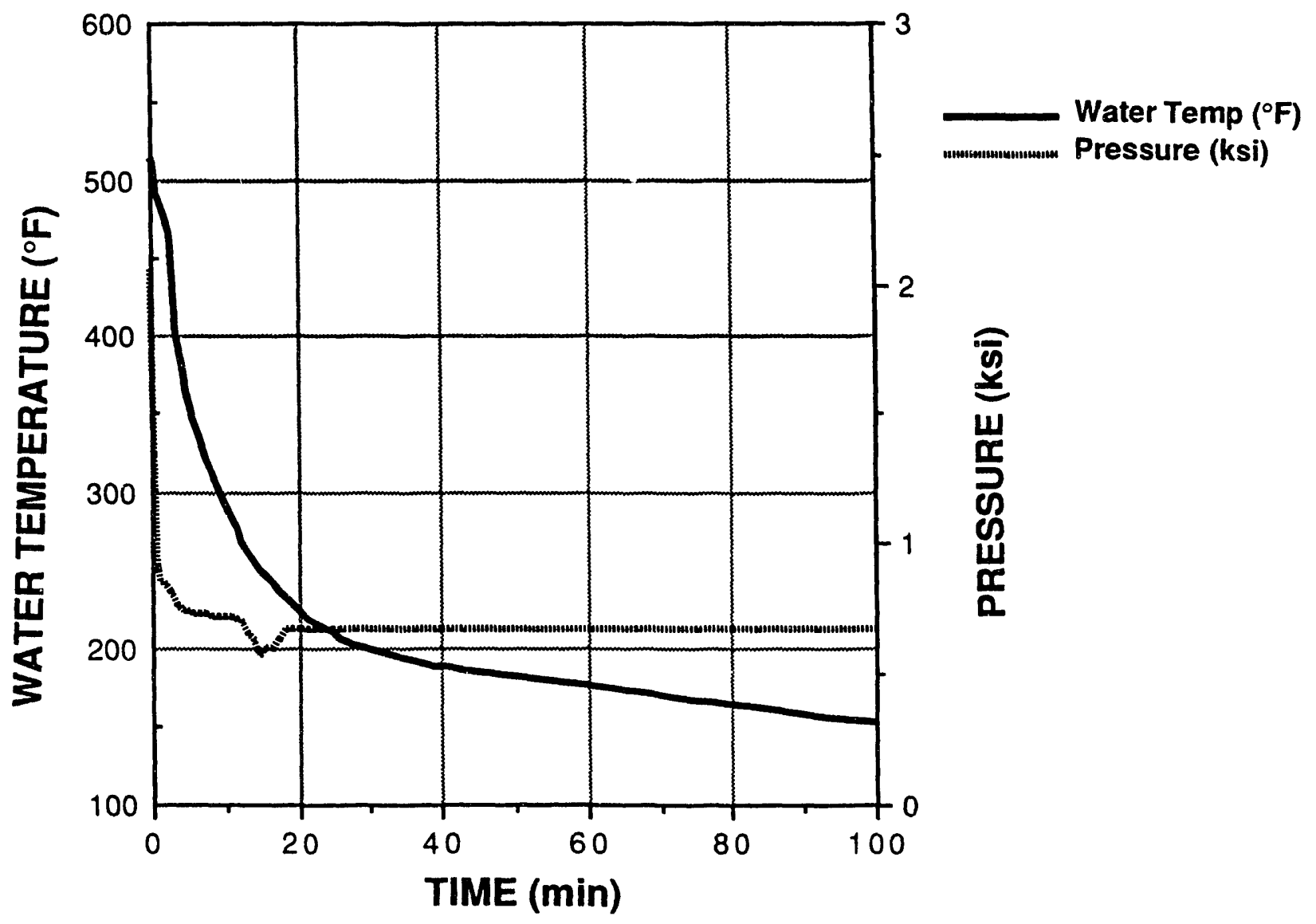

Fig. A.1 Yankee Rowe SBLOCA7 thermal and pressure transient. 


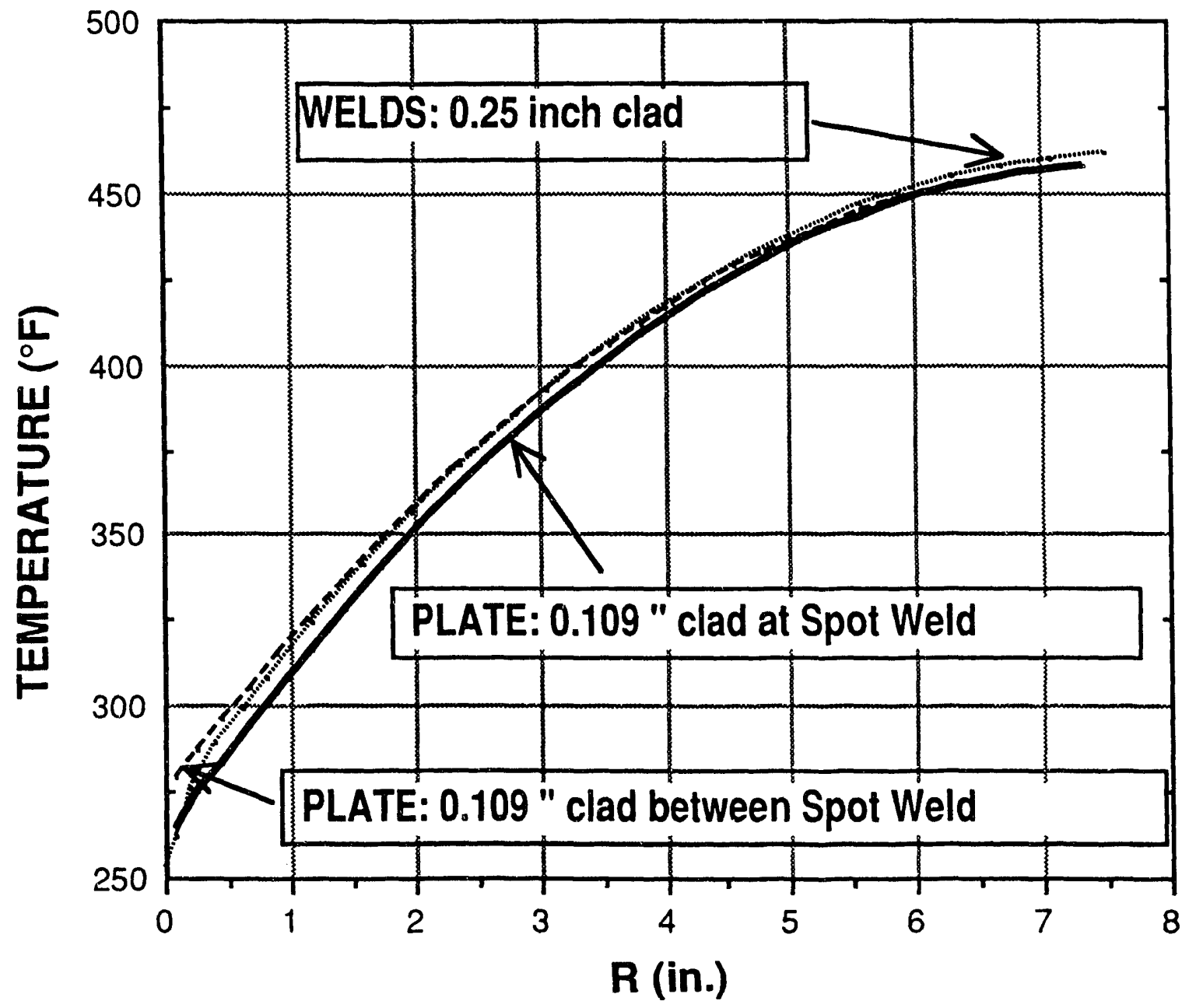

Fig. A.2. Thermal response of Yankee Rowe vessel to SBLOCA7 transient (time $=20 \mathrm{~min}$ ). 


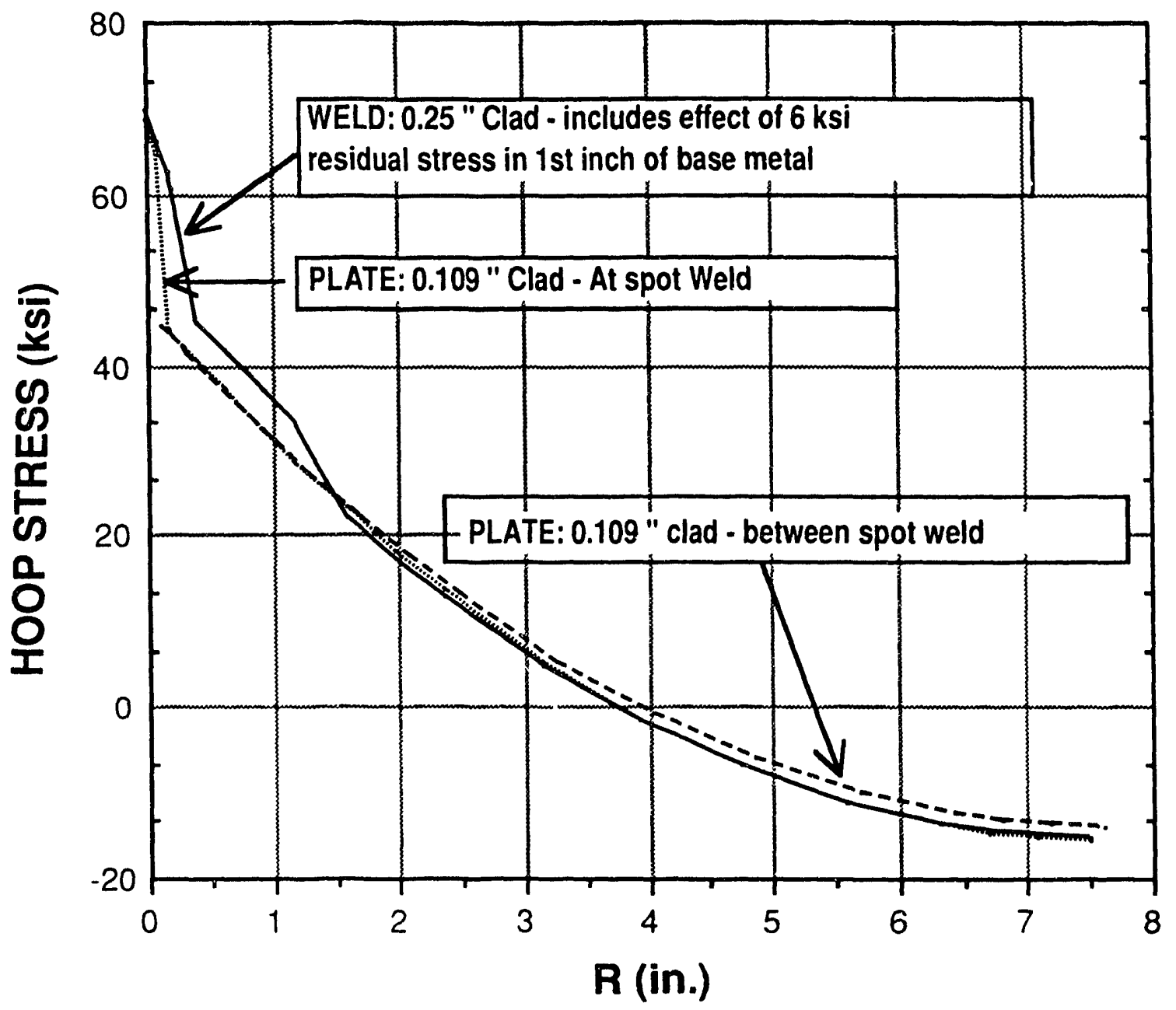

Fig. A.3. Hoop stress distributions (time $=20 \mathrm{~min}$ ). 


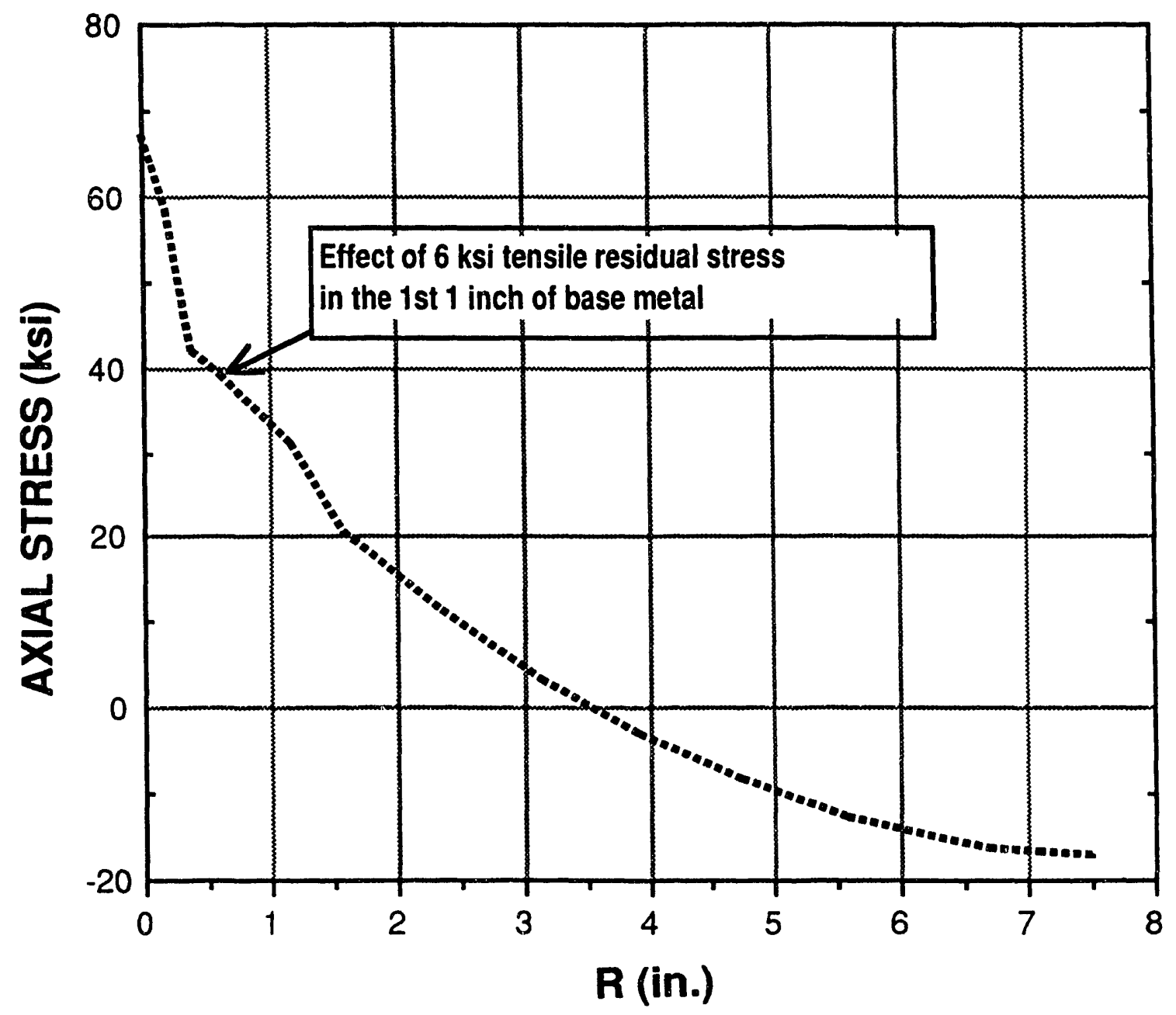

Fig. A.4. Axial stress distribution (time $=20 \mathrm{~min}$ ). 


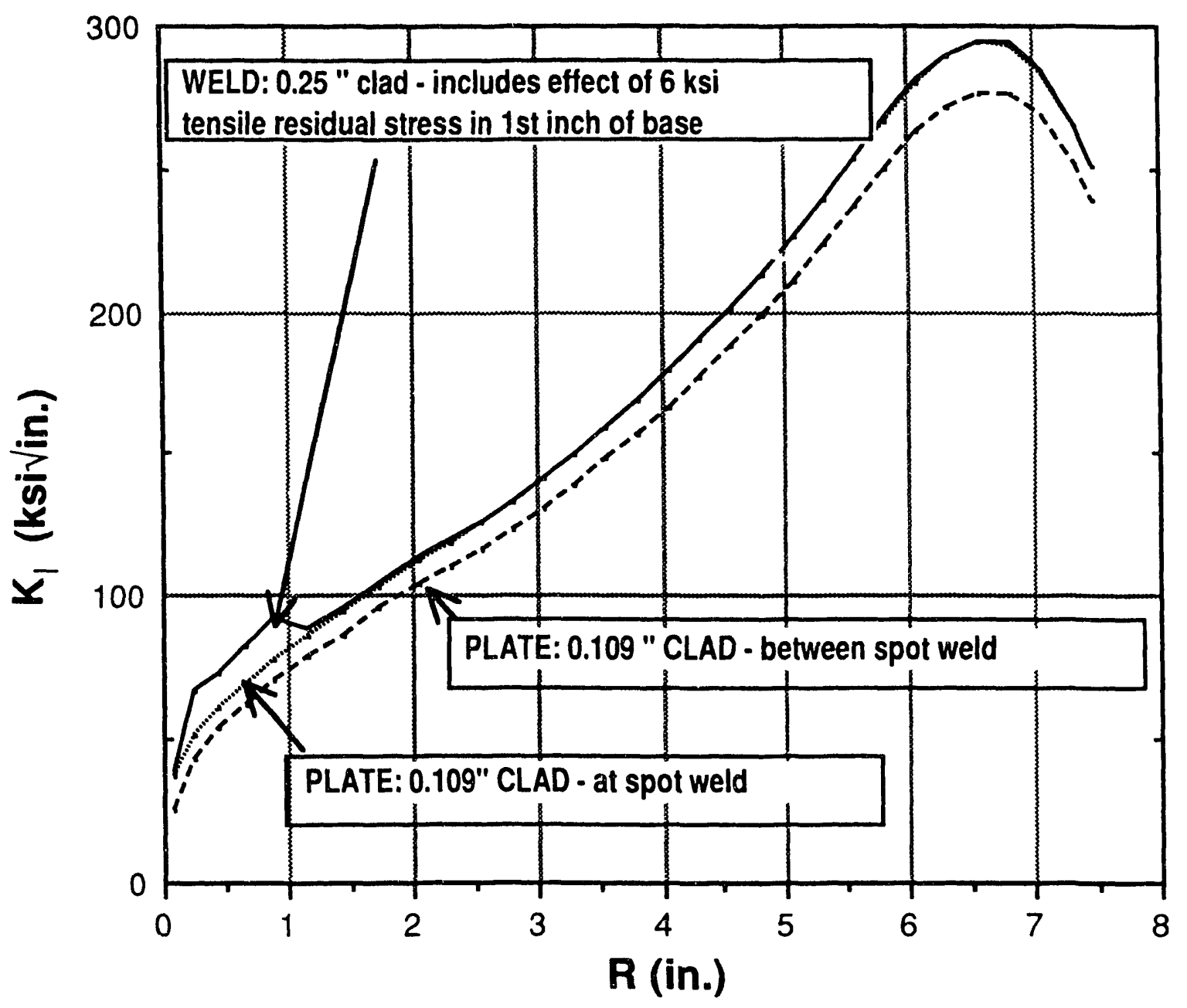

Fig. A.5. $\mathrm{K}_{\mathrm{I}}$ distributions for axial surface flaws (time $=20 \mathrm{~min}$ ). 


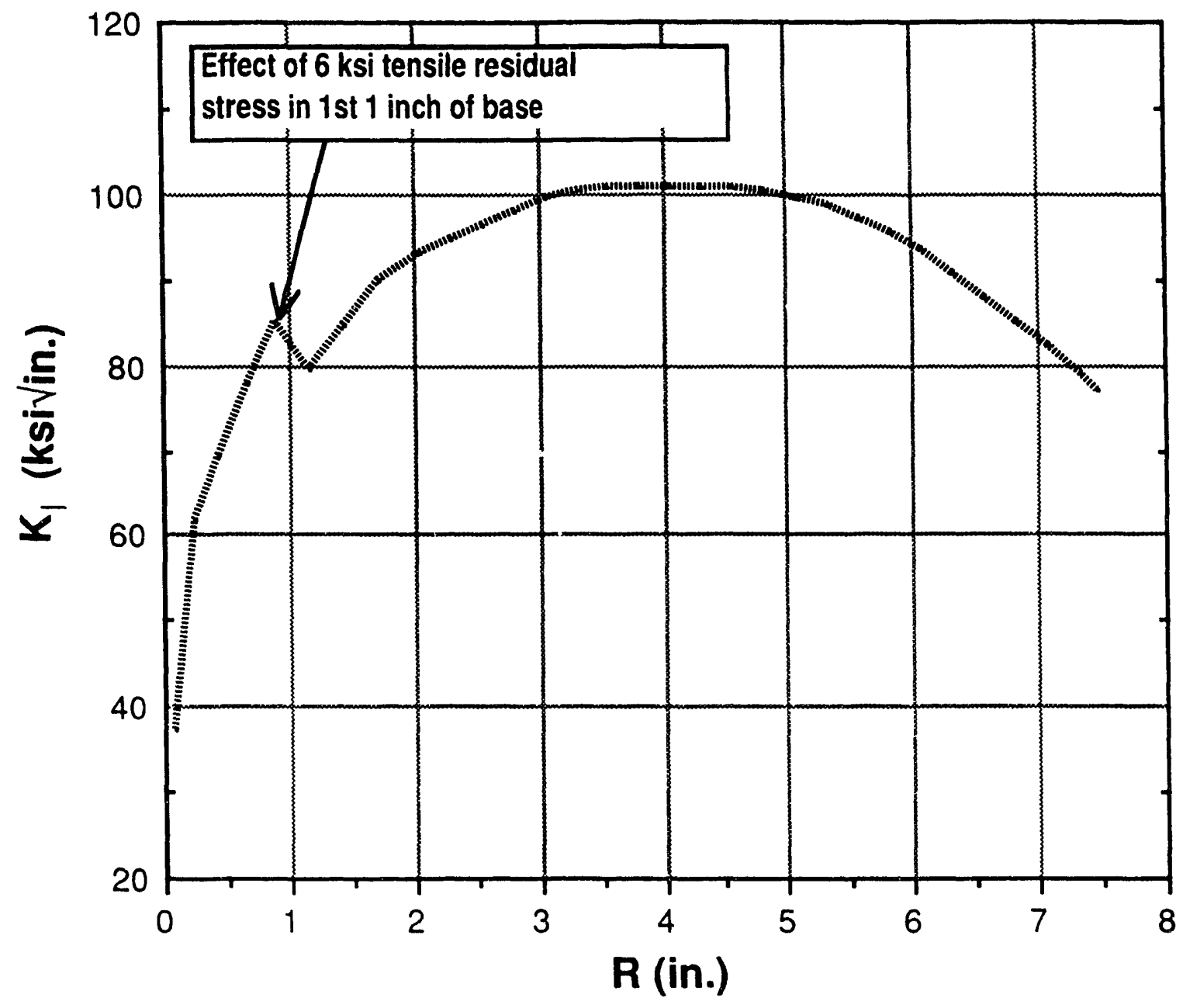

Fig. A.6. $\mathrm{K}_{\mathrm{I}}$ distributions for circumferential surface flaws (time $=20 \mathrm{~min}$ ). 


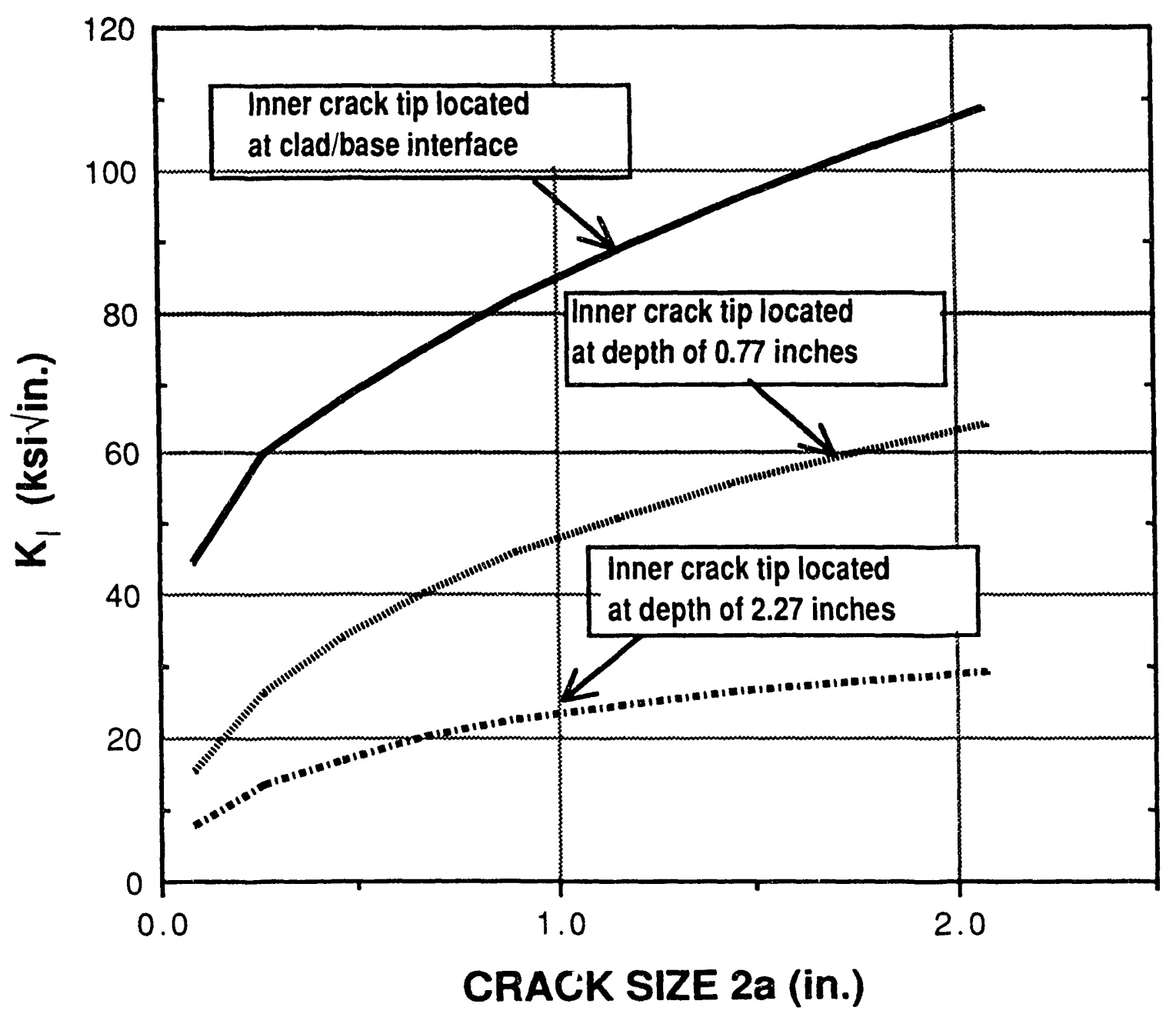

Fig. A.7. $\mathrm{K}_{\mathrm{I}}$ for embedded flaws located in welds (time $=20 \mathrm{~min}$ ). 


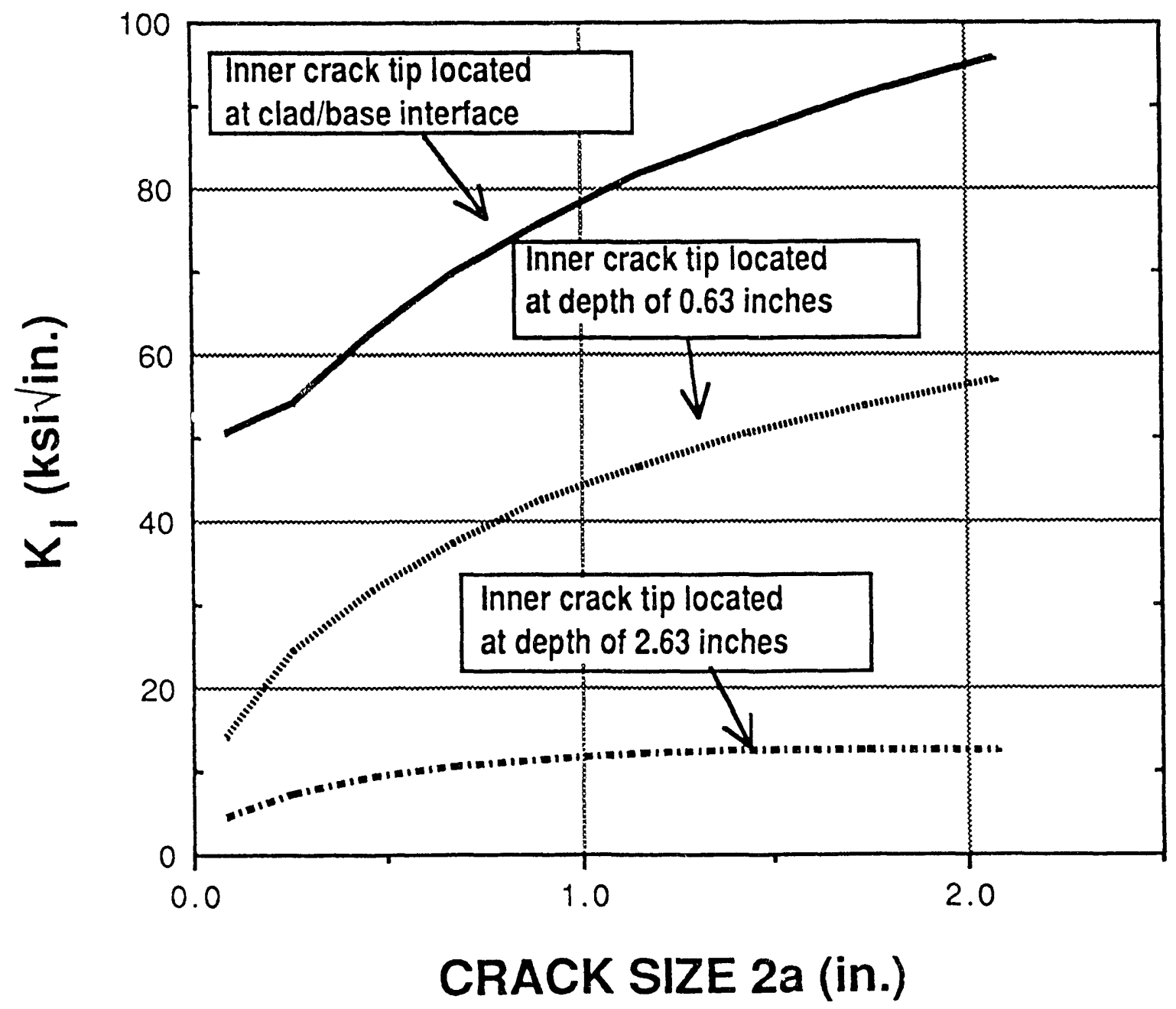

Fig. A.8. $\mathrm{K}_{\mathrm{I}}$ for embedded flaws located in plate (time $=20 \mathrm{~min}$ ). 


\section{Appendix B: Surface Flaw Model and PFM Methodology}

Figure B.1. Surface-Flaw Model.

Figure B.2. Surface-Flaw PFM Methodology. 


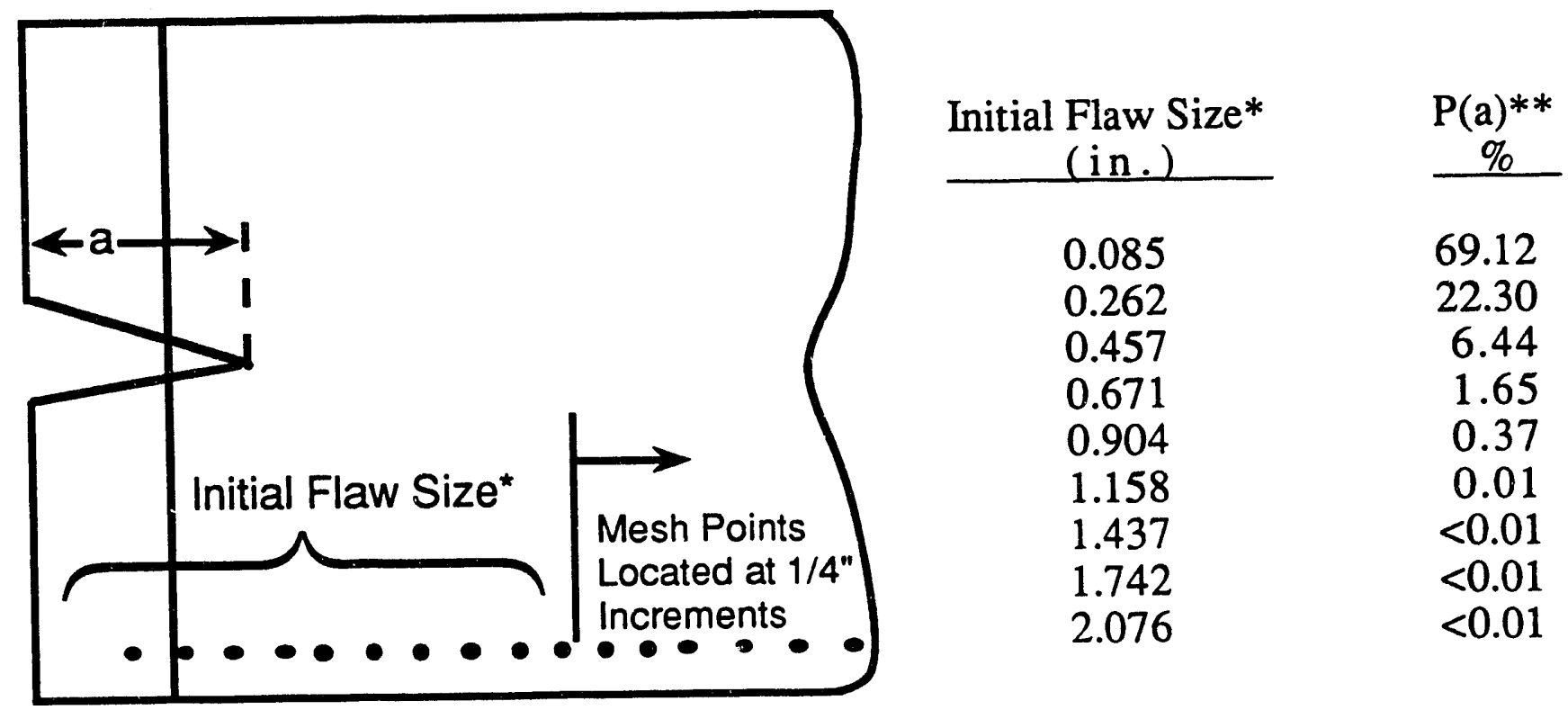

*Default values from OCA-P

***Probability of Occurance - Determined from the integration of the product of the Marshall flaw size and probability of nondetection function.

[asize] - Array of nine possible initial crack sizes.

[a] - Array of discrete mesh points where surface flaw tip can be located.

Note: For surface flaws [asize] $=[$ a] for first nine discrete mesh points.

$T(a, t)$ - Temperature for each surface flaw mesh point for each transient time step. Used for calculating fracture toughness of surface flaw tip.

$\mathrm{K}_{\mathrm{I}}(\mathrm{a}, \mathrm{t})$ - SIF for each surface flaw mesh point for each transient time step. Used for predicting initiation/arrest of surface flaws. Calculated using $\mathrm{K}^{*}$ superposition method.

Fig. B.1. Surface-flaw model. 
PFM METHODOLOGY FOR SURFACE FLAWS

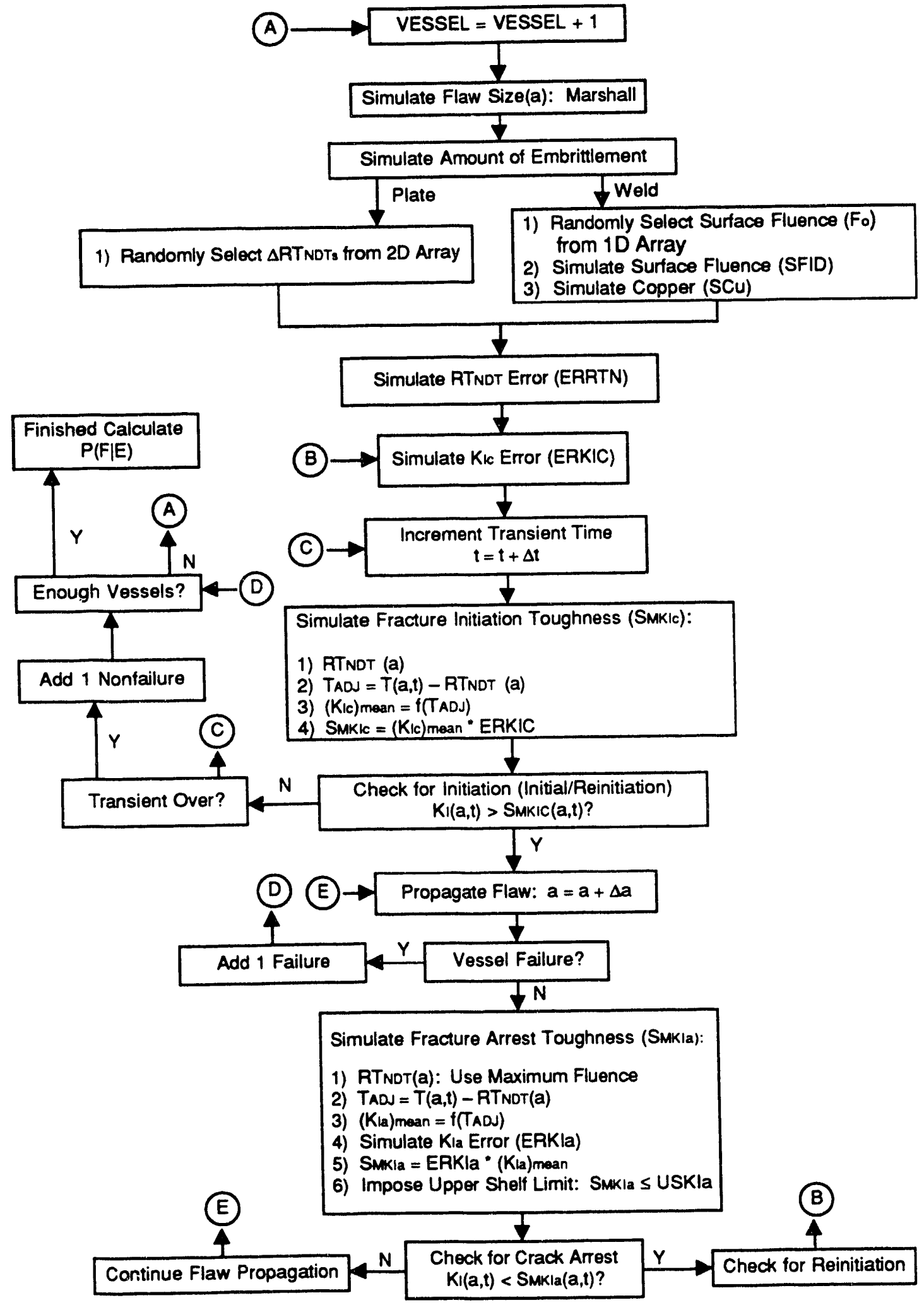

Fig. B.2. Surface-flaw PFM methodology. 


\section{Appendix C: Subclad Flaw Model and PFM Methodology}

Figure C.1. Subclad-Flaw Model.

Figure C.2. Subclad-Flaw PFM Methodology. 


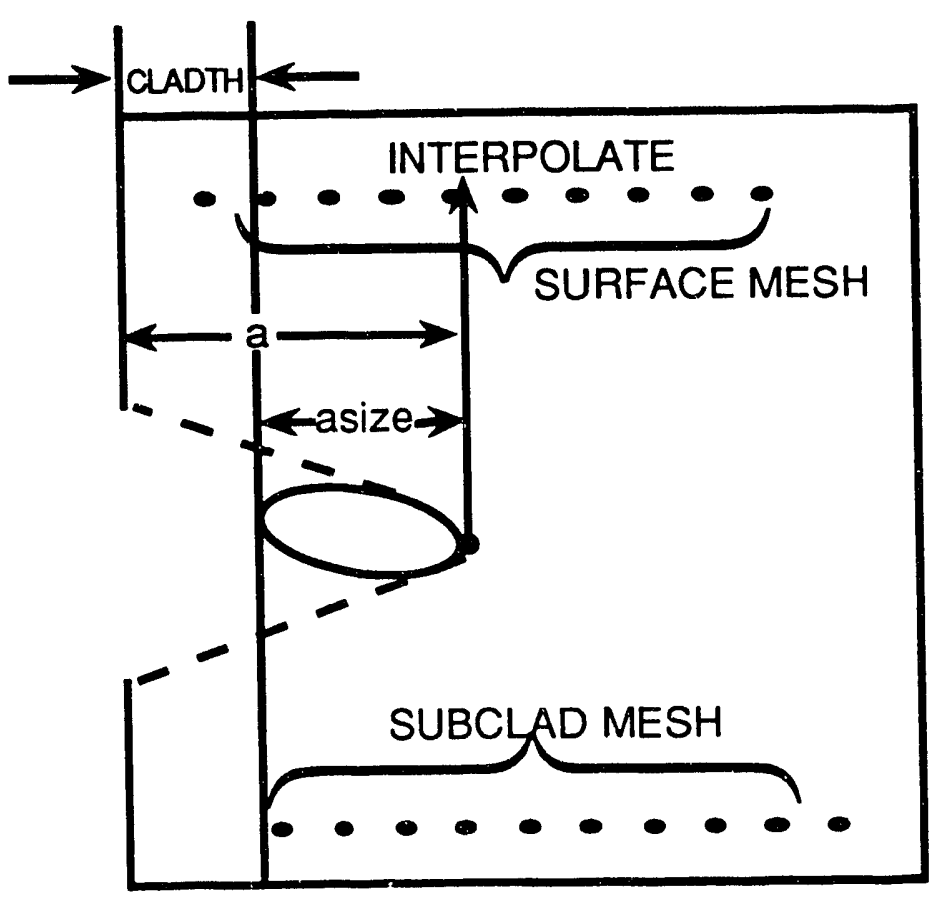

Flaw will propagate along

Subclad mesh.

Initial flaw sizes and probability of occurrance are the same as for surface flaws (from Marshall).

[asize] - Array of nine possible initial crack sizes

[a] - Array of discrete mesh points where subclad crack tip may be located. $\mathrm{a}=$ asize + cladth

$\mathrm{K}_{\mathrm{I}}(\mathrm{a}, \mathrm{t})$ - SIF for surface flaws with crack tip located at [a] for each transient time step. Calculated using $\mathrm{K}^{*}$ superposition method.

NOTE: Subclad flaws which are considered as surface flaws have a different location for crack outer tip than regular surface flaws. The crack outer tip is located at $(\mathrm{a}+$ Cladth). To obtain $\mathrm{K}_{\mathrm{I}}$ for surface flaw located at a + Cladth, interpolate between two surface $\mathrm{K}_{\mathrm{I}}$ 's for the two surface mesh points which bracket $(\mathrm{a}+$ Cladth $)$.

acrit - Critical flaw size for determining cladding failure.

Fig. C.1. Subclad-flaw model. 
tcrit - Critical time at which cladding will fail if flaw size exceeds acrit.

$\mathrm{T}(\mathrm{a}, \mathrm{t})$ - Temperature for each subclad mesh point [a] for each transient time Step. Used for calculating fracture toughness of subclad flaw.

Criteria for cladding failure:

$$
a \geq \text { acrit and } t \geq \text { tcrit }
$$

Dynamic effects (via $\mathrm{K}_{\mathrm{Id}}$ ) is included for only that time step at which the cladding has failed.

Positive Effect of Unbroken Cladding Simulated as:

$$
\mathrm{K}_{\mathrm{I}}(\mathrm{a}, \mathrm{t})=\left[\mathrm{K}_{\mathrm{I}}(\mathrm{a}, \mathrm{t})\right]_{\text {surface flaw }} * 0.65
$$

Fìg. C.1. (Continued) 
PFM METHODOLOGY FOR SUBCLAD FLAWS

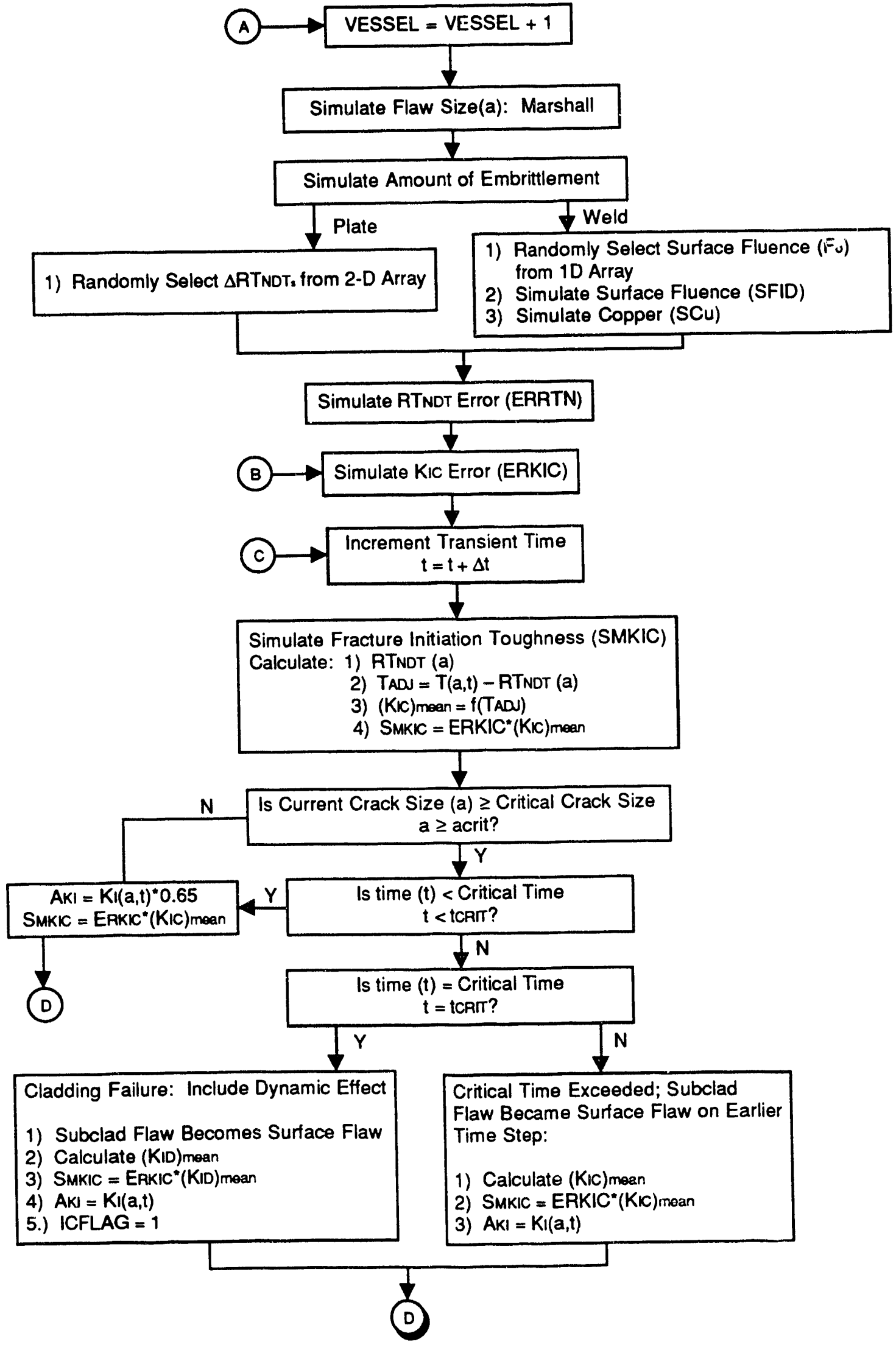

Fig. C.2. Subclad-flaw PFM methodology. 


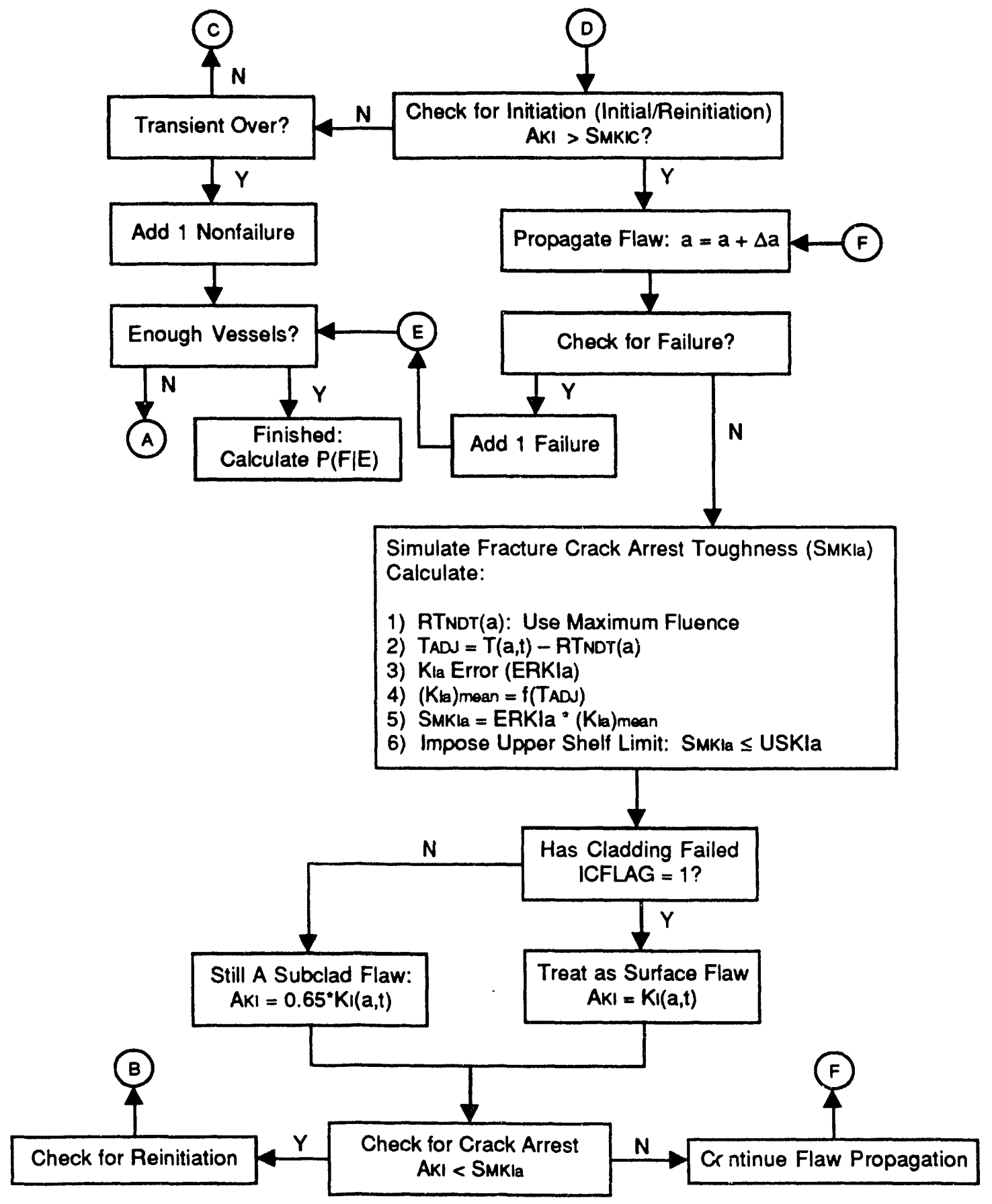

Fig. C.2. (Continued) 


\section{Appendix D: Embedded Flaw Model and PFM Methodology}

Figure D.1. Embedded-Flaw Model.

Figure D.2. Embedded-Flaw PFM Methodology. 


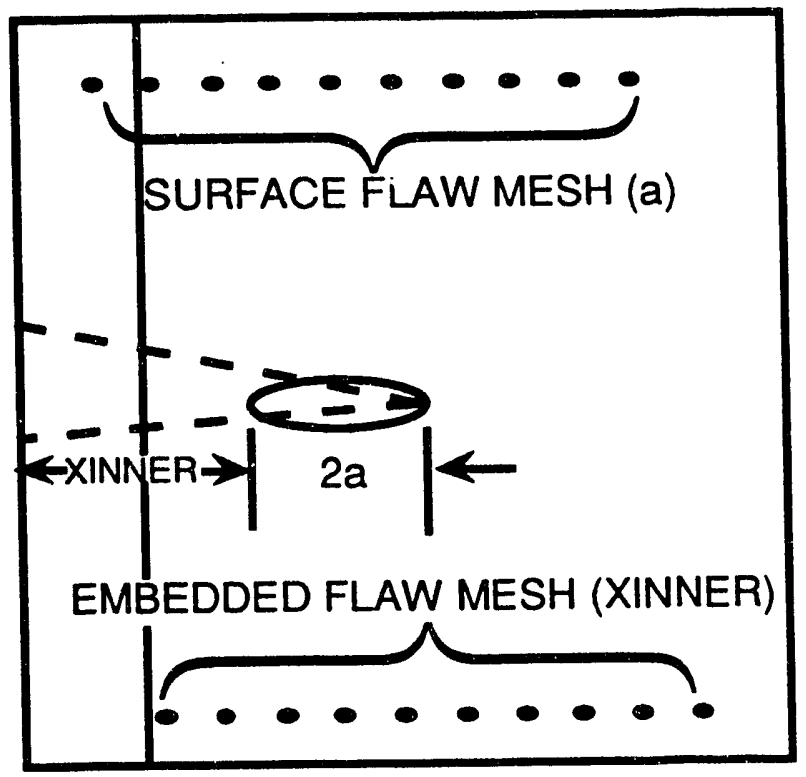

Inner Crack Tip Location Chosen Randomly From Uniform Distribution of Equal Spaced Points.

Initial Flaw Sizes (2a) and the Probability of Occurance are the Same as Applied to Surface Flaws (from Marshall)

[asize] - Array of nine possible initial crack sizes

[XINNER] - Array of discrete mesh points where embedded flaw inner crack tip may be located. Used for claculating fracture toughness of embedded inner flaw tip.

$\mathrm{T}(\mathrm{XINNER}, \mathrm{t})$ - Temperature at each mesh point for each time step in transient.

$\mathrm{K}_{\mathrm{I}}(\mathrm{XINNER}, 2 \mathrm{a}, \mathrm{t})$ - SIF for each combination of XINNER and flaw size (2a) for each transient time step. Used for checking for initial initiation of embedded flaw inner tip. Calculated using ASME methodology for subsurface flaws.

[a] - Array of discrete points where surface flaw tip can be located.

$\mathrm{K}_{\mathrm{I}}(\mathrm{a}, \mathrm{t})$ - SIF for each surface flaw mesh point for each transient time step. Used for checking initiation/arrest of surface flaws.

$T(a, t)$ - Temperature for each surface flaw mesh point for each transient time step. Used for calculating fracture toughness of surface flaw tip.

Fig. D.1. Embedded-flaw model. 
If embedded flaw inner tip initiates, cladding is assumed to fail and embedded flaw becomes surface flaw. Surface flaw propagates along surface flaw mesh.

Dynamic effect (via $\mathrm{K}_{\mathrm{Id}}$ ) is included for only the time step at which cladding failed.

Fig. D.1. (Continued) 


\section{PFM METHODOLOGY FOR EMBEDDED FLAWS}

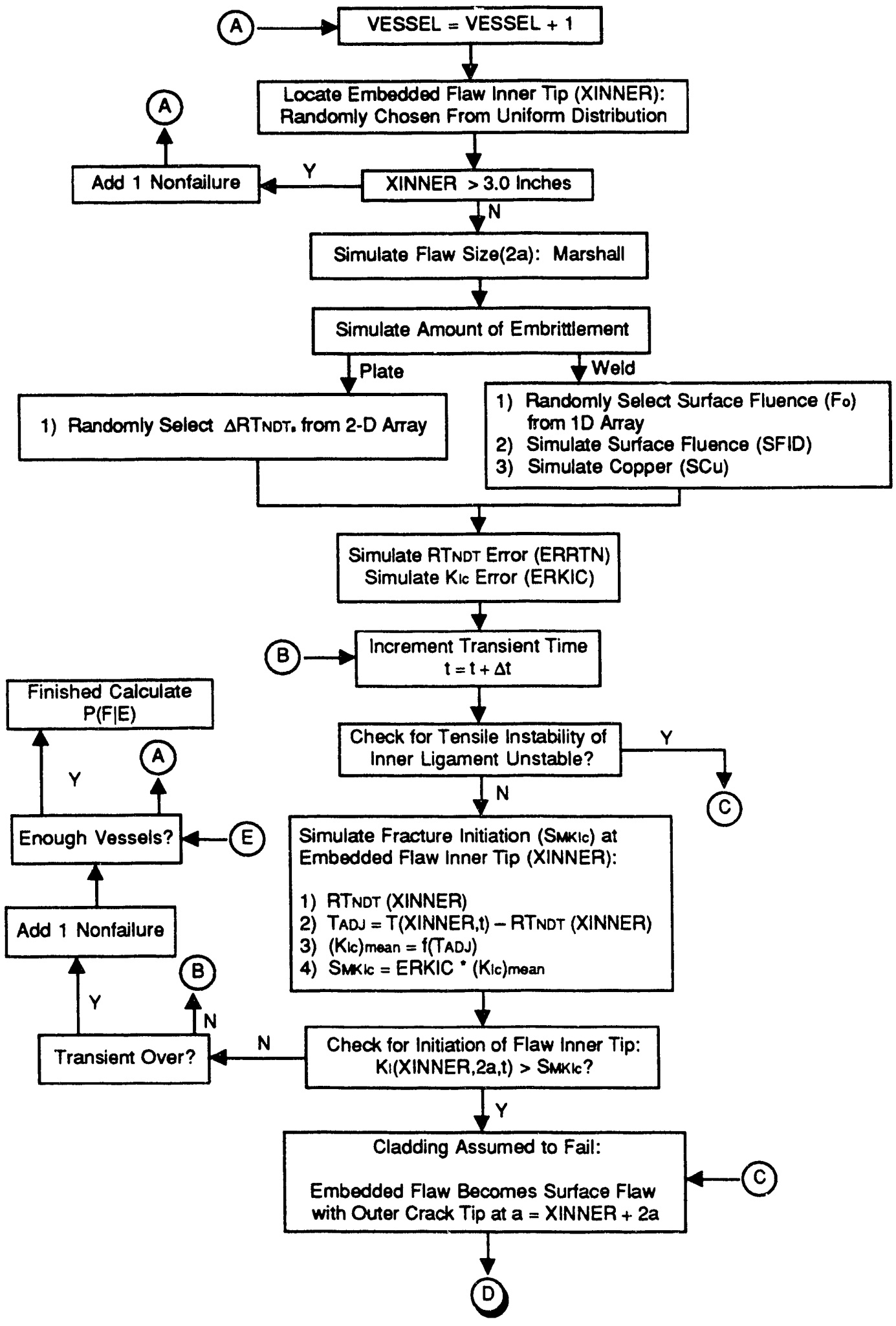

Fig. D.2. Embedded-flaw PFM methodology. 


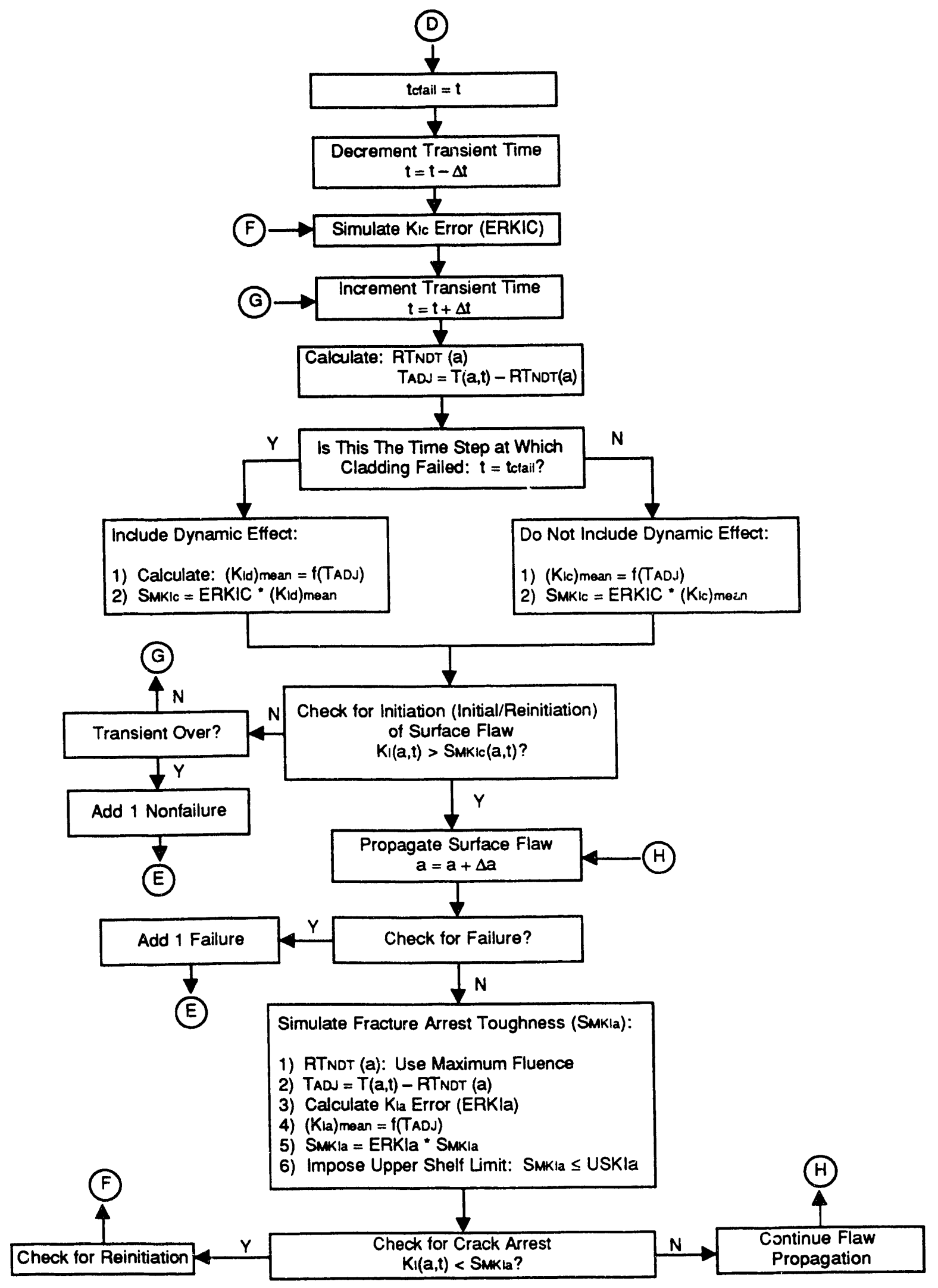

Fig. D.2. (Continued) 


\section{Appendix E: Methodology for Simulating Fracture Toughness for Welds}




\section{METHODOLOGY USED FOR SIMULATING FRACTURE}

TOUGHNESS FOR WELDS:

Specified: Fluence Map (1-D)

Nickel

$\Delta$ RT NDT: RG 1.99 Rev. 2

\section{SENSITIVITY WRT COPPER}
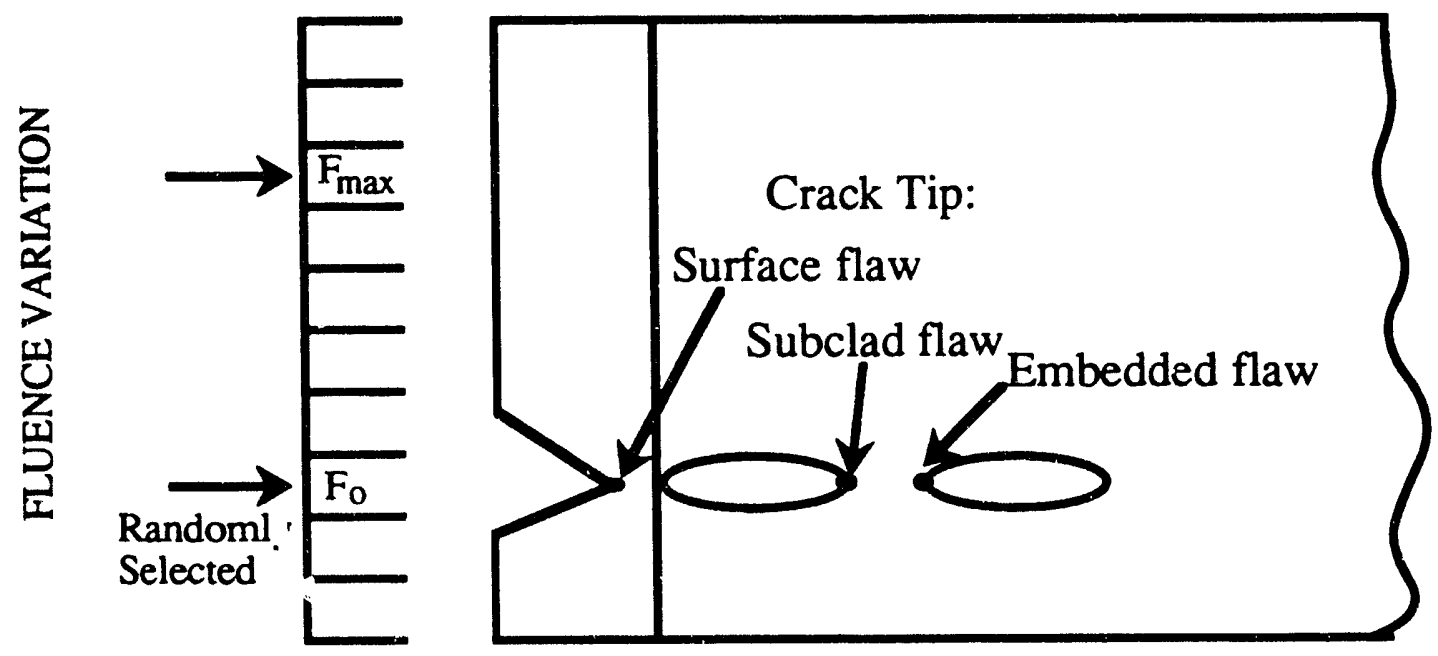

Step 1: Simulate Fluence

a) $\mathrm{F}_{\mathrm{O}}$ - Value of mean surface fluence is randomly chosen from uniform distribution, i.e., each fluence value has equal probability of being chosen.

$F_{\max }-$ Maximum value of surface fluence in fluence variation map.

b) Probabilistically Simulate Surface Fluence:

Simulated surface fluence (SFID) chosen from normal distribution about randomly selected mean fluence $F_{0}$. 


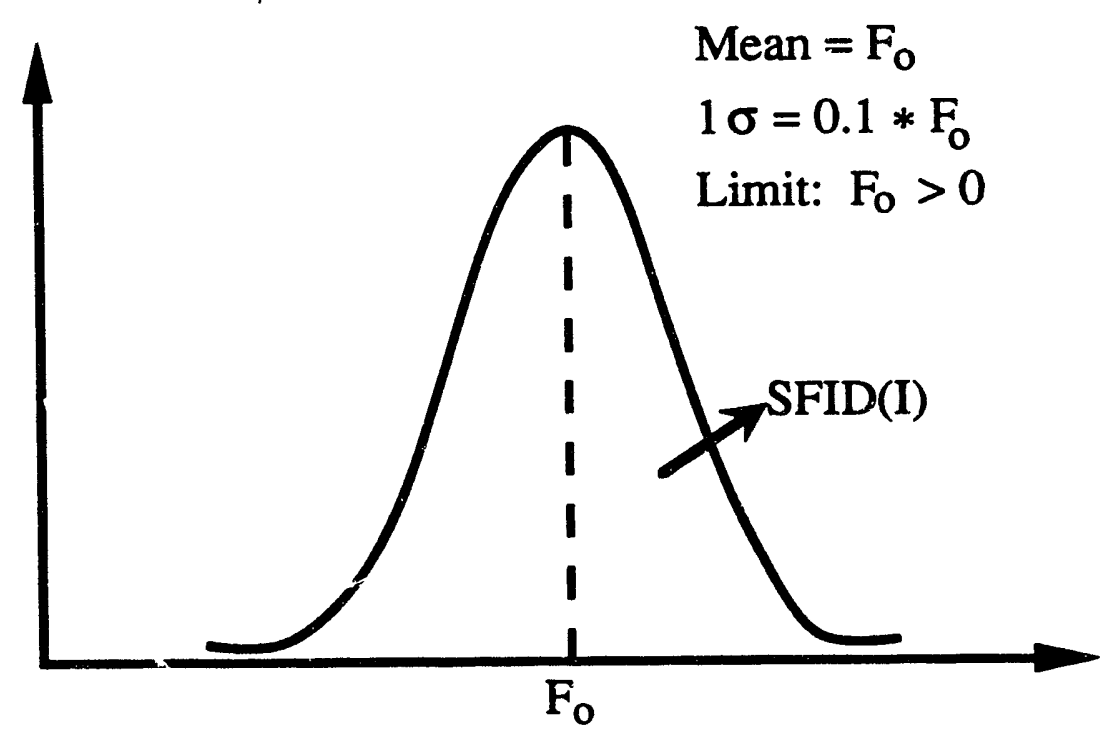

SURFACE FLUENCE

c) Different attenuated fluence curves are used to predict initial crack initiation [SFID(I)], crack arrest(s), and subsequent reinitiation(s) [SFID(A)].

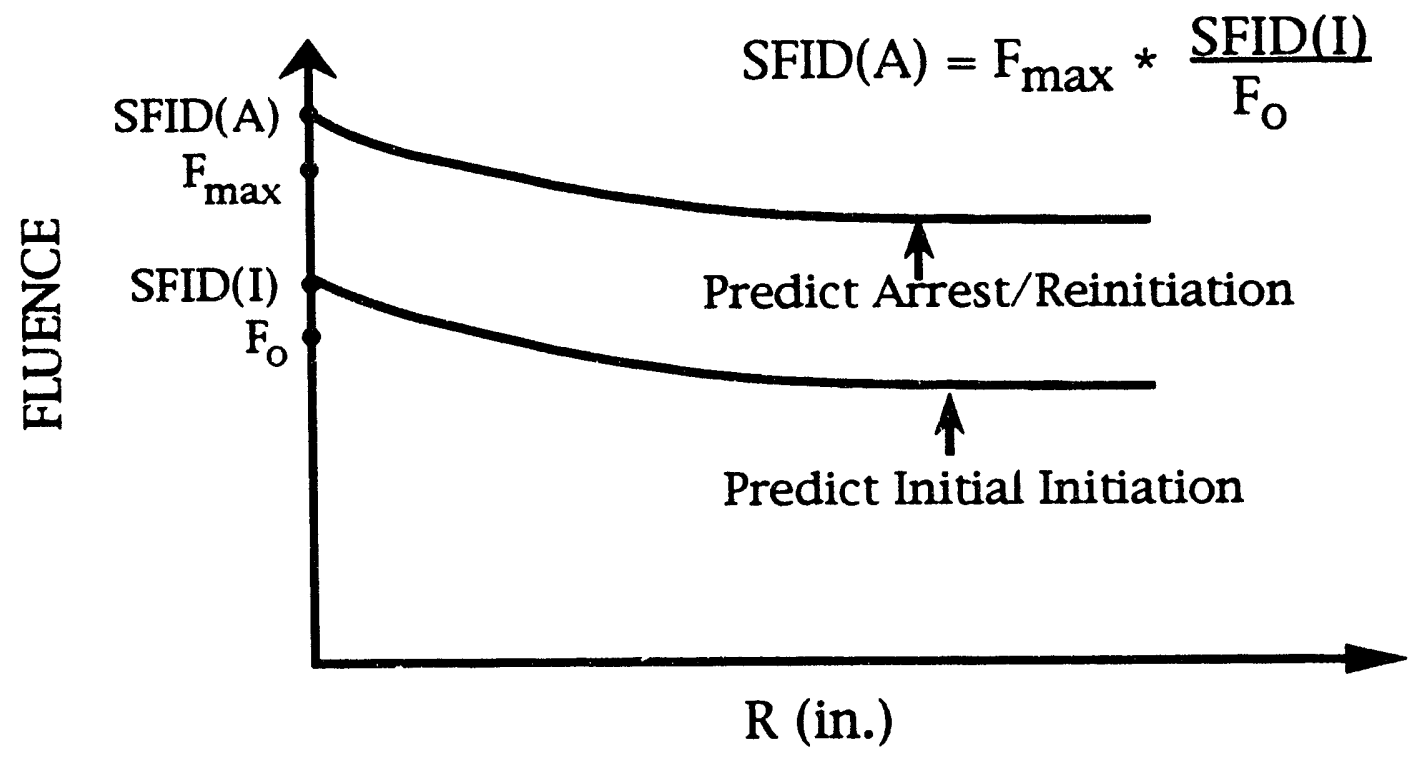


Step 2: Probabilistically simulate copper ( $\mathrm{SCu})$ :

Randomly chosen from normal distribution about mean $\mathrm{Cu}$.

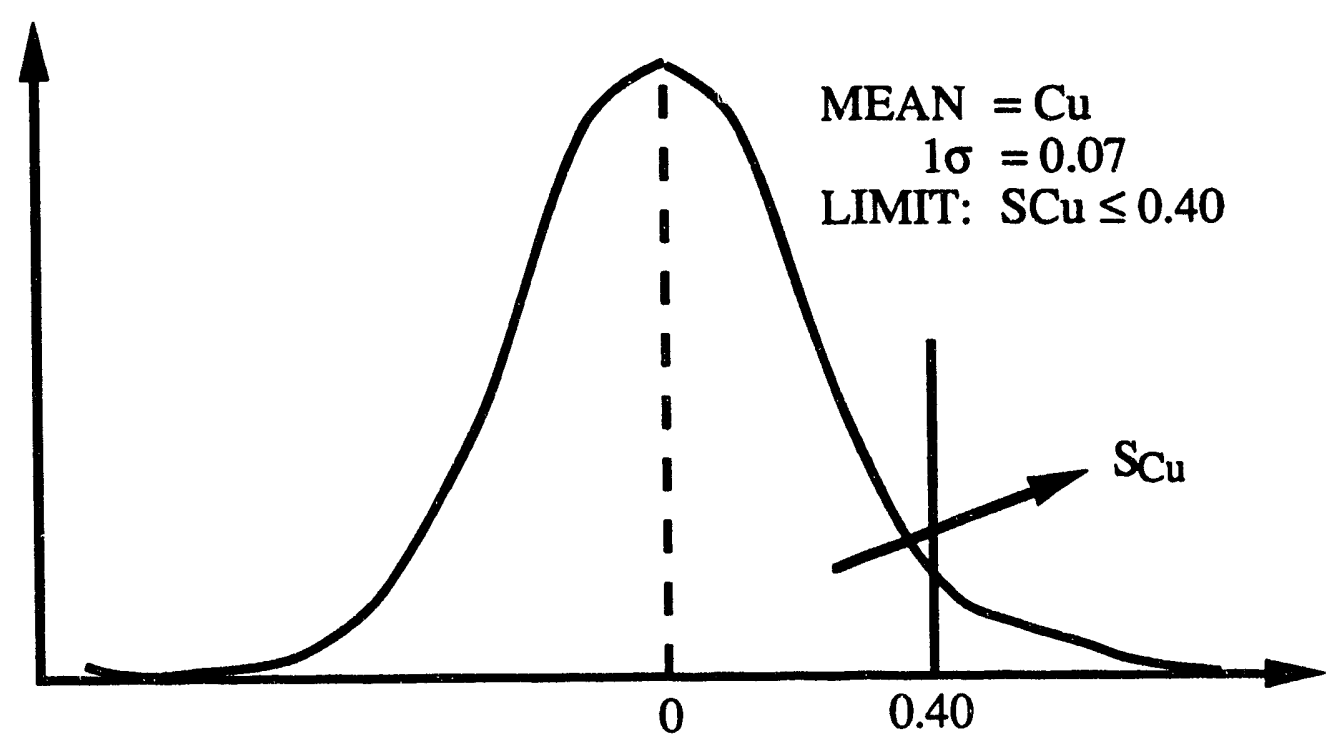

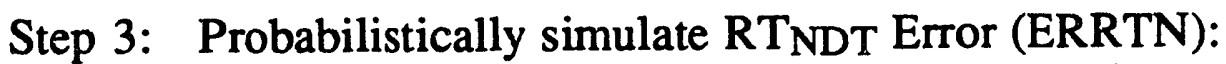

Randomly chosen from normal distribution about mean $=0$.

Note: ERRTN is calculated once per vessel.

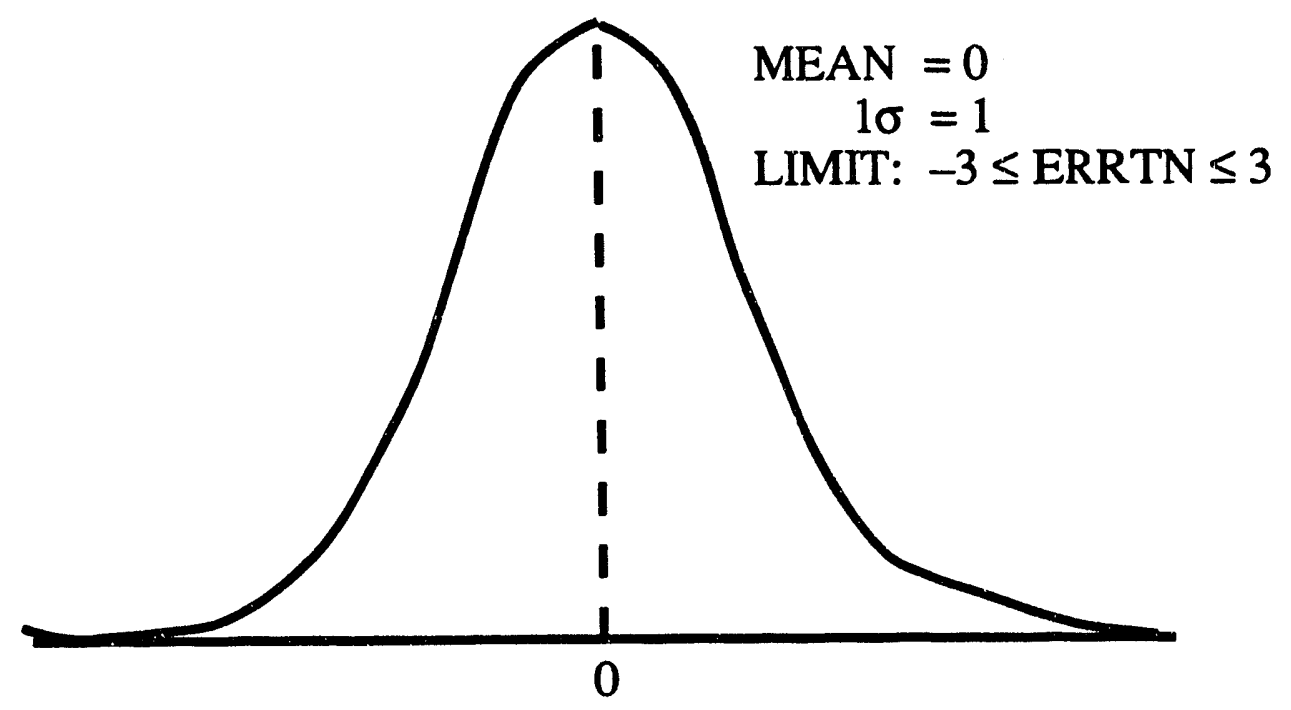


Step 4: Compute $\Delta$ RT NDT per RG 1.99 Rev. 2.

$\Delta \mathrm{RT}_{\mathrm{NDT}}(\mathrm{a})=\mathrm{CF} * \mathrm{SFID}$

$[0.28-0.1 \log (\mathrm{SFD})]$

where:

for initiation: SFID $=\operatorname{SFID}(\mathrm{I}) * \exp (-0.24 * \mathrm{a})$

arrest/reinitiation: $\operatorname{SFID}=\operatorname{SFID}(A) * \exp (-0.24 * a)$

$\mathrm{CF}=$ chemistry factor $=\mathrm{f}(\mathrm{SCu}, \mathrm{Ni})$

Step 5: Calculate embrittlement (RT NDT)

$$
\mathrm{RT}_{\mathrm{NDT}}=\mathrm{RT}_{\mathrm{NDT0}}+\Delta \mathrm{RT}_{\mathrm{NDT}}+\mathrm{ERRTN} * \sqrt{\sigma_{R T N D T 0}^{2}+\sigma_{\triangle R T N D T}^{2}}+\mathrm{LTCF}
$$

where:

$\mathrm{RT}_{\mathrm{NDT}}=$ value of $\mathrm{RT}$ NDT used in fracture toughness calculations

$\mathrm{RT}_{\text {NDTo }}=$ initial (unirradiated) value of $\mathrm{RT}_{\mathrm{NDT}}$

$=10^{\circ} \mathrm{F}$ for welds

$=30^{\circ} \mathrm{F}$ for plate

$\Delta \mathrm{RT}_{\mathrm{NDT}}=$ shift in $\mathrm{RT}_{\mathrm{NDT}}$ due to irradiation as a function of simulated fluence (attenuated to wall depth location corresponding to crack tip location) and simulated copper as predicted by

RG $\quad 1.99$ Rev. 2 for welds. (Nickel $=0.6=$ constant)

$\sqrt{\sigma_{R T N D T 0}^{2}+\sigma_{\triangle R T N D T}^{2}}=$ square root of the sum of the square of $1 \sigma$ variability for $\mathrm{RT}_{\mathrm{NDT}}$ and $\triangle \mathrm{RT}_{\mathrm{NDT}}\left(1 \sigma\right.$ for $\mathrm{RT}_{\mathrm{NDTo}}=17^{\circ} \mathrm{F}$ and $1 \sigma$ for $\Delta R T_{N D T}=24^{\circ} \mathrm{C}$ ). This represents the

$1 \sigma$ uncertainty for the specified value of RTNDTo and the $1 \sigma$ uncertainty in the predictive correlation used to caluclate $\Delta \mathrm{RT}$ NDT.

ERRTN $=$ Random number between -3 and +3 chosen from uniform distribution. The product of ERRTN and $\sqrt{\sigma_{R T N D T 0}^{2}+\sigma_{\triangle R T N D T}^{2}}$ essentially increases the uncer tainty of RTNDT from $1 \sigma$ to $3 \sigma$.

LTCF $=$ Low temperature correction factor $=50^{\circ} \mathrm{F}$. This accounts for the lack of self-annealing due to the fact that Yankee Rowe 
operates at $\sim 500^{\circ} \mathrm{F}$. The $\Delta \mathrm{RT}$ NDT values predicted by RG $1.99 \mathrm{Rev}$. 2 are based on an operating temperature of $550^{\circ} \mathrm{F}$.

Step 6: Calculate $\mathrm{T}_{\mathrm{ADJ}}=\mathrm{T}(\mathrm{a}, \mathrm{t})-\mathrm{RT}_{\mathrm{NDT}(\mathrm{a})}$

Step 7: Calculate fracture toughness error (ERKIc and ERIKa):

These terms account for the scatter of the fracture toughness about the mean. These terms are recalculated for each crack tip position.

Randomly chosen from normal distribution about mean $=1.0$

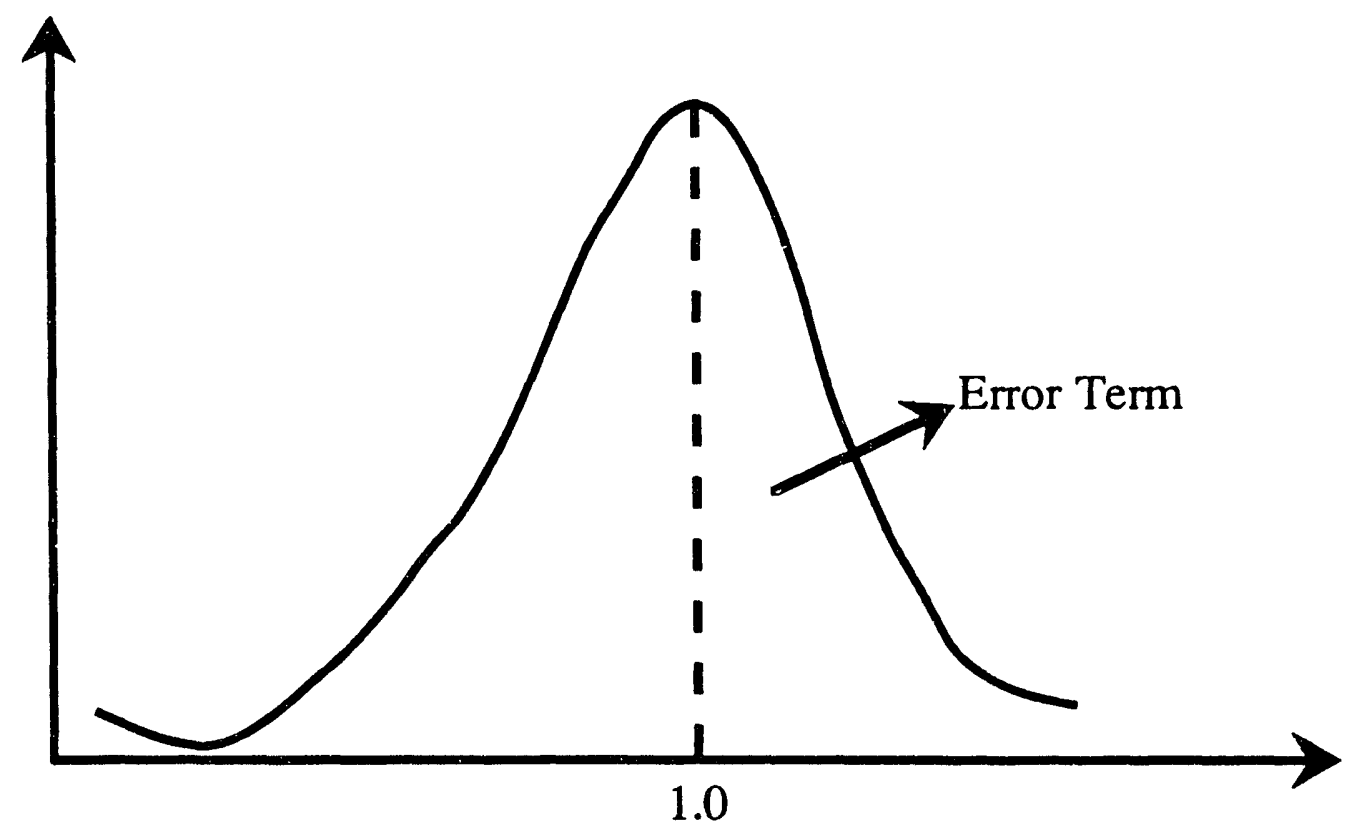

Initiation $1 \sigma=0.15 \therefore 0.55 \leq$ ERKIC $\leq 1.45$

Arrest $1 \sigma=0.10 \therefore 0.70 \leq$ ERKIA $\leq 1.30$

Step 8: Calculate mean fracture toughness $=\mathrm{f}\left(\mathrm{T}_{\mathrm{ADJ}}\right)$

$\left(\mathrm{K}_{\mathrm{Ic}}\right)_{\text {mean }}=1.43 *$ ASME Lower Bound $\mathrm{K}_{\mathrm{Ic}}$ Curve

$\left(\mathrm{K}_{\mathrm{Ia}}\right)_{\text {mean }}=1.25 *$ ASME Lower Bound $\mathrm{K}_{\mathrm{Ia}}$ Curve

Step 9: Calculate simulated fracture toughness used in predicting initial initiation/arrest/reinitiation.

SMKIC $=$ ERKIC $*\left(\mathrm{~K}_{\mathrm{Ic}}\right)_{\text {mean }}$

SMKIA $=$ ERKIA $*\left(K_{\text {Ia }}\right)_{\text {mean }} \quad$ SMKIA $\leq 200 \mathrm{ksi} \sqrt{\text { in. }}$ 


\section{Appendix F: Methodology for Simulating Fracture Toughness for Plates}




\section{METHODOLOGY USED FOR SIMULATING FRACTURE}

\section{TOUGHNESS FOR PLATES:}

Specified: 2-D Fluence Map

$\triangle \mathrm{RT}_{\text {NDT }}$ Correlations (Odette)

Upper Plate $-\triangle \mathrm{RT}_{\mathrm{NDT}}\left({ }^{\circ} \mathrm{F}\right)=183^{\circ} \mathrm{F} 0.315$

Lower Plate $-\Delta \mathrm{RT}_{\mathrm{NDT}}\left({ }^{\circ} \mathrm{F}\right)=183^{\circ} \mathrm{F} 0.315+80$

SENSITIVITY WRT RTNDTS - VALUE OF RTNDT AT VESSEL INNER SURFACE

Problem: Specified Fluence Map not Necessarily Consistent with Specified Value of RTNDT and Odette Correlation

Prior to performing PFM analysis, the 2-D fluence map is first normalized WRT specified value of $\mathrm{RT}_{N D T}$ and then transformed to a $\triangle R T_{N D T}$ map:

Step 1: Value of $\mathrm{RT}_{\mathrm{NDT}_{\mathrm{S}}}$ specified

Step 2: Calculate value of surface $\triangle R T_{N D T}$ $\Delta \mathrm{RT}_{\mathrm{NDT}_{\mathrm{S}}}=\mathrm{RT}_{\mathrm{NDT}_{\mathrm{S}}}-\mathrm{RT}_{\mathrm{NDT}_{\mathrm{O}}}$

Step 3: Calculate value of surface fluence $F_{o}$ which produces $\Delta R T_{N D T}$ when using appropriate Odette correlation:

(a) Upper Plate: $\mathrm{F}_{\mathrm{O}}{ }^{*}=\left(\Delta \mathrm{RT}_{\mathrm{NDT}_{\mathrm{S}}} / 183\right)^{1 / 0.315}$

(b) Lower Plate: $\mathrm{F}_{\mathrm{O}}{ }^{*}=\left[\left(\Delta \mathrm{RT}_{\mathrm{NDT}_{\mathrm{S}}}-80\right) / 183\right)^{1 / 0.315}$

Step 4: Normalize the entire 2-D fluence map by $\left(\mathrm{F}_{0} * / \mathrm{F}_{\max }\right)$ where $\mathrm{F}_{\max }$ is the maximum value of surface fluence in the 2-D map. This implicitly assumes that the specified value of $\mathrm{RT}_{\mathrm{NDT}}$ corresponds to the location of maximum fluence. 
Step 5: Transform the normalized 2-D surface fluence map to a $\Delta R T_{N D T_{s}}$ map using the appropriate Odette correlation.

$\left[\begin{array}{c}\text { Normalized } \\ \text { 2D } \\ \text { Fluence Map }\end{array}\right]$

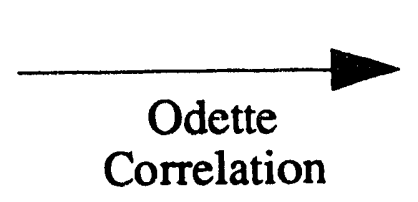

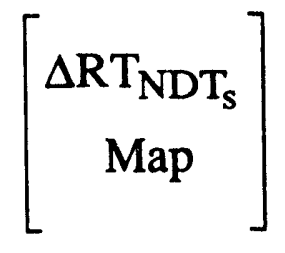

During the PFM Analysis:

Step 1: For each simulated vessel, a value of $\Delta \mathrm{RT}_{\mathrm{NDT}_{\mathrm{S}}}$ is randomly selected from a uniform distribution.

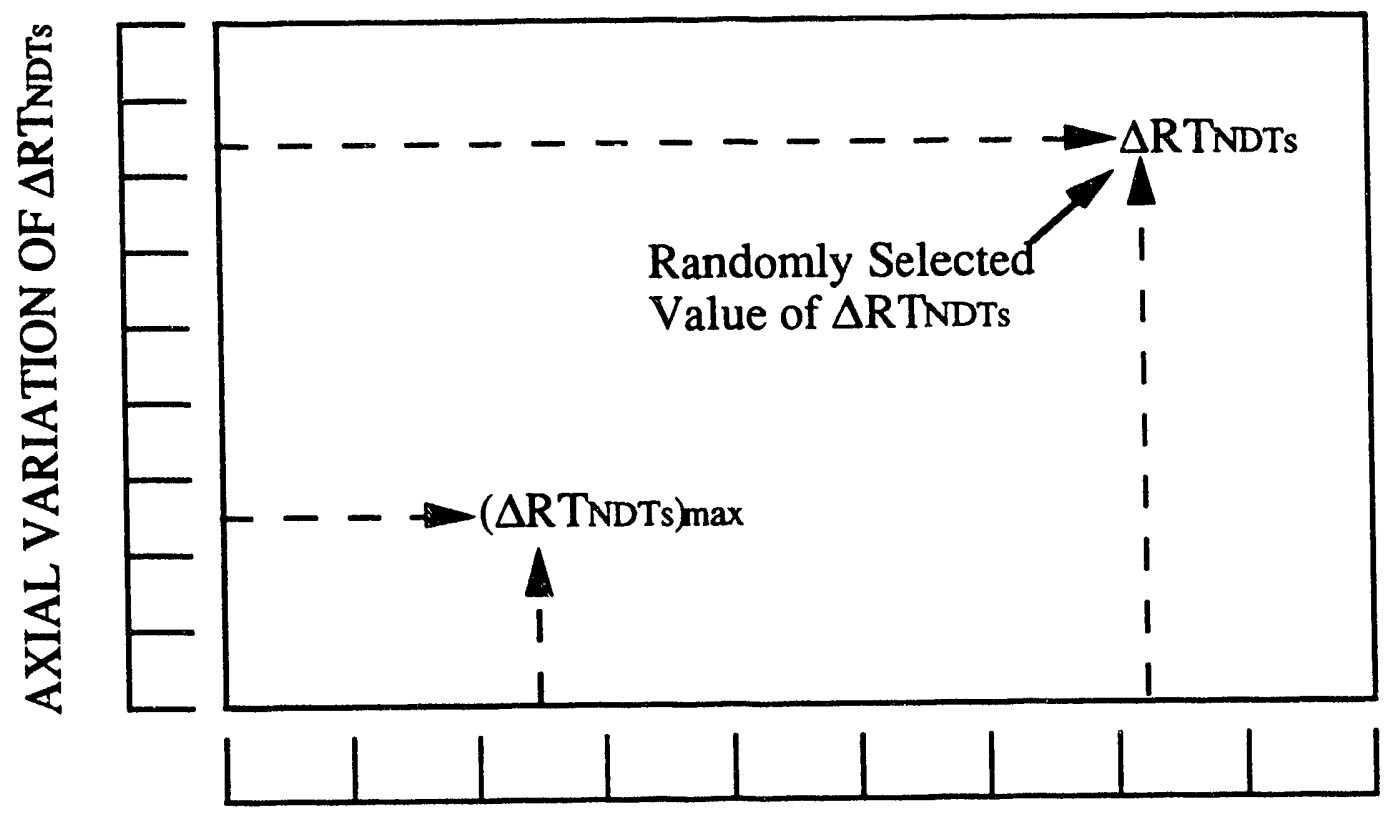

AZIMUTHAL VARIATION OF $\triangle$ RTNDTs

Step 2: Calculate radiation induced damage $(\Delta \mathrm{RT}$ NDT) attenuated to specific wall depth (a):

for initiation: $\quad \Delta \mathrm{RT}_{\mathrm{NDT}}(\mathrm{a})=\left(\Delta \mathrm{RT}_{\mathrm{NDT}}-\mathrm{B}\right) \exp (-0.315 * 0.24 * \mathrm{a})+\mathrm{B}$

for reinitiation and arrest:

$$
\Delta \operatorname{RT}_{N D T}(a)=\left[\left(\Delta \mathrm{RT}_{\mathrm{NDT}_{\mathrm{S}}}\right)_{\max }-\mathrm{B}\right] \exp (-0.315 * 0.24 * \mathrm{a})+\mathrm{B}
$$


where:

$\Delta \mathrm{RT}_{\mathrm{NDT}_{\mathrm{S}}}=$ value of $\Delta \mathrm{RT}_{\mathrm{NDT}}$, randomly selected from map

$\left(\Delta \mathrm{RT}_{\mathrm{NDT}_{\mathrm{S}}}\right)_{\max }=$ maximum value of $\Delta \mathrm{RT}_{\mathrm{NDT}_{\mathrm{S}}}$ in 2-D map

$\mathrm{B}=0$ for upper plate

$\mathrm{B}=80$ for lower plate.

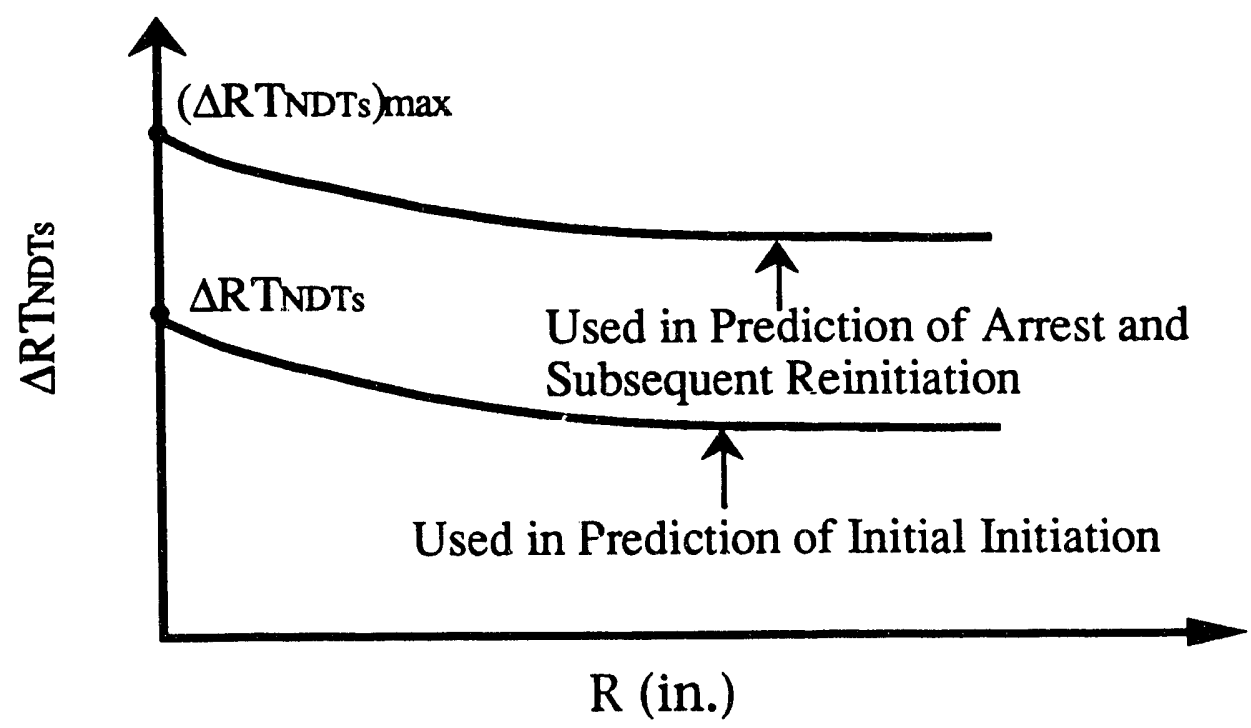

Step 3: Probabilistically simulate RTNDT error (ERRTN):

Randomly chosen from normal distribution about mean $=0$. ERRTN is calculated only once for each vessel. 


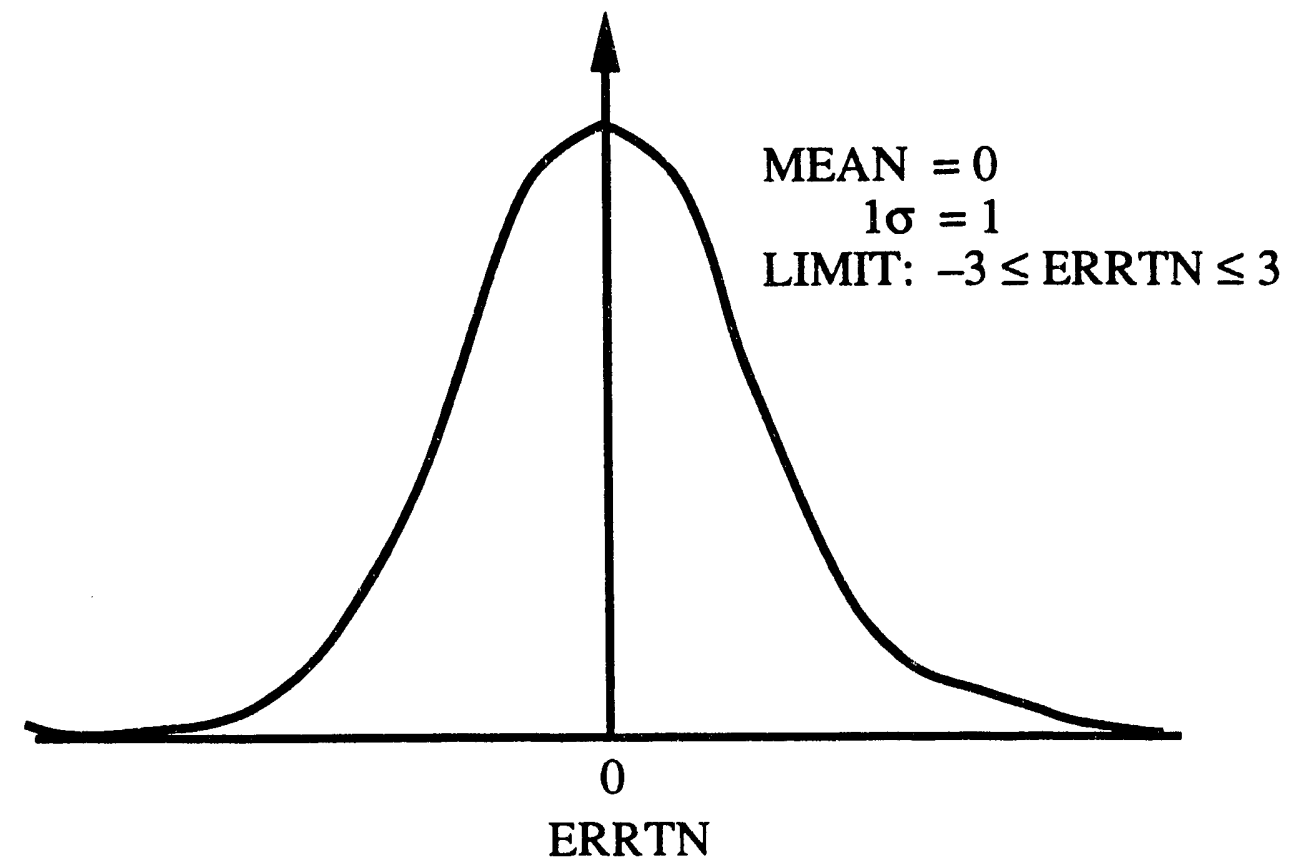

Step 4: Calculate embrittlement (RTNDT)

$$
\mathrm{RT}_{\mathrm{NDT}}(\mathrm{a})=\mathrm{RT}_{\mathrm{NDT} 0}+\Delta \mathrm{RT}_{\mathrm{NDT}}(\mathrm{a})+\mathrm{ERRTN} \sqrt{\sigma_{R T N D T 0}^{2}+\sigma_{\Delta R T N D T}^{2}}
$$

Step 5: Calculate $\mathrm{T}_{\mathrm{ADJ}}=\mathrm{T}(\mathrm{a}, \mathrm{t})-\mathrm{RT}_{\mathrm{NDT}}(\mathrm{a})$

Step 6: Calculate fracture toughness error (ERKIc and ERIKa):

These terms account for the scatter of the fracture toughness about the mean. These terms are calculated for each crack tip position. ERKIc and ERKIa are randomly selected from a normal distribution about a mean $=1.0$. 


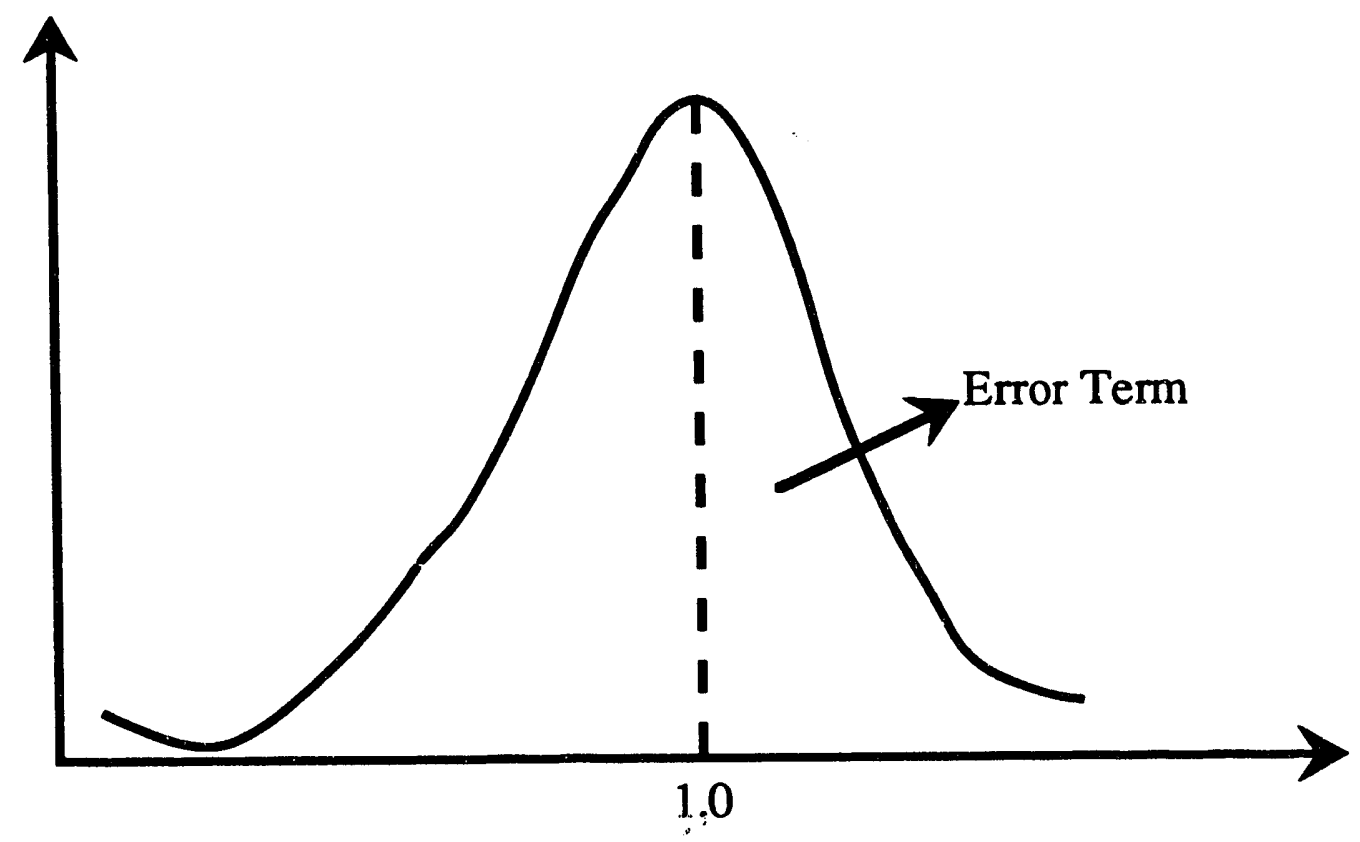

Initiation $1 \sigma=0.15 \therefore 0.55 \leq$ ERKIC $\leq 1.45$

Arrest $1 \sigma=0.10 \therefore 0.70 \leq$ ERKIA $\leq 1.30$

Step 7: Calculate mean fracture toughness $=f\left(T_{A D J}\right)$

$\left(\mathrm{K}_{\mathrm{Ic}}\right)_{\text {mean }}=1.43 *$ ASME Lower Bound $\mathrm{K}_{\mathrm{Ic}}$ Curve

$\left(\mathrm{K}_{\mathrm{Ia}}\right)_{\text {mean }}=1.25 *$ ASME Lower Bound $\mathrm{K}_{\mathrm{Ia}}$ Curve

Step 8: Calculate simulated fracture toughness used in predicting initial initiation/arrest/reinitiation.

SMKIC $=$ ERKIC $*\left(\mathrm{~K}_{\mathrm{Ic}}\right)_{\text {mean }}$

SMKIA $=$ ERKIA $*\left(\mathrm{~K}_{\mathrm{Ia}}\right)_{\text {mean }} \quad \mathrm{SMKIA} \leq 200 \mathrm{ksi} \sqrt{\mathrm{in}}$. 


\section{Appendix G: Residual Stress Considerations}

Figure G.1. Hoop-stress distributions for axial welds (at time $=20 \mathrm{~min}$ ) for three residual-stress cases.

Figure G.2. $\mathrm{K}_{\mathrm{I}}$ distributions for axial welds (at time $=20 \mathrm{~min}$ ) for three residual-stress cases.

Figure G.3. Best-estimate unadjusted conditional probability of failure for upper axial weld for three residualstress cases. 


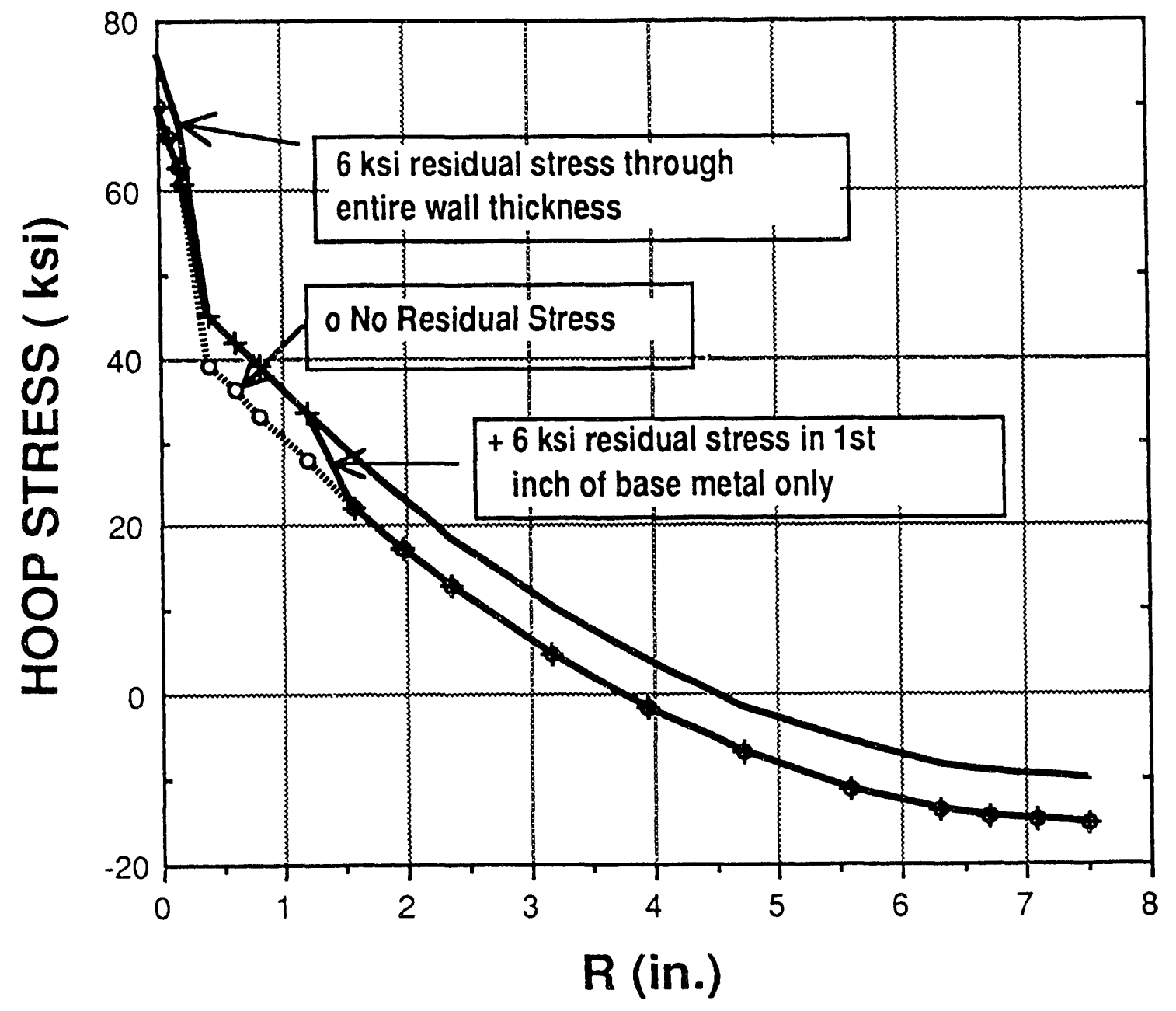

Fig. G.1. Hoop-stress distributions for axial welds (at time $=20 \mathrm{~min}$ ) for three residual-stress cases. 


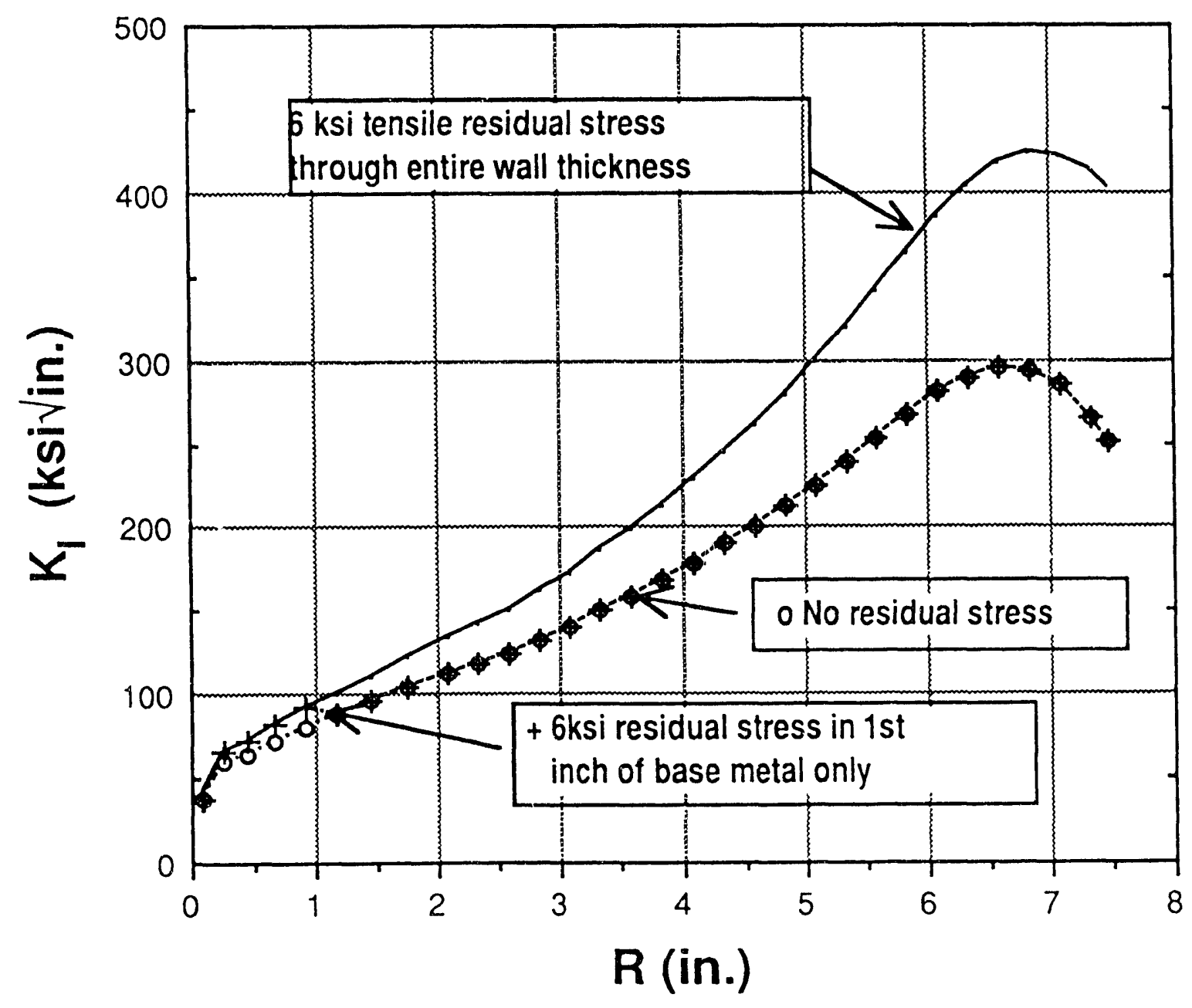

Fig. G.2. $\mathrm{K}_{\mathrm{I}}$ distributions for axial welds (at time $=20 \mathrm{~min}$ ) for three residual-stress cases. 


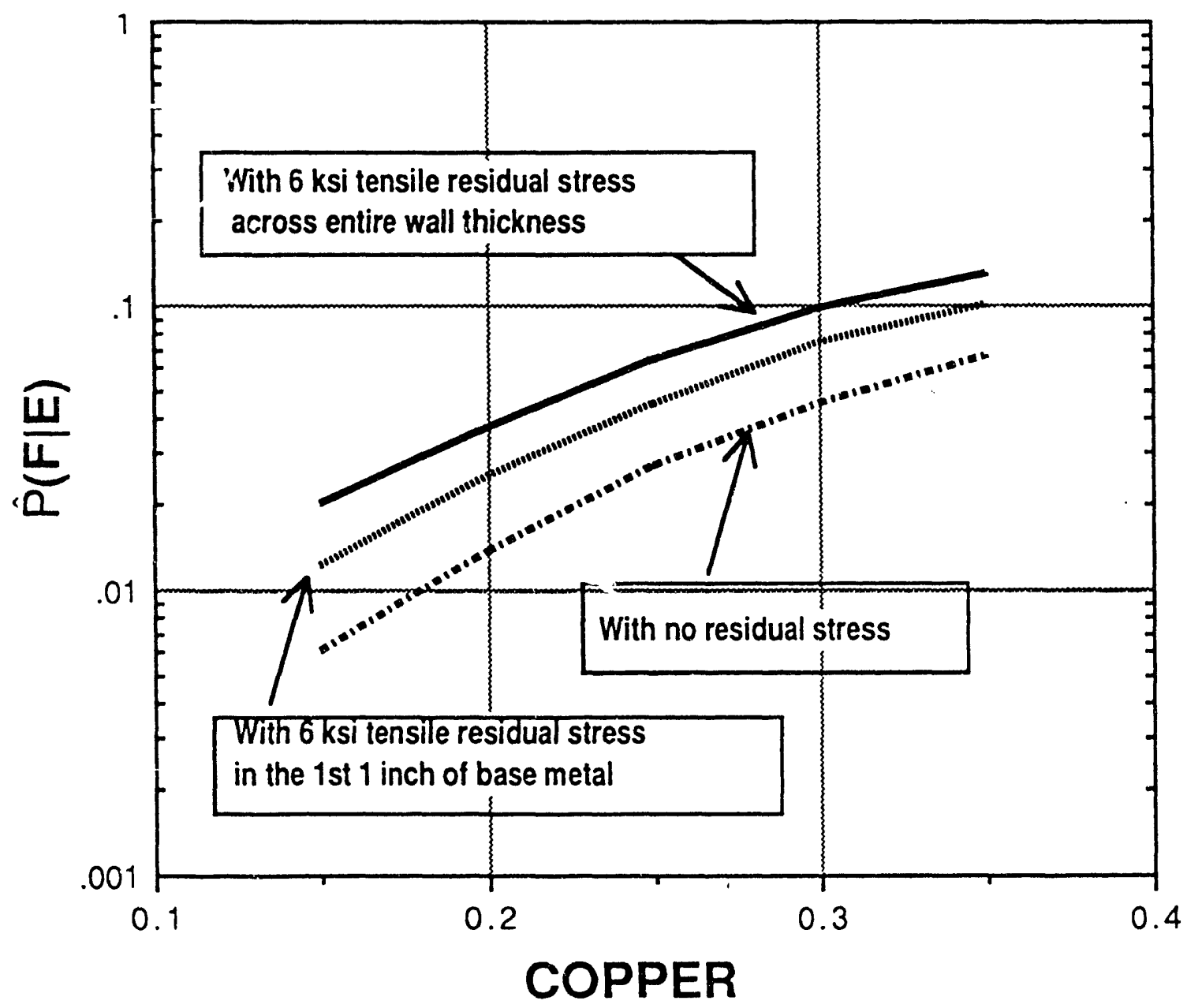

Fig. G.3. Best-estimate unadjusted conditional probability of failure for upper axial weld for three residualstress cases. 


\section{Appendix H: Dynamic Fracture Considerations}

Figure H.1. Experimental dynamic fracture toughness data.

Figure H.2. $\mathrm{K}_{\text {Id }}$ lower-bound curve approximation.

Figure H.3. Ratio of mean dynamic fracture toughness to IPTS mean X̌Ic curve. 


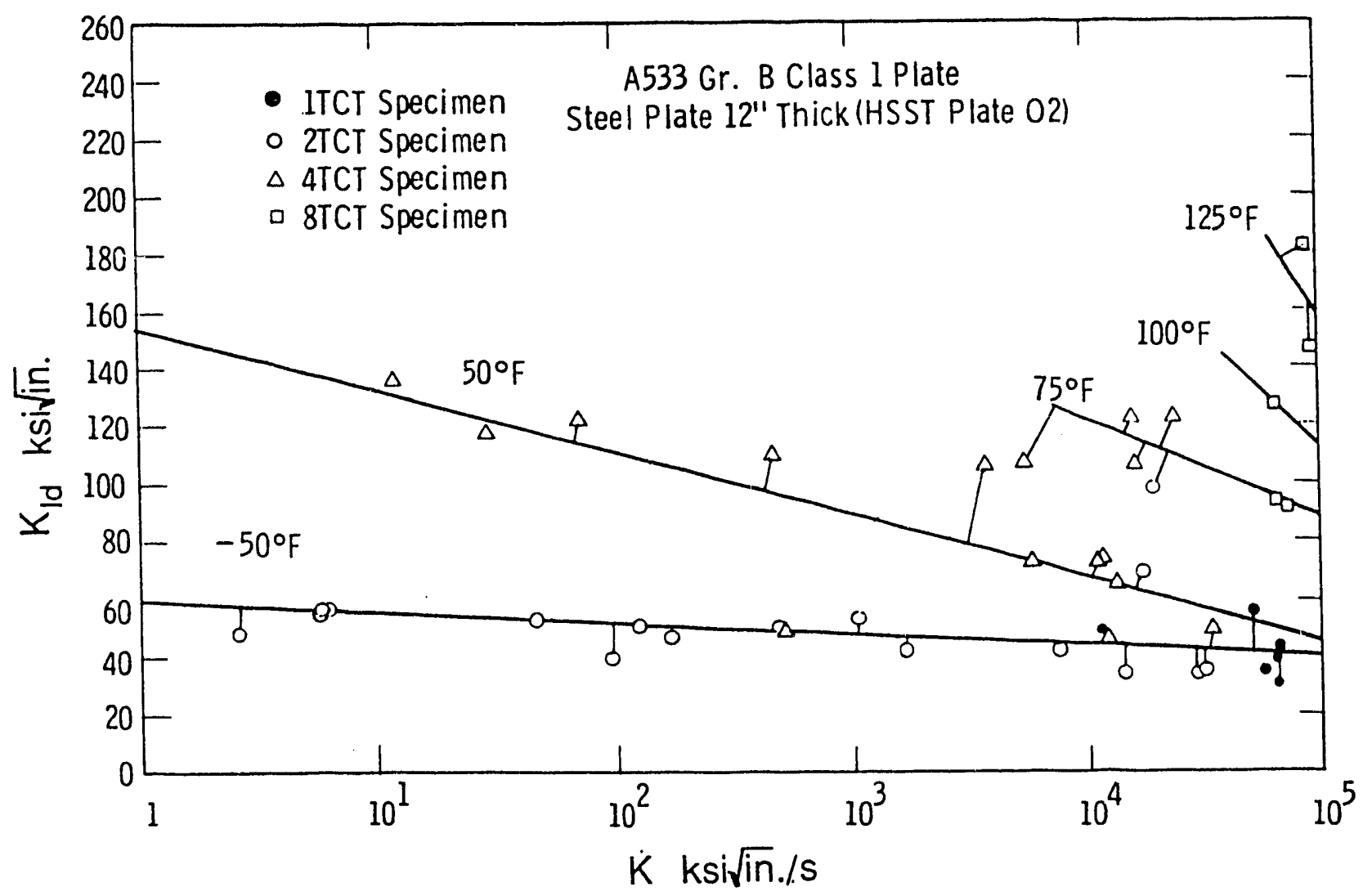

Fig. H.1. Experimental dynamic fracture toughness data. 


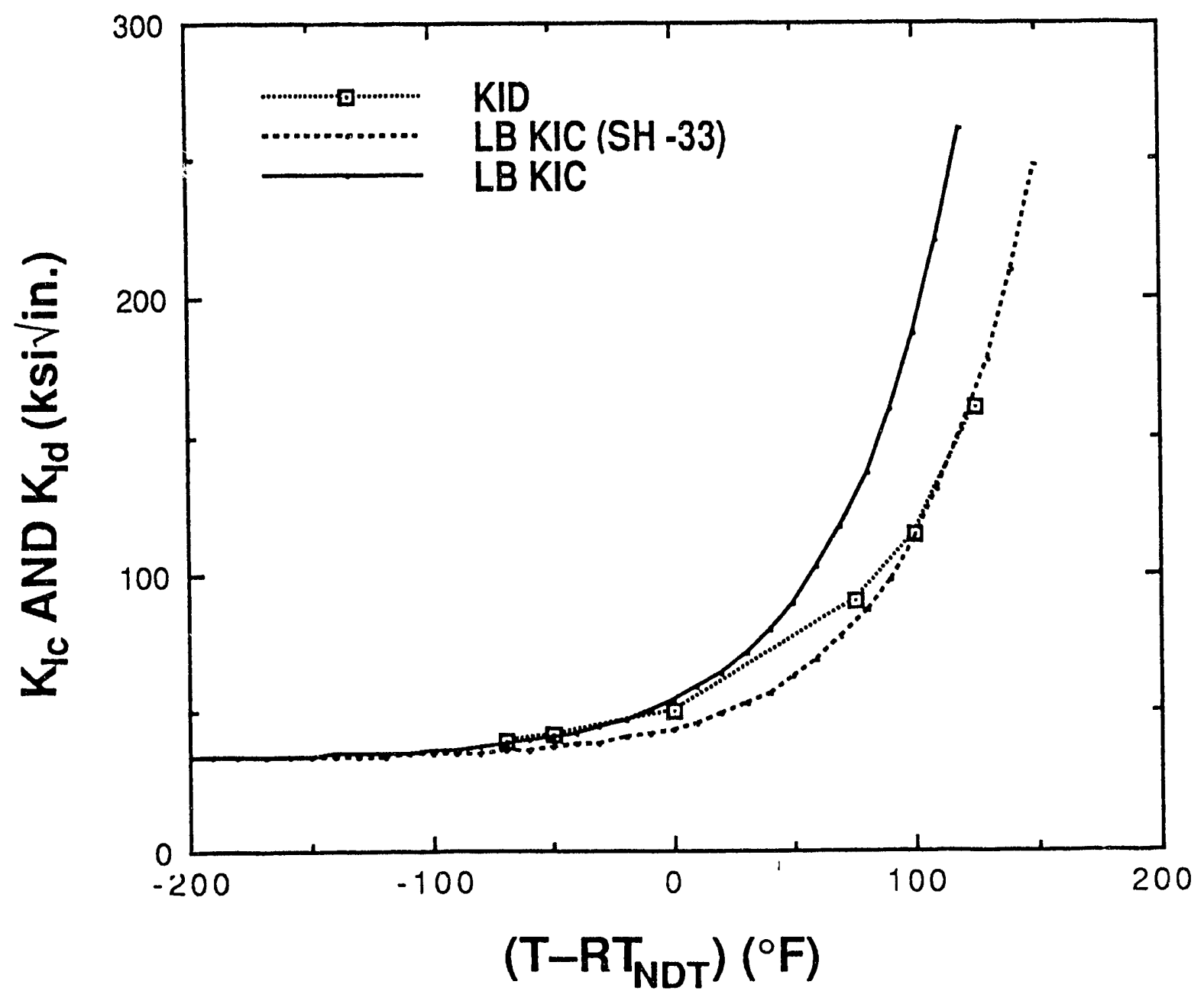

Fig. H.2. $\mathrm{K}_{\mathrm{Id}}$ lower-bound curve approximation. 


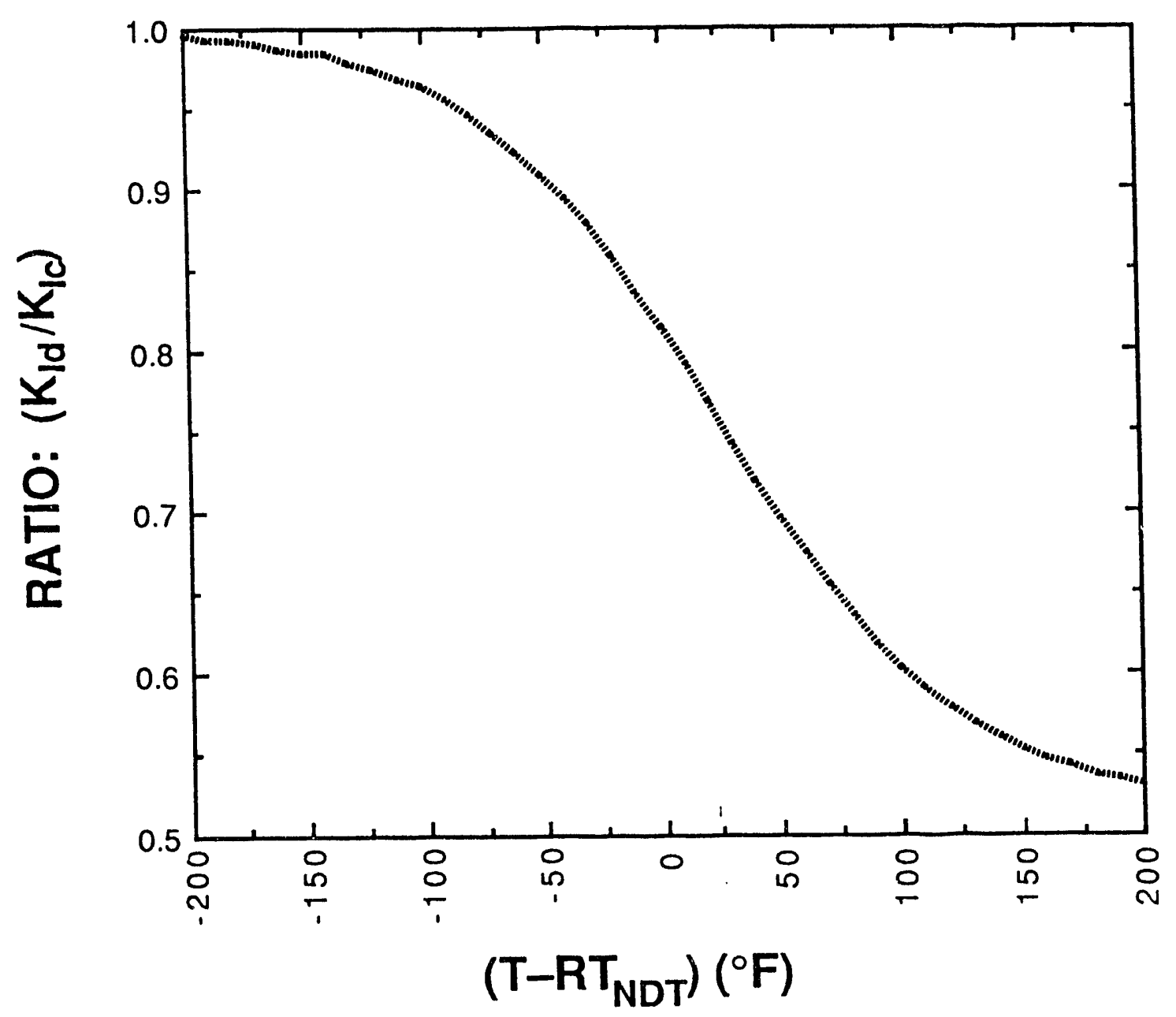

Fig. H.3. Ratio of mean dynamic fracture toughness to IPTS mean $\mathrm{K}_{\mathrm{Ic}}$ curve. 


\section{Appendix I: Clad-Rupture Studies for Subclad Flaws}

Finite-element fracture analyses were conducted in order to determine the minimum subclad flaw depths and their corresponding times in the transient for which rupture of the cladding is predicted. Two cladding thicknesses were considered; one with 0.109 -in.-clad thickness for plate material and another with 0.25 -in.-clad thickness for weld material. Table I.1 shows the relevant geometry and material parameters employed in the study. A nonlinear material description (Fig. I.1) was utilized for the stainless steel cladding while elastic-only properties were employed for base material. The cladding properties shown simulate irradiated properties $1\left(\sim 2 \times 10^{19}\right.$ $\mathrm{n} / \mathrm{cm}^{2}$ ). The pressure-thermal transient (SBLOCA7), shown in Fig. A.1, Appendix A, represents the loading condition for the studies.

Elastic-plastic stress and J-integral calculations were performed using the ABAQUS2 finite-element structural analysis program executing on an IBM RISC/6000 workstation. Figures I.2-I.4 show a typical finite element mesh that was utilized to analyze various depths of subclad flaws under 0.25 in. cladding. A similar mesh was used for 0.109 in. cladding. A generalized plane strain (2-D flaw) model was employed with collapsed eight-noded isoparametric elements at the crack tip to create a singularity and simulate blunting.

Figure I.5 shows J-integral calculations at various times in the transient for each end of a 2 -in. subclad flaw under 0.25 in. cladding. Throughout the transient, J-values are higher near the clad/base interface than at the deepest point of the flaw, indicating that a subclad flaw has a greater propensity to rupture the cladding than to run in the other direction through the vessel wall. Accurate $\mathrm{J}$-integral calculations at the clad/base interface are complicated by the fact that the J-contours must necessarily pass through two dissimilar materials. Stateof-the-art computational techniques, such as the virtual crack extension algorithm in $\mathrm{ABAQUS}$, require that $\mathrm{J}$-contours pass through a single homogeneous material. In order to rigorously satisfy this condition it was necessary to consider subclad flaws that slightly "penetrate" the cladding so that J-contours could be taken through small elements in cladding material only. A penetration depth of $1 / 32$ of the cladding thickness (see Fig. 1.4) was utilized in the computations reported here. This penetration depth is consistent with fractographic results for Jo-Block specimens 3 in which cracks can be observed to penetrate the cladding by about that amount. Additional calculations were performed at the outset of the study using a $1 / 16$ clad thickness penetration model to investigate the sensitivity with respect to small penetration depths. These results are presented in Table $\mathrm{I} .2$ and indicate only a slight sensitivity for a wide range of subclad flaw depths. Hence, it was decided that a 1/32 penetration model would suffice for the present studies.
Two failure criteria were employed in the studies, one based on J and another based on a critical level of stress in the cladding. The first accounts for failure by fracture while the second considers failure by necking or tensile instability. In order to produce initial results in a timely manner, it was decided to apply a simplified and conservative criteria for tearing instability based on $\mathrm{J} I \mathrm{c}$ using data from the 7 th irradiated series ${ }^{1}\left(\mathrm{~J}_{\mathrm{IC}}=538 \mathrm{in}\right.$. $-\mathrm{lb} / \mathrm{in}^{2}{ }^{2}$ at $\mathrm{T}=200^{\circ} \mathrm{F}$ ). The need for more refined analyses would then be judged by the effect of the initial resis..; on the overall failure probability. A complication, however, in applying the small specimen data to the present studies is that there is a back-free surface effect in the clad cylinder with subclad flaw that is not present in the small specimens. Thus, it was decided to use a slightly more conservative value of $\mathrm{J}_{\mathrm{Ic}}=500$ for the $\mathrm{J}$ failure criteria.

Figure I.6 gives the computed J-values throughout the transient "near" the clad/base interface for a range of subclad flaws under 0.25 in. cladding. Each flaw depth has a maximum $J$-value at $t \sim 21-22 \mathrm{~min}$. Figure 1.7 shows the J-values from Fig. 1.6 at 21 min plotted against subclad flaw depth and indicates that the critical subclad flaw crack depth for 0.25 in. cladding is acrit $=1.65$ in.

Figure 1.8 gives $\mathrm{J}$-values near the clad/base interface for subclad flaws under $0.109 \mathrm{in}$. cladding. As will be discussed below, subclad flaws in 0.109 in. cladding reach a critical level of stress before J exceeds J Ic.

The Jo-Block specimen ${ }^{3}$ shown in Fig. I.9 has been used for measuring strength properties of cladding over a subclad flaw. This specimen is basically a tensile bar that simulates the basic geometry, deformation, and failure behavior features of cladding over a subclad flaw in a vessel wall. It consists of two machined steel blocks with the ends butted together to form a "crack." Opposite edges are clad such that subclad flaw tips are generated where the cladding is laid across the interface of the two blocks. The "rupture stress and strain" in the cladding can be determined from a simple tensile test in conjunction with posttest cross-section measurements. Tests $^{3}$ at ORNL show that the rupture stress in the cladding is $-90 \%$ of the flow stress, where flow stress is the average of yield and ultimate. Hence, rupture of the cladding is assumed to occur in the present studies if the "average" stress in the cladding at any time in the transient exceeds 0.9 flow stress.

Like the J-value calculations, the Mises stress in the cladding reaches a maximum value at $t \sim 21$ min into the transient for each subclad flaw depth analyzed. Figure 1.10 shows "average" Mises stresses in a 0.25 in. cladding at $\mathrm{t} \sim 21 \mathrm{~min}$ for the range of flaws studied. As can be seen, none of the flaws in the range fail based on stress; however, as shown earlier, a 1.65-in. subclad flaw does fail based on J. For a 0.109 in. cladding, however, a critical level of stress is reached in the cladding before a critical value of $\mathrm{J}$ is reached. Figure I.11 shows Mises stresses in the cladding for subclad flaws ranging from 
0.33 in. to 0.78 in. deep. It is observed that a 0.78 -in. subclad flaw has a stress level that very nearly exceeds 0.9 flow stress and, indeed, convergent stress solutions were not able to be obtained for flaws deeper than 0.8 in. (see Table I.2). Extrapolating the curve in Fig. I.11 to 0.9 flow stress indicates that the critical subclad flaw depth is -0.85 in. for 0.109 in. cladding. In light of the fact that the 0.78 in. subclad flaw took many iterations for convergence and that a slightly deeper flaw doesn't converge at all for times much earlier in the transient, it was decided to take a conservative approach and declare failure by critical stress for a subclad flaw depth of 0.75 in. under 0.109 in. cladding.

Table 1.3 summarizes the results of the clad rupture studies. A 0.75-in. subclad flaw ruptures a 0.109 in. cladding at $\mathrm{t} \sim 21 \mathrm{~min}$ into the transient while a 1.65-in. subclad flaw ruptures a 0.25 in. cladding at $t \sim 21 \mathrm{~min}$ into the transient.

\section{References}

1. F. M. Haggag, W. R. Corwin, and R. K. Nanstad, Irradiation Effects on Strength and Toughness of Three-Wire Series-Arc Stainless Steel Weld Overlay Cladding, NUREG/CR-5511 (ORNL/TM11439), Oak Ridge National Laboratory, Oak Ridge, Tennessee (February 1990). ${ }^{a}$

2. ABAQUS User Manual, Version 4-8, Hibbit, Karlsson \& Sorensen, Inc., Providence, Rhode Island (1989). ${ }^{\mathrm{b}}$
3. W. J. McAfee, J. W. Bryson, R. D. Cheverton, and G. C. Robinson, " A Specimen and Method for Evaluating the Effect of Cladding on the Behavior of Subclad Flaws", PVP-Vol. 213/MPC-Vol. 32, Pressure Vessel Integrity, ASME $1991^{b}$

$a_{\text {Available for purchase from GPO Sales Program. }}$

${ }^{b}$ Available for puirchase from ónganization sponsoring publication cited, and/or authors, and/or recipients (documented letters). 


\section{Yankee-Rowe Vessel:}

Inner vessel radius $=54.5 \mathrm{in}$.

Wall thickness $=7.875$ in.

Clad thickness $=0.109$ in., 0.25 in.

\section{Stainless Steel Cladding:}

Modulus of Eeasticity $=27,000 \mathrm{ksi}$

Poisson's ratio $=0.3$

Coefficient of thermal expansion $=9.9 \times 10-6 /{ }^{\circ} \mathrm{F}$

Thermal conductivity $=10 \mathrm{Btu} / \mathrm{h}-\mathrm{ft}-{ }^{\circ} \mathrm{F}$

Specific heat $=0.12 \mathrm{Btu} / \mathrm{b}-{ }^{\circ} \mathrm{F}$

Density $=488 \mathrm{lb} / \mathrm{ft}^{3}$

\section{A533B Base Metal:}

Modulus of elasticity $=28,000 \mathrm{ksi}$

Poisson's ratio $=0.3$

Coefficient of thermal expansion $=7.85 \times 10-6 /{ }^{\circ} \mathrm{F}$

Thermal conductivity $=24 \mathrm{Btu} / \mathrm{h}-\mathrm{ft}-{ }^{\circ} \mathrm{F}$

Specific heat $=0.12 \mathrm{Btu} / \mathrm{lb}-{ }^{\circ} \mathrm{F}$

Density $=488 \mathrm{lb} / \mathrm{ft}^{3}$

No temperature dependence of material properties included in analyses.

Initial vessel temperature $=515^{\circ} \mathrm{F}$

Initial water temperature $=515^{\circ} \mathrm{F}$

Coefficient of convective heat transfer $=504 \mathrm{Btu} / \mathrm{h}-\mathrm{ft} 2-^{\circ} \mathrm{F}$ 
Table I.2. Comparison of J-values near clad/base interface for two different clad penetration models: $1 / 32$ in. and $1 / 16$ in.

\begin{tabular}{|c|c|c|c|}
\hline Clad penetration & $\begin{array}{l}\text { Subclad flaw } \\
\text { depth } \\
\text { (in.) }\end{array}$ & J-value (in.-lb/in.2) & $\begin{array}{c}\text { Time } \\
(\mathrm{s})\end{array}$ \\
\hline \multicolumn{4}{|c|}{0.250 in. cladding } \\
\hline $1 / 32$ & $\begin{array}{l}2.00^{*} \\
1.50 \\
1.00 \\
0.50\end{array}$ & $\begin{array}{l}664 \\
426 \\
245 \\
105\end{array}$ & $\begin{array}{l}1298 \\
1297 \\
1290 \\
1267\end{array}$ \\
\hline $1 / 16$ & $\begin{array}{l}2.00 * \\
1.50 \\
1.00 \\
0.50\end{array}$ & $\begin{array}{l}601 \\
403 \\
250 \\
113\end{array}$ & $\begin{array}{l}1301 \\
1304 \\
1307 \\
1290\end{array}$ \\
\hline \multicolumn{4}{|c|}{0.109 in. cladding } \\
\hline $1 / 32$ & $\begin{array}{l}0.78^{*} \\
0.55 \\
0.33\end{array}$ & $\begin{array}{r}250 \\
160 \\
85\end{array}$ & $\begin{array}{l}1290 \\
1307 \\
1272\end{array}$ \\
\hline $1 / 16$ & $\begin{array}{l}0.78^{*} \\
0.55 \\
0.33\end{array}$ & $\begin{array}{r}228 \\
155 \\
88\end{array}$ & $\begin{array}{l}1290 \\
1309 \\
1276\end{array}$ \\
\hline
\end{tabular}

*NOTE: Not able to get a convergent stress solution for larger subclad flaws. 
Table I.3. Results of cladding-rupture studies

\begin{tabular}{cccc}
\hline $\begin{array}{c}\text { Cladding Thickness } \\
\text { (in.) }\end{array}$ & $\begin{array}{l}\text { acrit } \\
\text { (in.) }\end{array}$ & $\begin{array}{c}\text { Time } \\
(\mathrm{min})\end{array}$ & $\begin{array}{c}\text { Failure* } \\
\text { by }\end{array}$ \\
\hline 0.109 & 0.75 & $\approx 21$ & Stress \\
0.25 & 1.65 & $\approx 21$ & $\mathrm{~J}$ \\
\hline
\end{tabular}

*Failure Criteria:

1. Clad stress $>0.9$ flow stress

2. $\mathrm{J}>\mathrm{J}_{\mathrm{Ic}}$ 


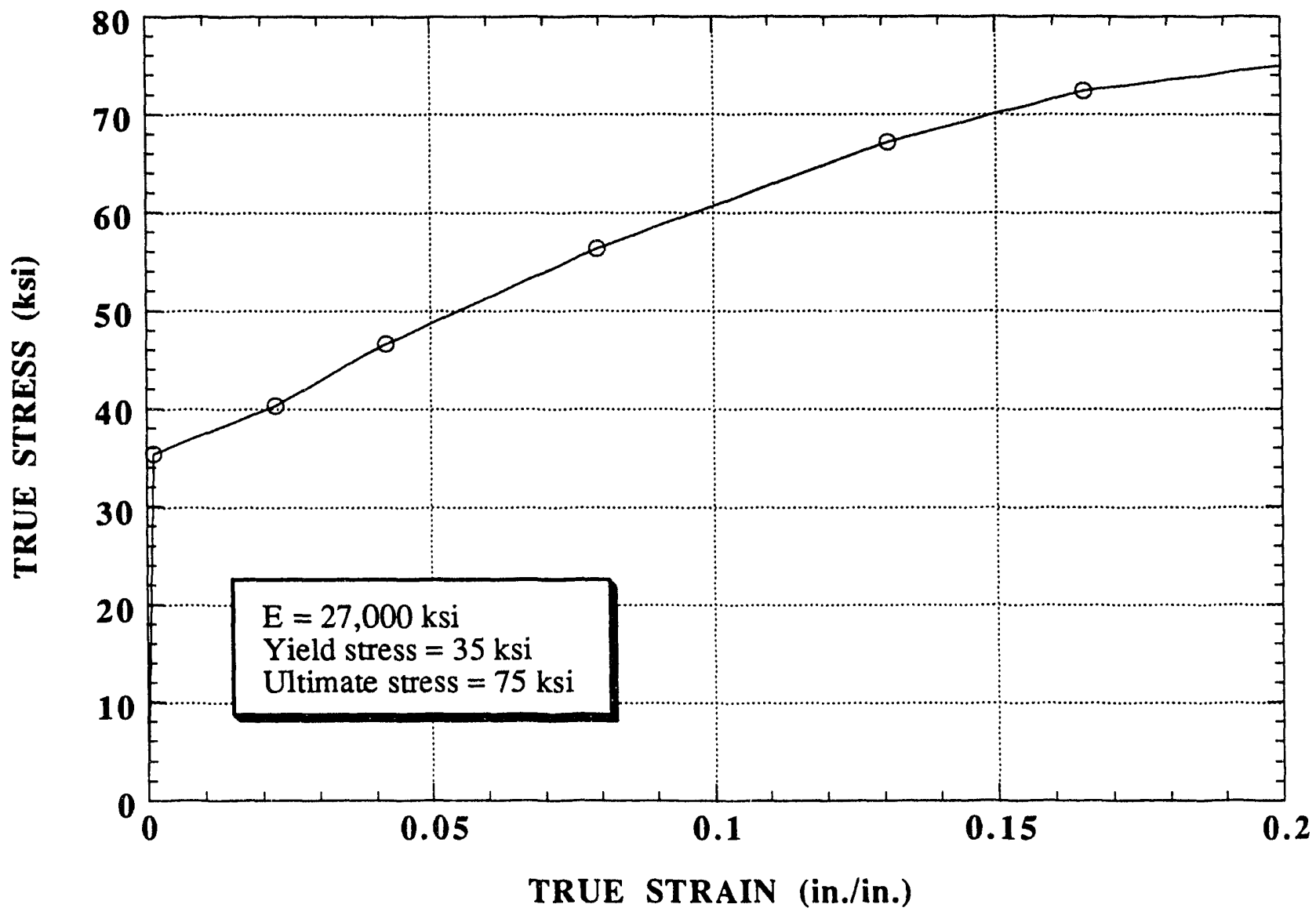

Fig. I.1. Stress/strain curve for 7 th irradiation series three-wire cladding material $\left(\mathrm{T}=550^{\circ} \mathrm{F}\right)$. 
ABAQUS

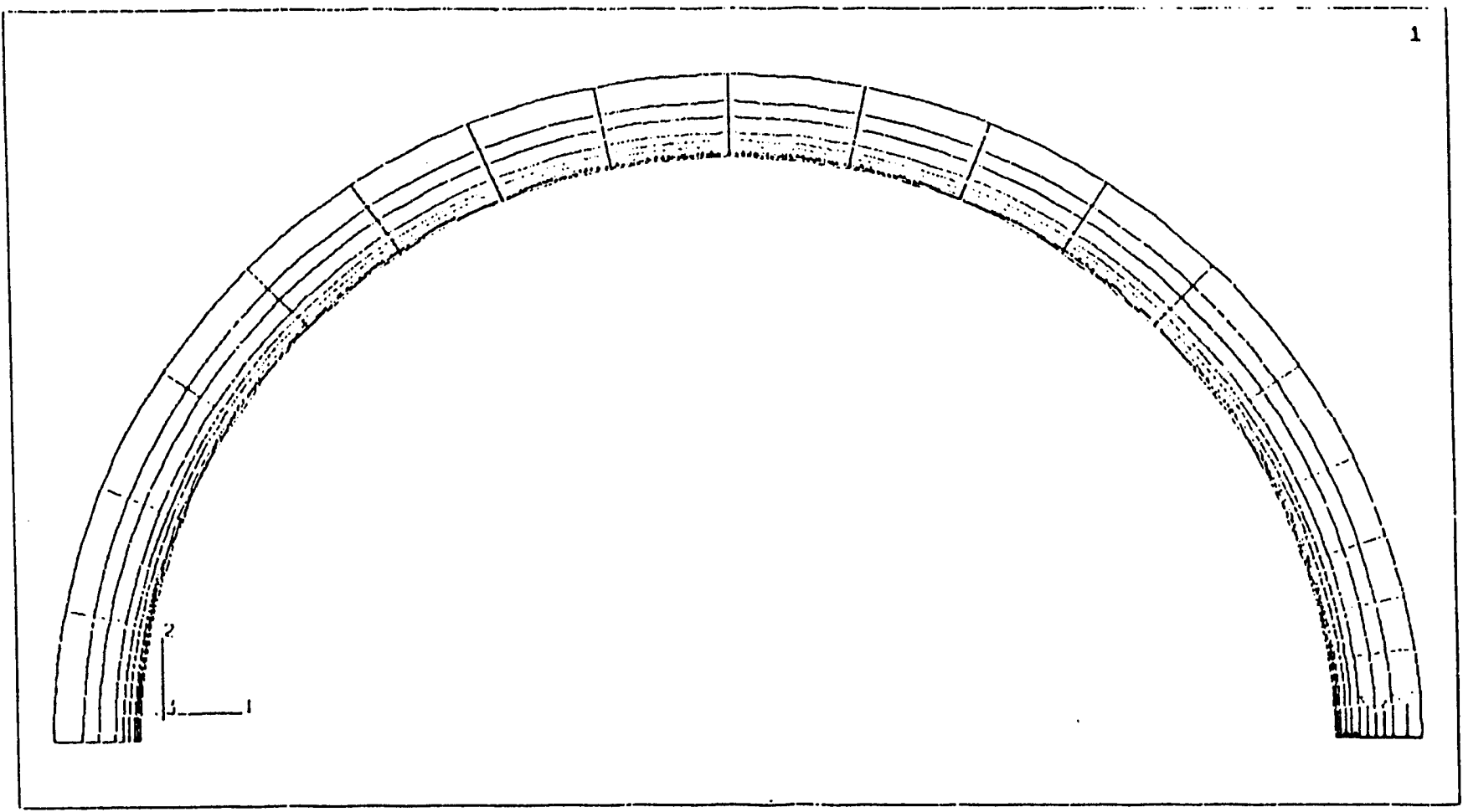

Fig. I.2. Finite-element model employed for cladding-rupture studies. 


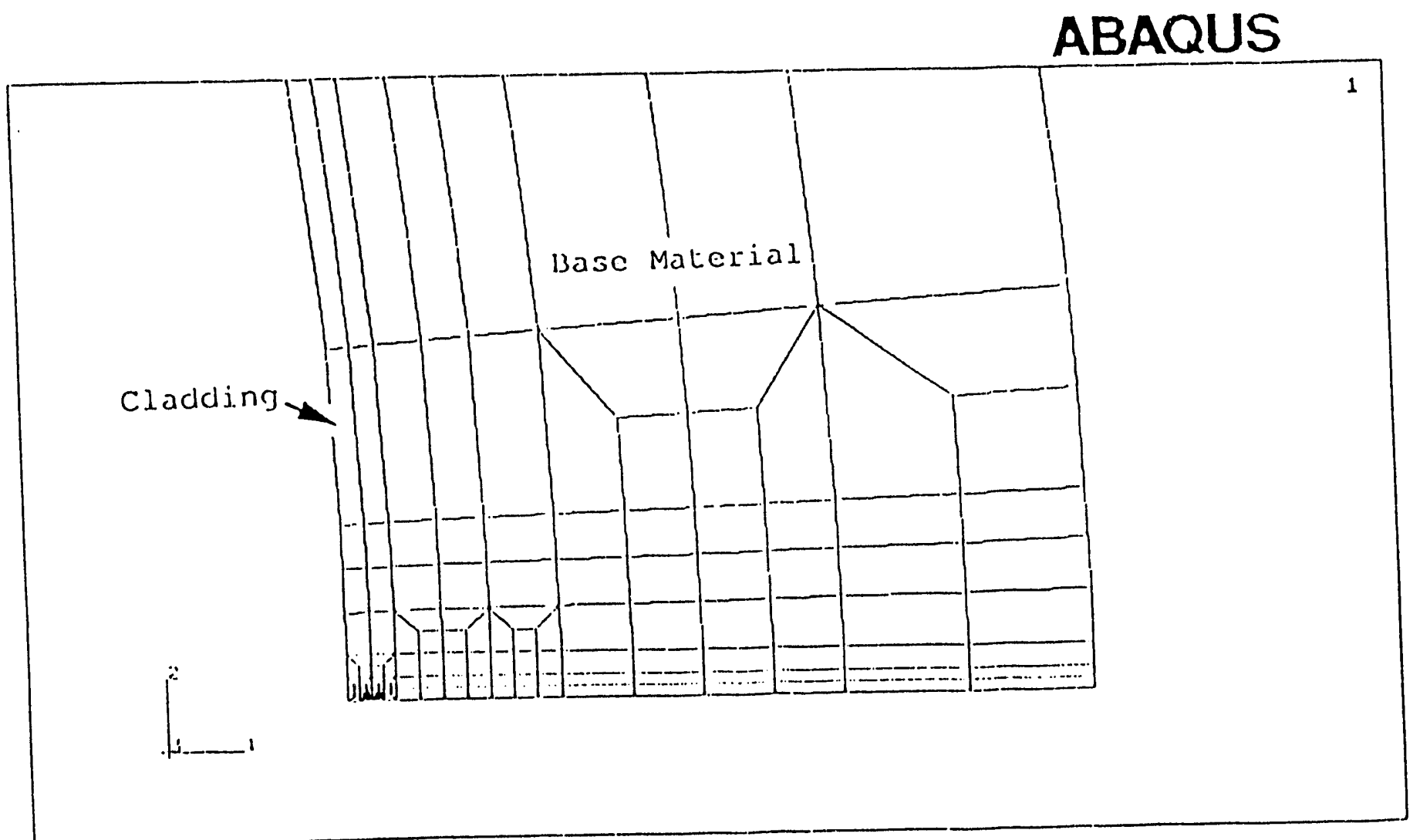

Fig. I.3. Enlargement of crack tip region. 
ABAQUS

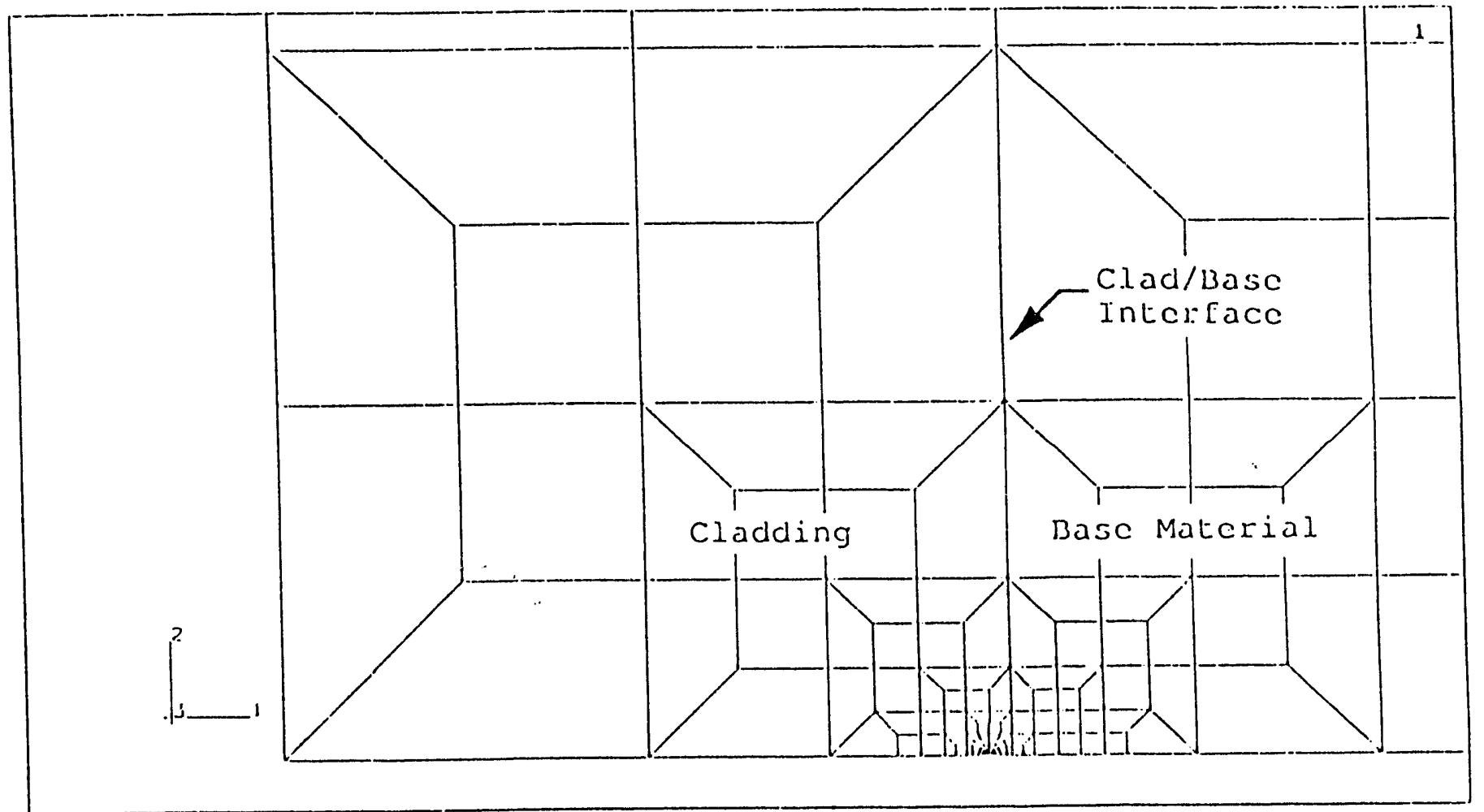

Fig. I.4. Further enlargement of crack tip region. 


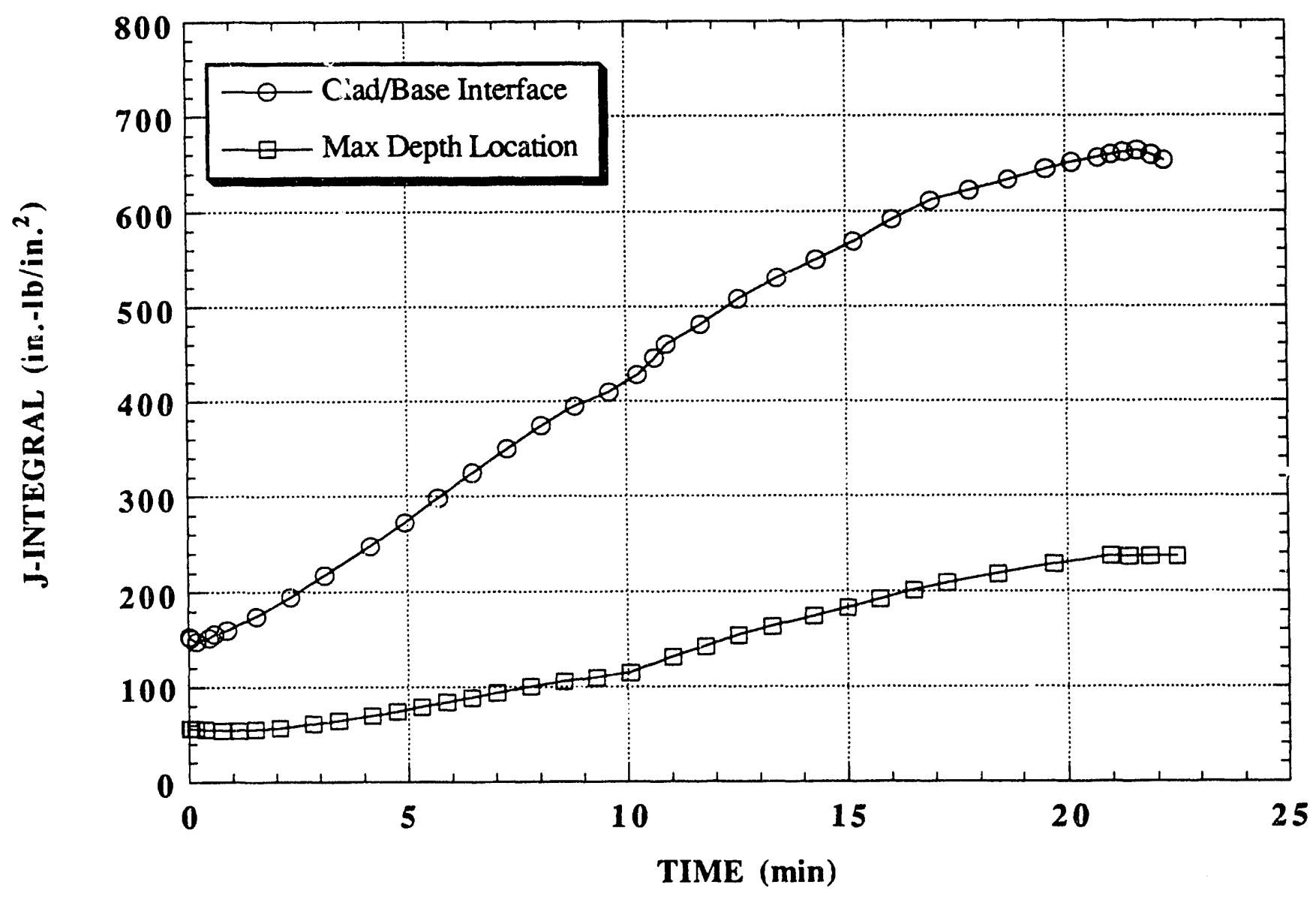

Fig. 1.5. J-integral values at each crack tip for a 2-in. subclad flaw, SBLOCA7 transient, 0.25 -in. cladding. 


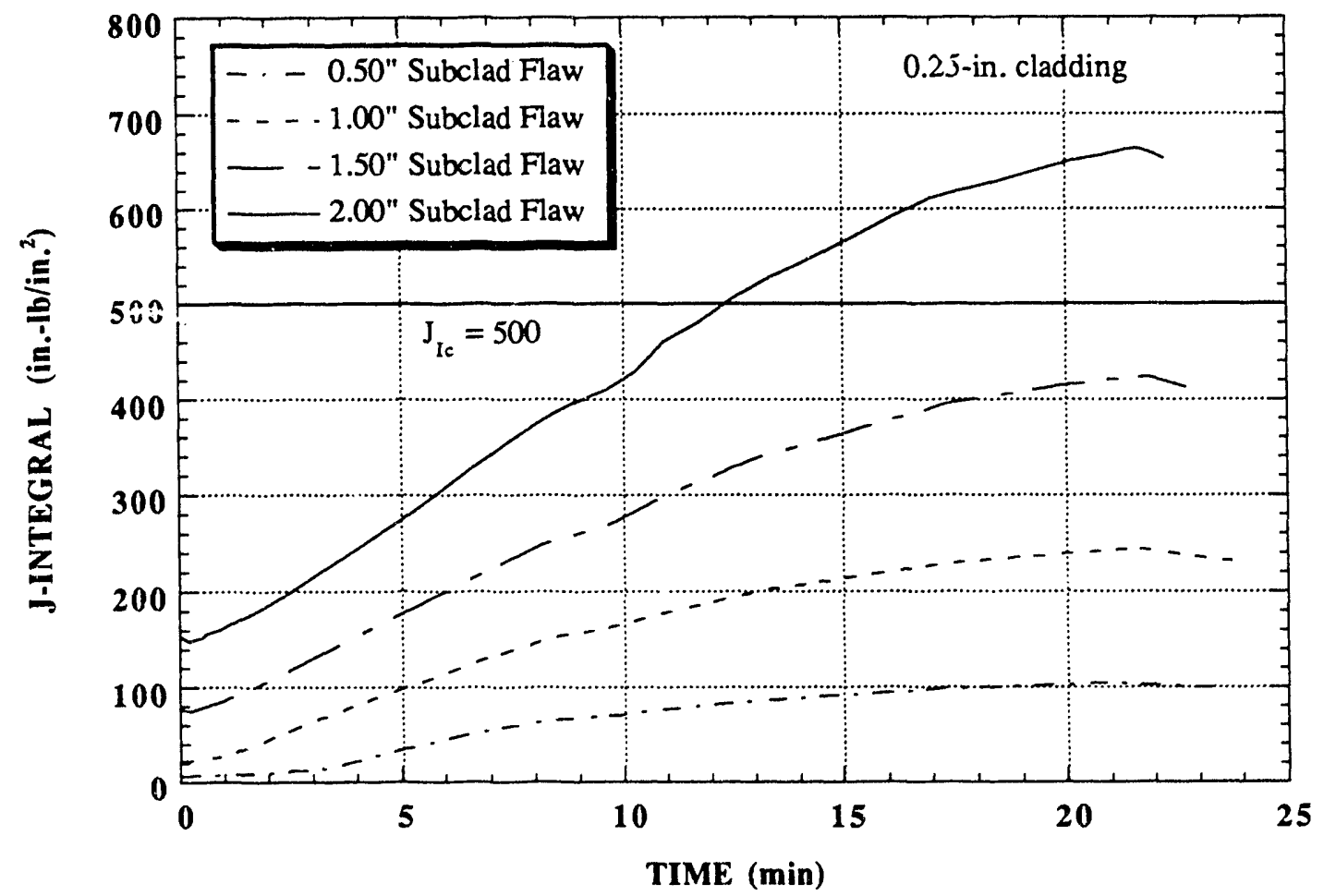

Fig. I. . J-values near clad/base interface, 0.25 -in. cladding 


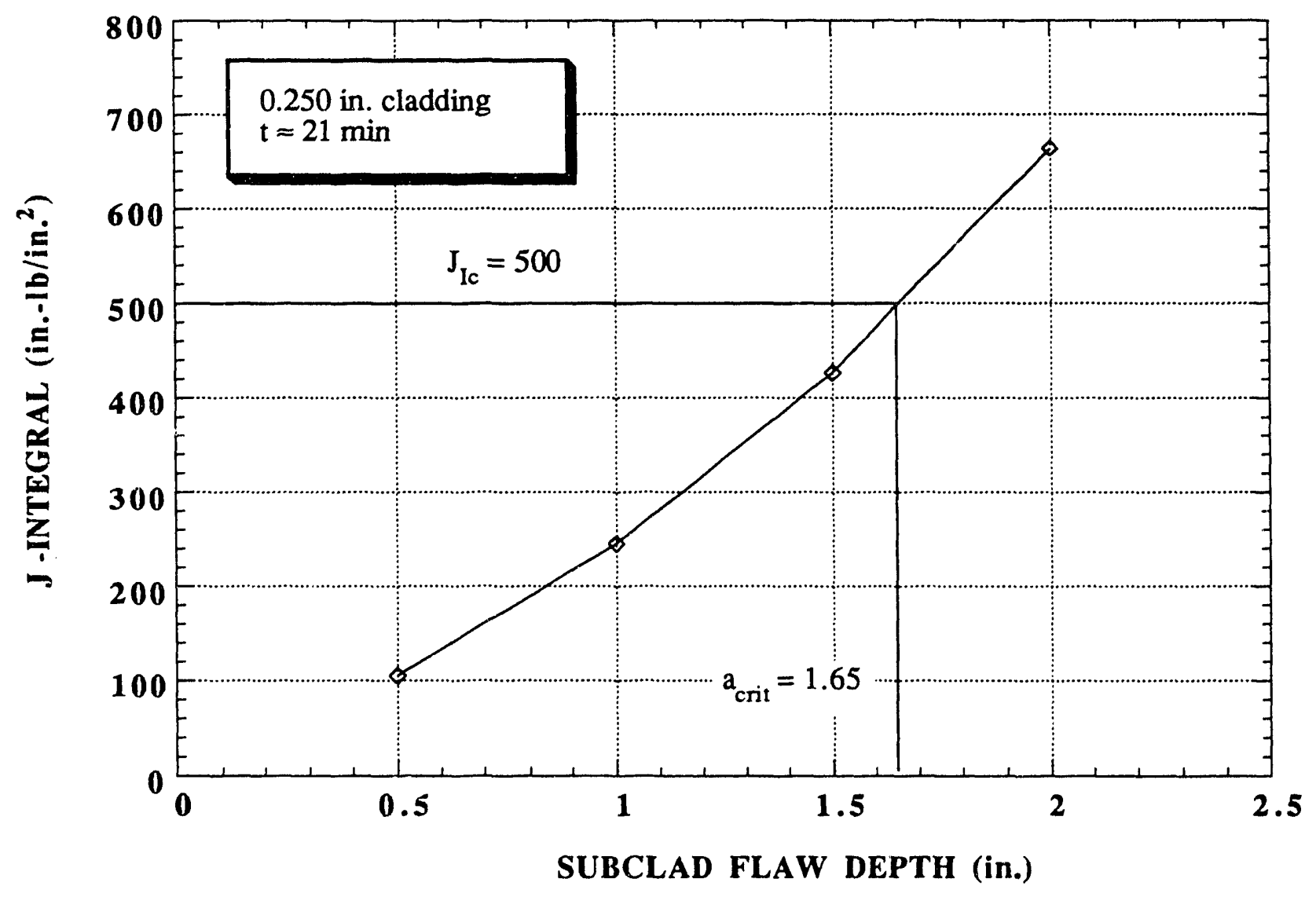

Fig. 1.7. A 1.65 -in. subclad flaw ruptures a 0.25 -in. cladding. 


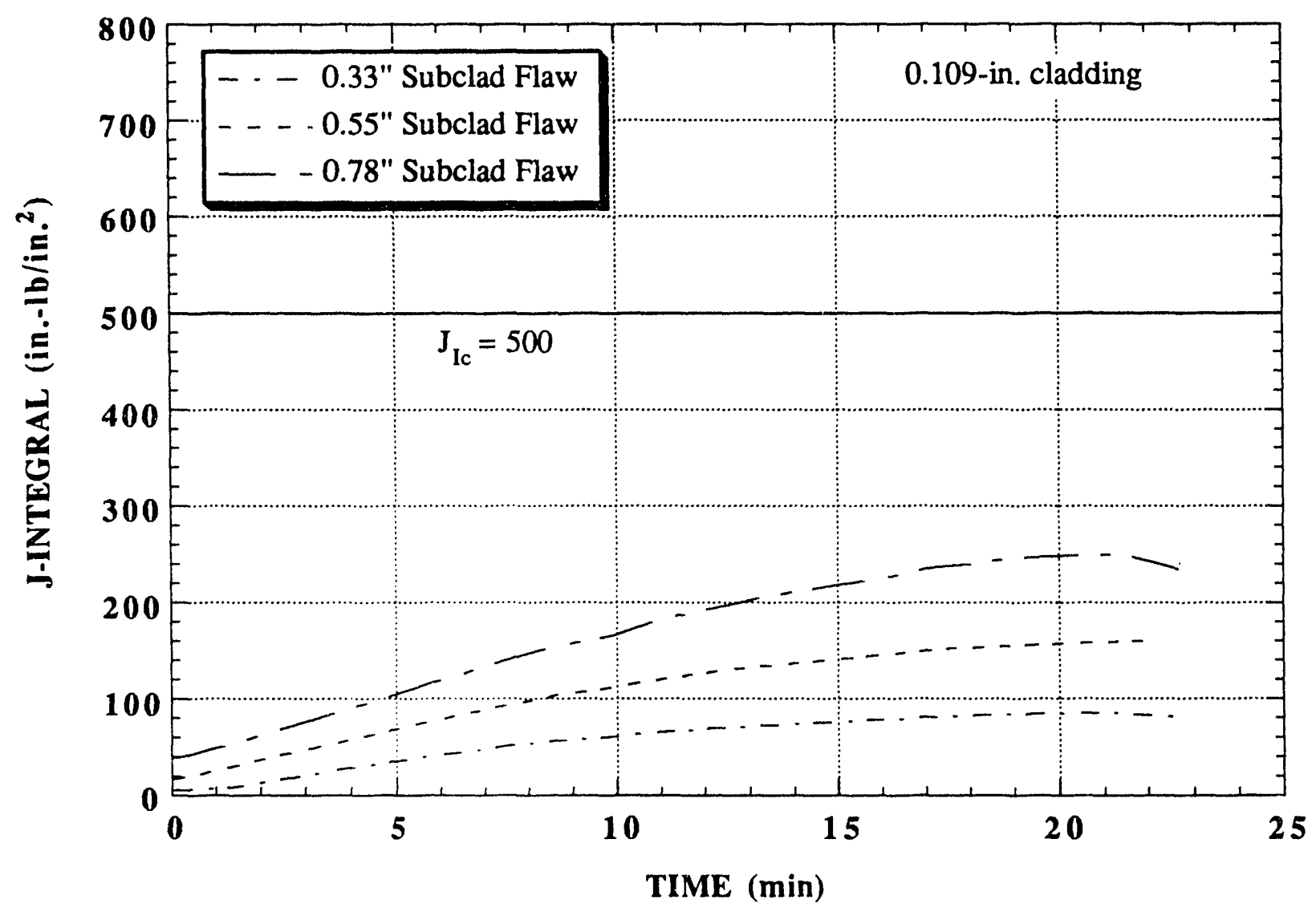

Fig. I.8. J-values near clad/base interface, 0.109-in. cladding. 


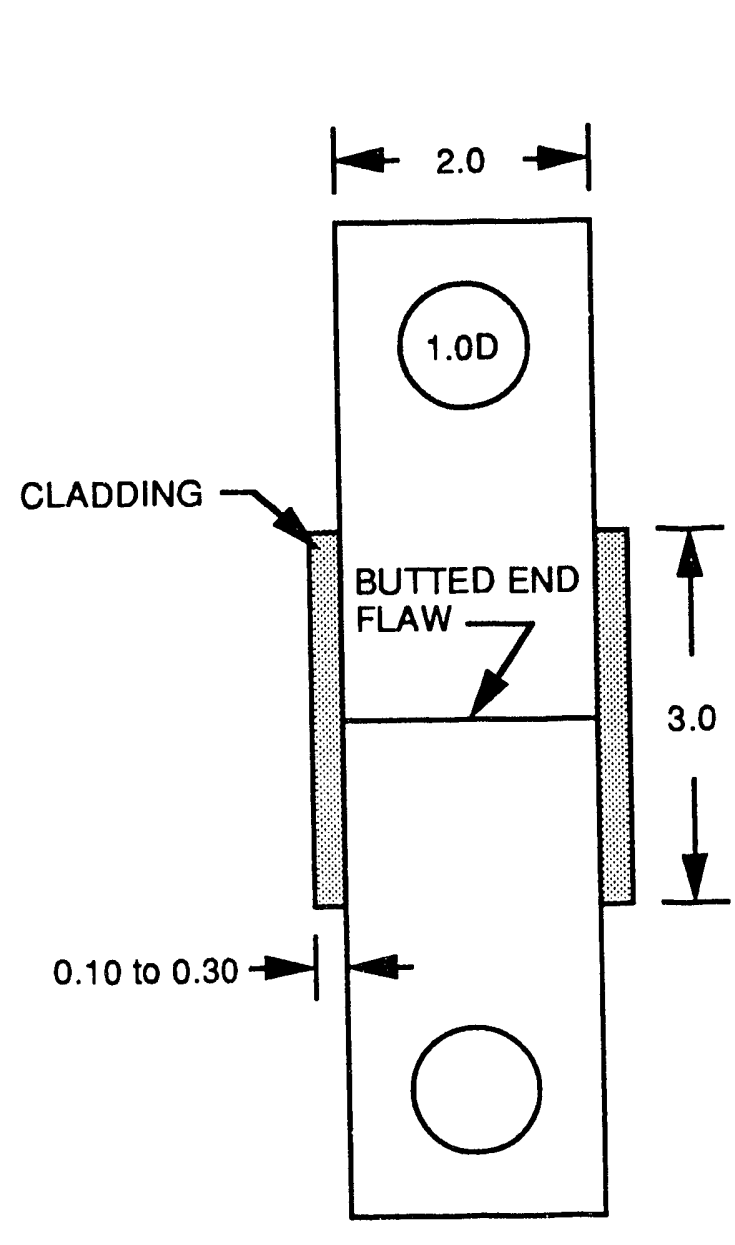

(a) Eront

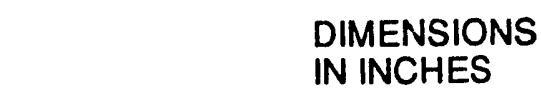

$\rightarrow 1.0$

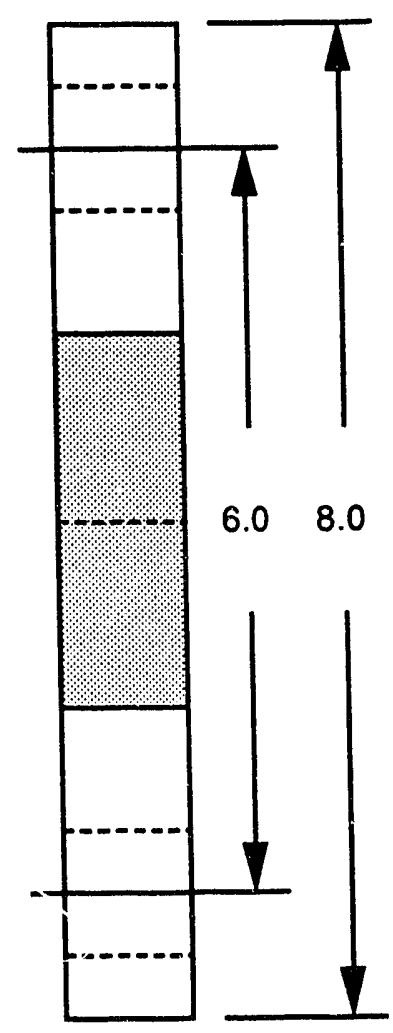

(b) Side

Fig. 1.9. Jo-Block specimen for measuring fracture properties of cladding over a subclad flaw. 


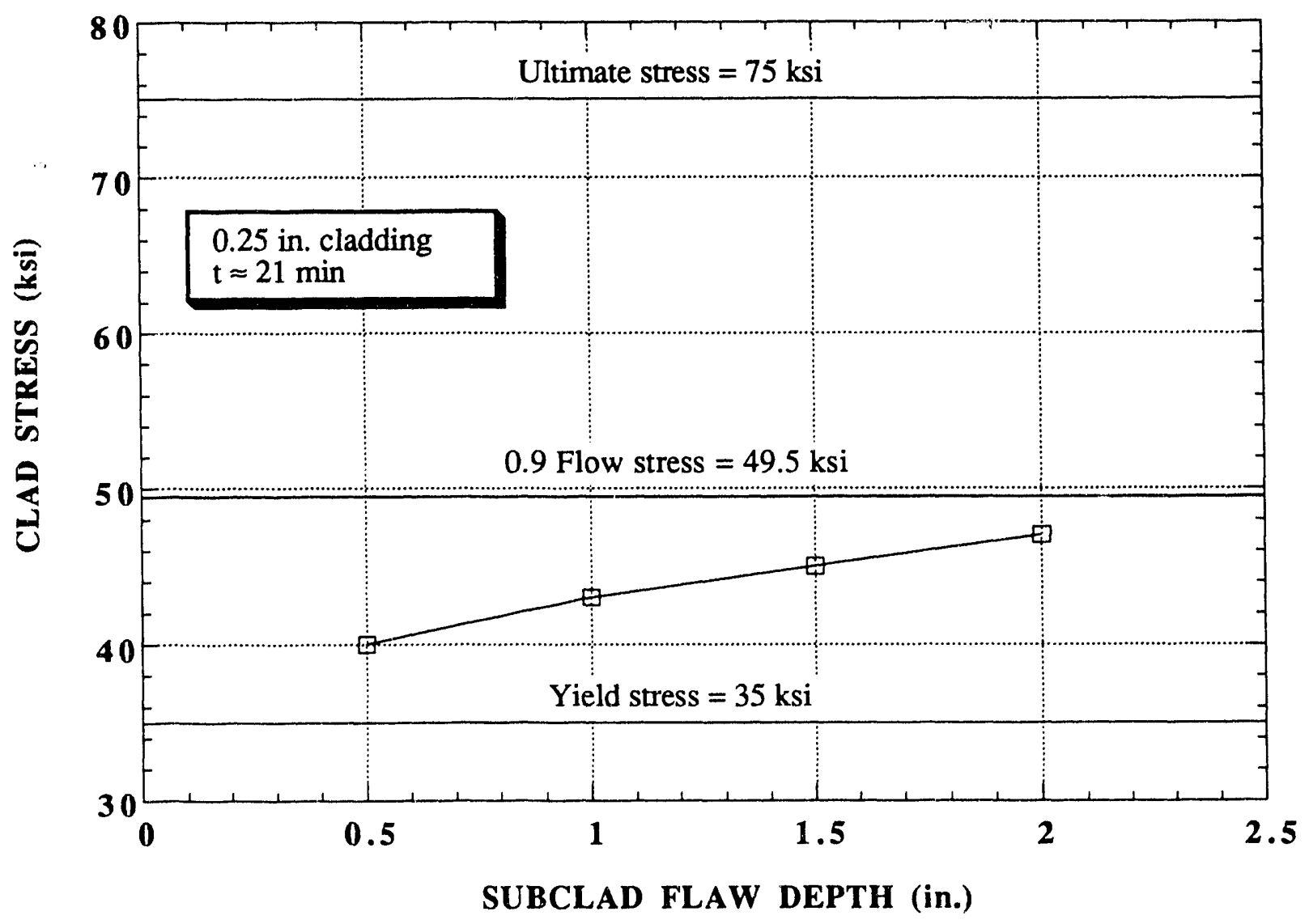

Fig. I.10. Mises stress in 0.25 -in. cladding, $t \approx 21 \mathrm{~min}$. 


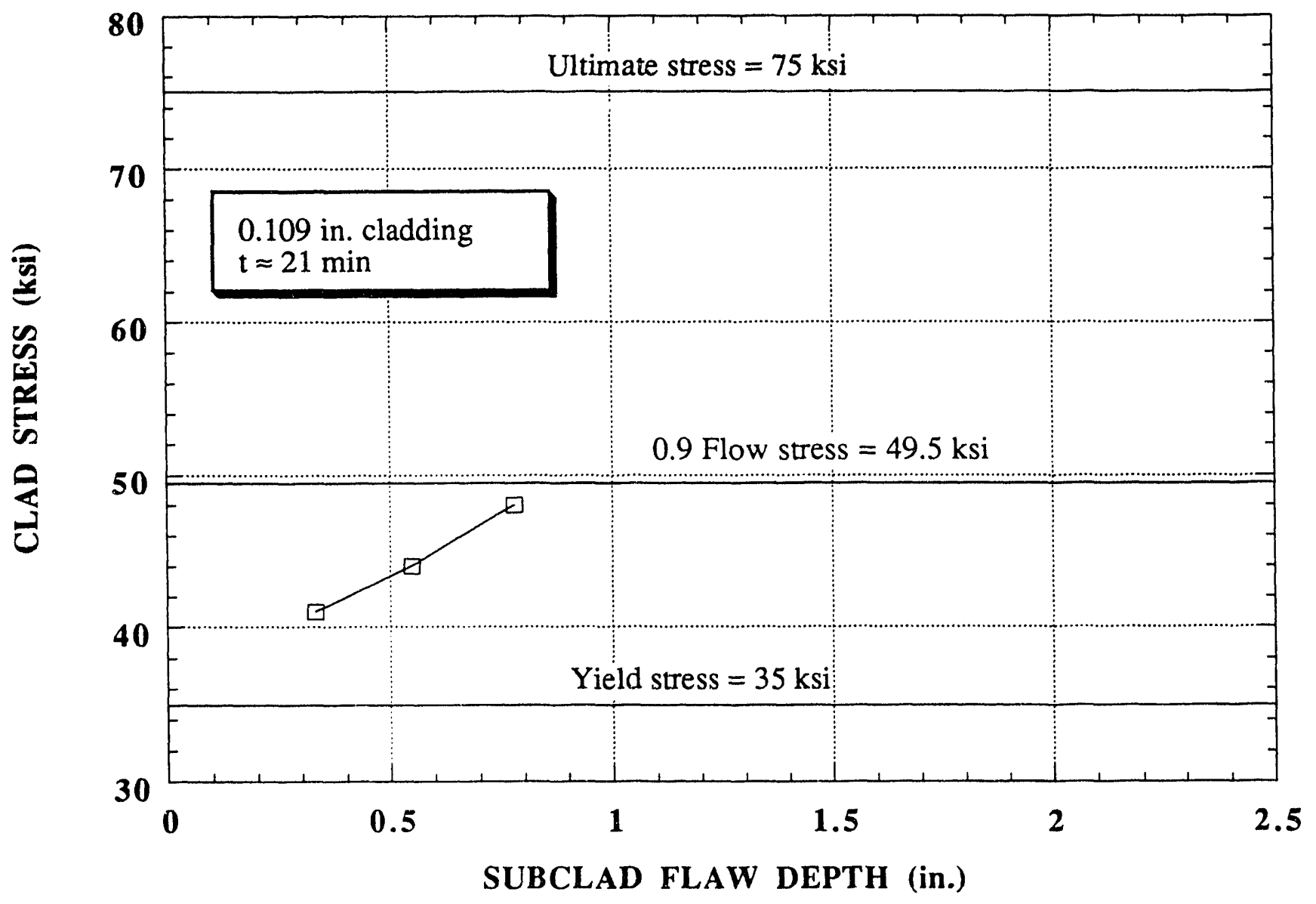

Fig. I.11. Mises stress in 0.109 -in. cladding, $\mathrm{t} \approx 21 \mathrm{~min}$. 


\section{Appendix J. Analysis of Noncontinous Clad/Base Interface}

Three-dimensional (3-D) thermoelastic analyses were performed to determine the variation in $\mathrm{K}_{\mathrm{I}}$ values for a straight axial flaw in an RPV due to the clad/base interface gap between the spot vidlds in the upper plate region, as described in Section 2. The vessel geometry and material properties are reported in Table 1. The loading condition used in these analyses is taken from the pressure-thermal transient, SBLOCA7, at a time of 20 min from initiation into the transient; the transient is shown in Fig. A.1, Appendix A.

The 3-D finite-element model of a cubic element from a cylinder is shown in Figs. J.1 and J.2. The model consists of 6060 nodes, 1148 twenty-noded isoparametric brick elements, and 56 wedge, elements at the crack front. The gap thickness in Fig. J.2 is taken to be 10 mils. Mesh convergence studies in Ref. 1 for RPV cylinders containing shallow flaws demonstrated that meshes on the order of 8700 degrees of freedom produced converged $\mathrm{K}_{\mathrm{I}}$ values within $1 \%$. The finite-element model of the cylinder employed in this study has $>15,000$ degrees of freedom and is estimated to provide comparable accuracy in $\mathrm{K}_{\mathrm{I}}$ values.

Generalized-plane-strain boundary conditions were imposed on the vertical surfaces of the model to simulate deformation restraint consistent with that found in an RPV shell, i.e., plane surfaces remain plane. This methodology permits the use of increased mesh refinement in the crack-tip region of the model. Loading due to internal pressure was applied on these surfaces in the form of resultant forces derived from a $\operatorname{Pr} / t$ stress distribution in the hoop direction and $\operatorname{Pr} / 2 t$ stress distribution in the axial direction, as shown in Fig. J.1. The through-wall temperature profile (at time $=20 \mathrm{~min}$ ) from Fig. A.2, Appendix A, was used to interpolate temperatures for the 3-D model.

Thermoelastic analyses were performed for the 3-D model using the ADINA/ORVIRT2,3 system and the material properties from Table 1 . Three different models were analyzed, one containing no flaw (model 1), and the second and third containing a 0.25 -in.-deep flaw with and without interface gaps (models 2 and 3 , respectively). The through-wall hoop stress distributions from models 1 and 2 are compared with corresponding results from OCA-P in Fig. J.3. The far-field stresses (away from the crack) for the two models compare well with OCA-P results.

The calculated $\mathrm{K}_{\mathrm{I}}$ for model 3 (no interface gap) had a uniform value of $39.3 \mathrm{ksi} \sqrt{\mathrm{in}}$. This value is compared with the $\mathrm{K}_{\mathrm{I}}$ values generated for model 2 (with interface gap) in Fig. J.4. When the gap was included, the peak $\mathrm{K}_{\mathrm{I}}$ value increased by $0.5 \%$ at the spot weld and decreased by $13 \%$ between the spot welds.

\section{References}

1. D. G. Ball et al., Martin Marietta Energy Systems, Inc., Oak Ridge National Lab., Stress Intensity Factor Influence Coefficients for Surface Flaws in Pressure Vessels, NUREG/CR-3723 (ORNLCSD/TM-216), Oak Ridge, Tenn., February 1985. ${ }^{\circ}$

2. K. J. Bathe, ADINA - A Finite Element Program for Automatic Dynamic Incremental Nonlinear Analysis, Report A-1, Massachusetts Institute of Technology, Cambridge, $1984 .^{b}$
3. B. R. Bass and J. W. Bryson, Union Carbide Corp., Nuclear Div., Oak Ridge National Lab., Applications of Energy Release Rate Technique to Part-Through Cracks in Plates and Cylinders, Volume 2. ORVIRT: A Finite Element Program for Energy Release Rate Calculations for 2-

Dimensional and 3-Dimensional Crack Models, NUREG/CR-2997/Volume 2 (ORNL/TM$8527 /$ 2), February $1983 .^{b}$

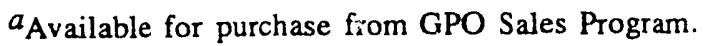

$b_{\text {Available for purchase from organization sponsoring }}$ publication cited, and/or authors, and/or recipients (documented letters).
} 

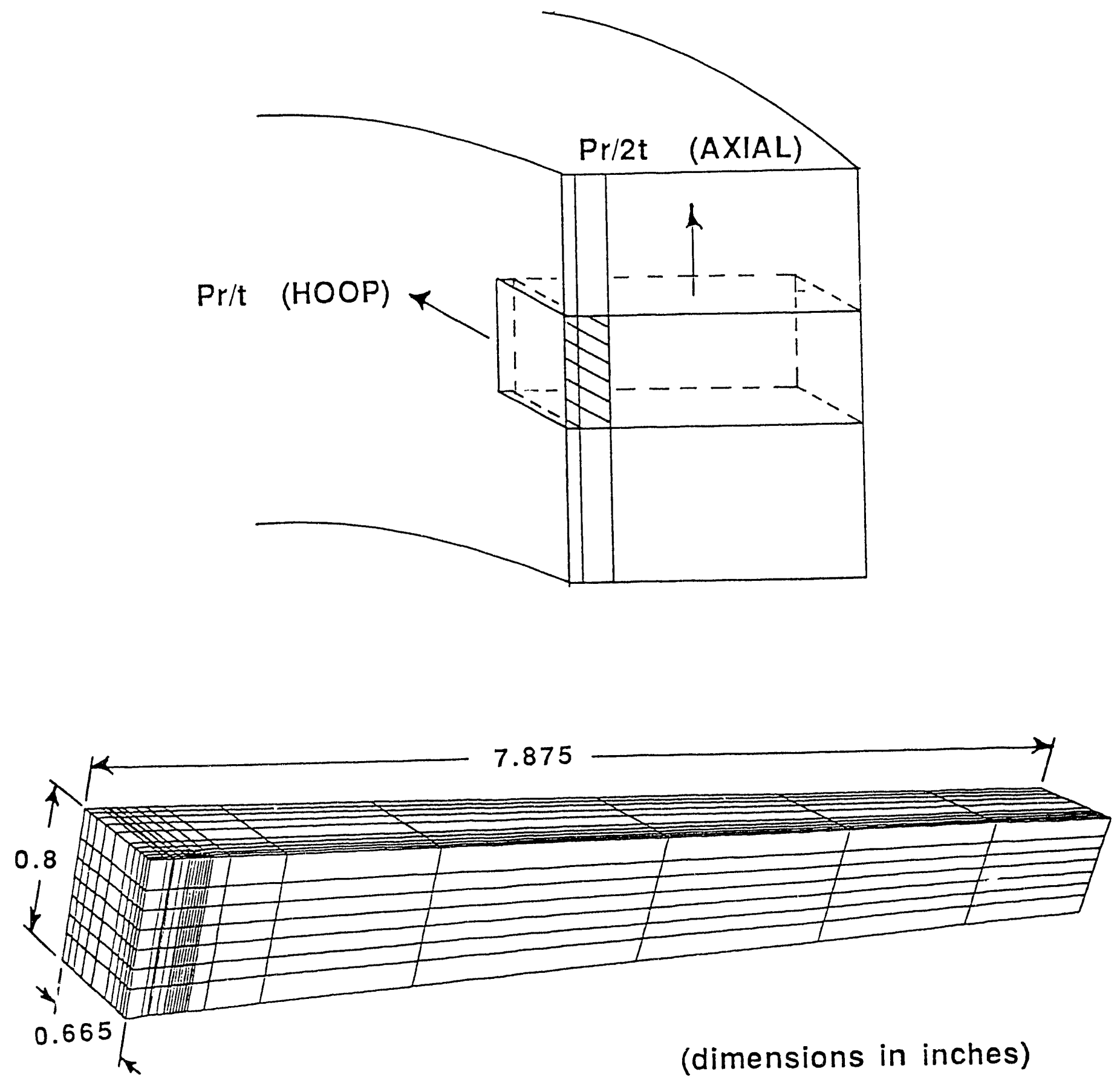

Fig. J.1. Schematic showing a portion of an RPV with a flaw which is modeled using finite-element techniques. 


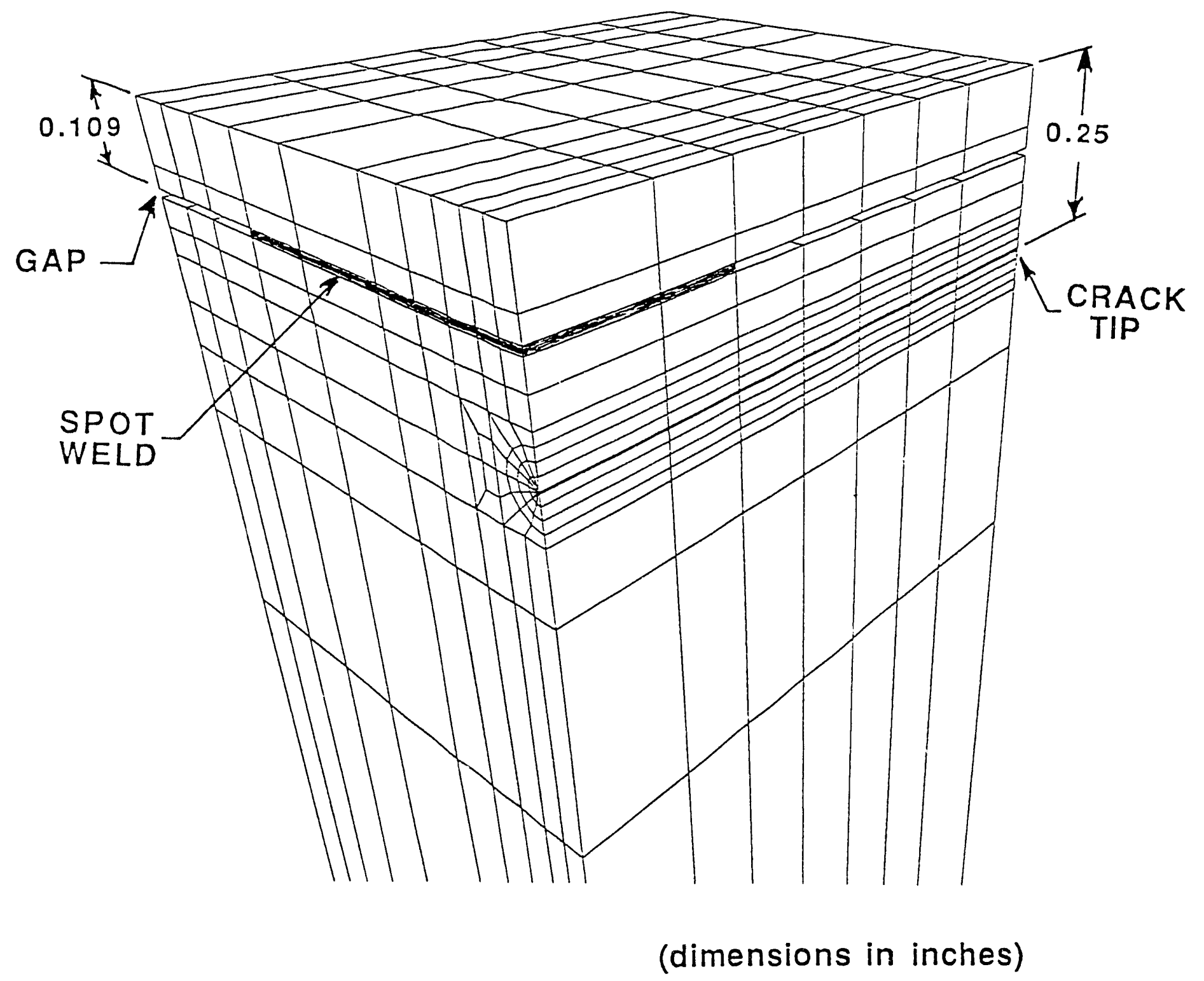

Fig. J.2. Detail of the finite-element model showing the gap interface. 


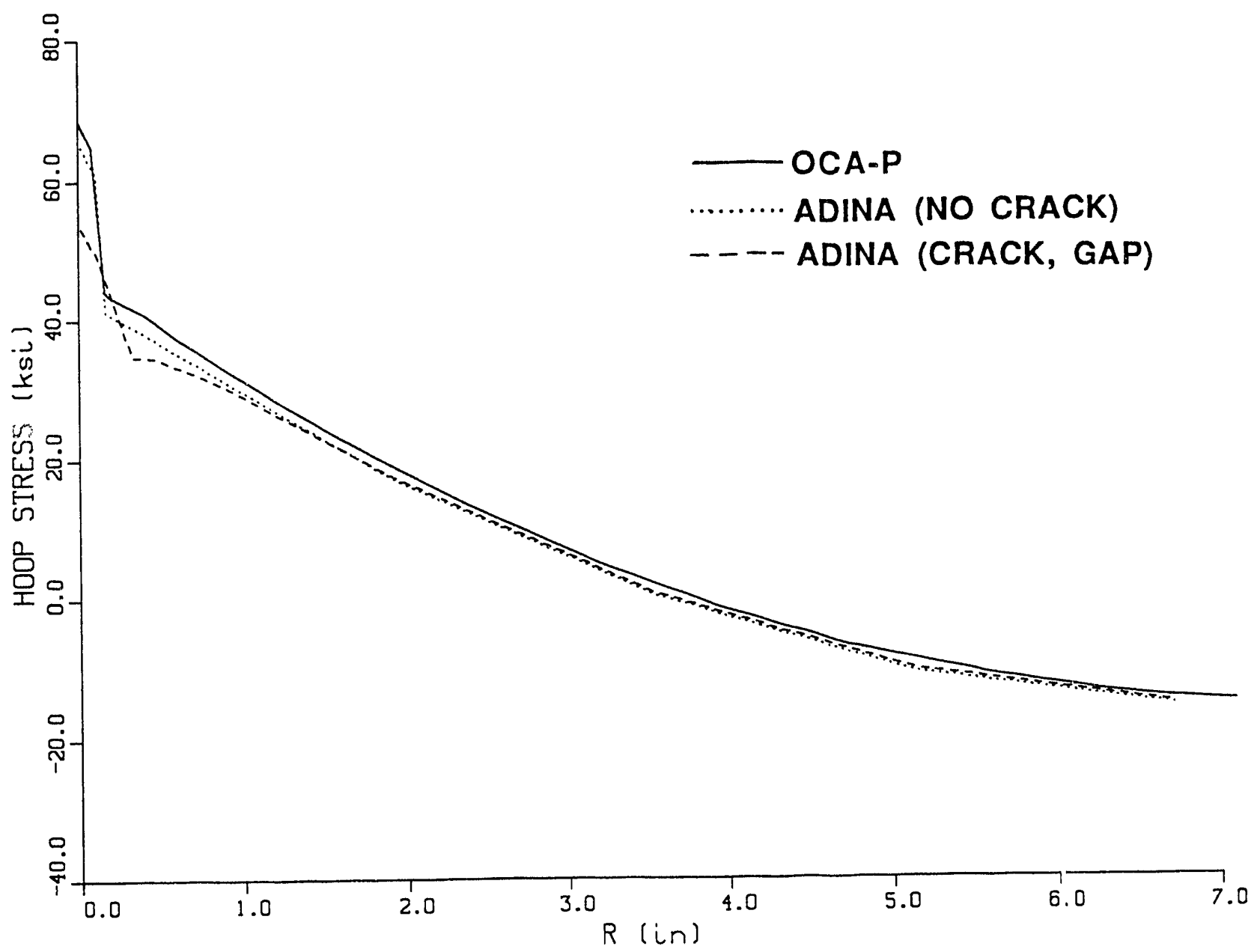

Fig. J.3. Hoop stress distribution for OCA-P and ADINA analyses (SBLOCA7 transient, $t=20 \mathrm{~min}$ ). 


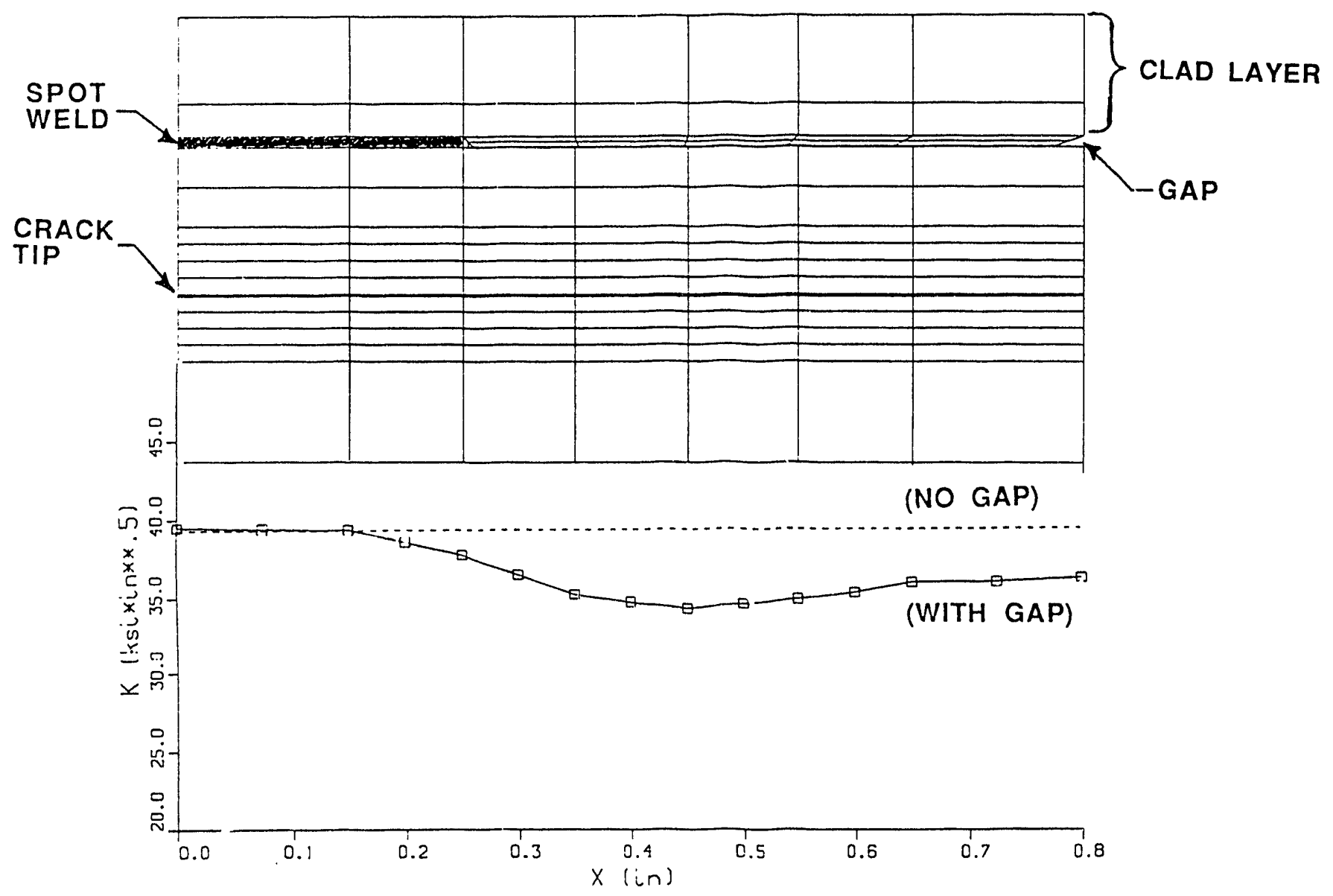

Fig. J.4. Distribution of $\mathrm{K}_{\mathrm{I}}$ values for finite-element models with ana without interface gap. 


\section{Internal Distribution}

1. B. R. Bass

9-16. J. W. Bryson

17. E. W. Carver

18-25. R. D. Cheverton

26. J. A. Clinard

27. J. M. Corum

28. W. R. Corwin

29-38. T. L. Dickson

39. J. E. Jones Jr.

40-47. J. A. Keeney

48. W. J. McAfee

49. D. E. McCabe

50. J. G. Merkle
51. R. K. Nanstad

52. D. J. Naus

53. C. B. Oland

54-58. W. E. Pennell

59. C. E. Pugh

60-67. D. K. M. Shum

68. Cynthia Southmayd

69. T. J. Theiss

70. ORNL Patent Section

71. Central Research Library

72. Document Reference Section

73-74. Laboratory Records

75. Laboratory Records (RC)

\section{External Distribution}

76. L. C. Shao, Director, Division of Engineering, U.S. Nuclear Regulatory Commission

77. C. Z. Serpan, Jr., Division of Engineering, U.S. Nuclear Regulatory Commission

78--79. S. N. M. Malik, Division of Engineering, U.S. Nuclear Regulatory Commission

80. M. E. Mayfield, Division of Engineering, U.S. Nuclear Regulatory Commission

81. A. Taboada, Division of Engineering, U.S. Nuclear Regulatory Commission

82. D. P. Bozarth, Science Applications International Corporation, 708 S. Illinois Ave., Oak Ridge, TN 37830

83. J. W. Minarick, Science Applications International Corporation, 708 S. Illinois Ave., Oak Ridge, TN $37830^{\prime}$

84. F. A. Simonen, Pacific Northwest Laboratories, P. O. Box 999, Richland, WA 99352

85. L. W. Ward, Idaho Nuclear Engineering Laboratories, EG\&G Idahr, Inc., 11428 Rockville Pike, Suite 410 , Rockville, MD 20852

86. K. A. Williams, Science Applications International Corporation, 2109 Air Park Rd., SE, Albuquerque, NM 87106

87. Commander and Director, USAE Waterways Experiment Station, Attn: CEWES-IM-MI-R, Alfrieda S. Clark, CD Dept./\#1072, 3909 Halls Ferry Road, Vicksburg, MS 39180-6199

88. Office of Assistant Manager for Energy Research and Development, DOE-ORO, Oak Ridge, TN 37831

89-90. Office of Scientific and Technical Information, P. O. Box 62, Oak Ridge, TN 37831 

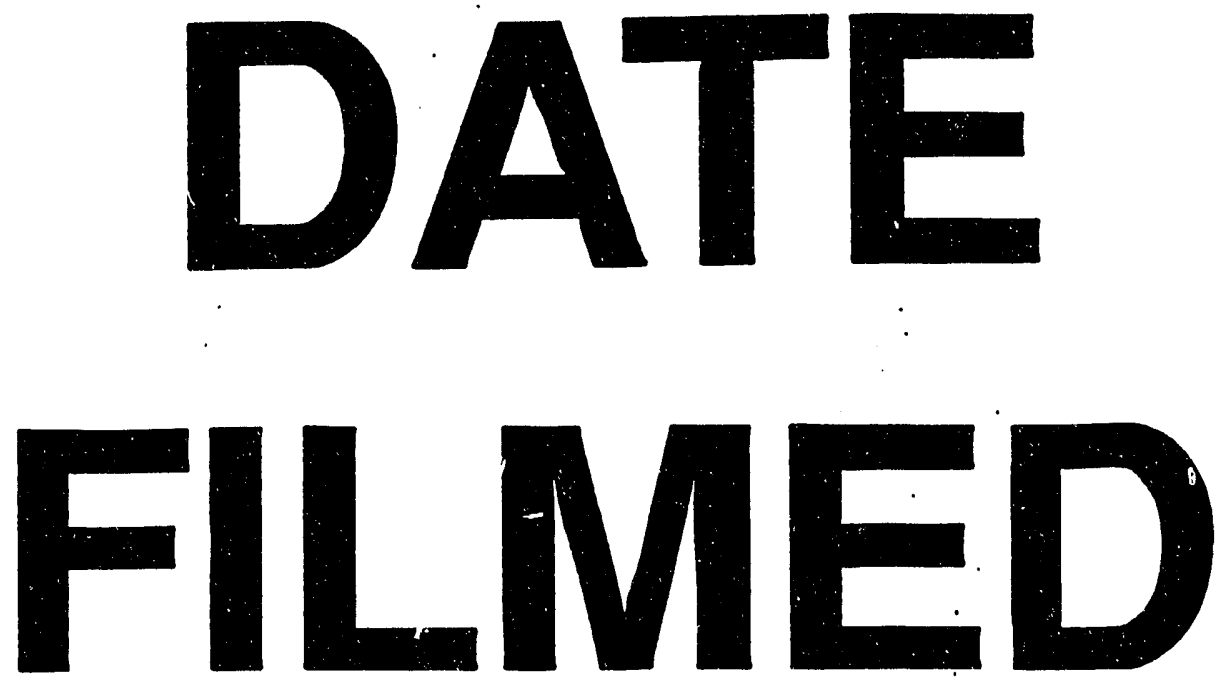

$10 / 20 / 93$
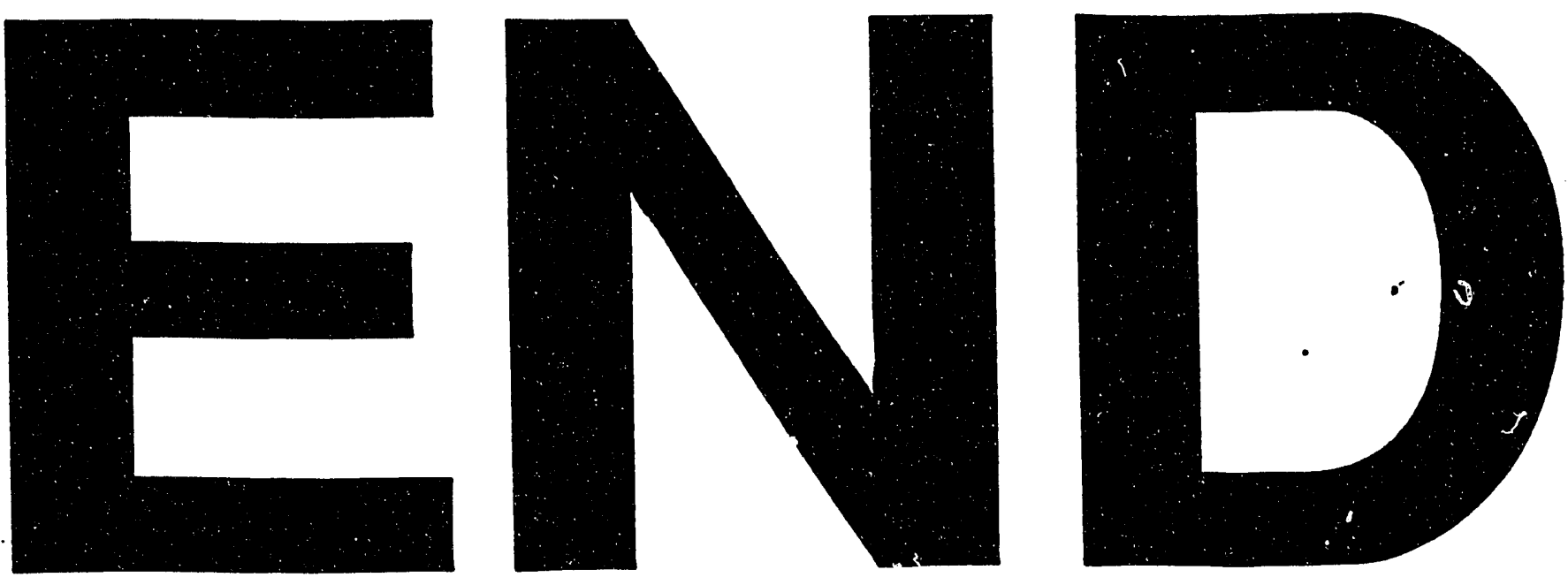